\title{
Three Essays on Utilizing Spatial Econometrics in Natural Resource Economics related to Water, Health, and Energy
}

\author{
Elham Erfanian \\ West Virginia University, elhamerfanian@mix.wvu.edu
}

Follow this and additional works at: https://researchrepository.wvu.edu/etd

Part of the Agricultural and Resource Economics Commons, Health Economics Commons, and the Regional Economics Commons

\section{Recommended Citation \\ Erfanian, Elham, "Three Essays on Utilizing Spatial Econometrics in Natural Resource Economics related to Water, Health, and Energy" (2019). Graduate Theses, Dissertations, and Problem Reports. 4053. \\ https://researchrepository.wvu.edu/etd/4053 \\ This Dissertation is protected by copyright and/or related rights. It has been brought to you by the The Research Repository @ WVU with permission from the rights-holder(s). You are free to use this Dissertation in any way that is permitted by the copyright and related rights legislation that applies to your use. For other uses you must obtain permission from the rights-holder(s) directly, unless additional rights are indicated by a Creative Commons license in the record and/ or on the work itself. This Dissertation has been accepted for inclusion in WVU Graduate Theses, Dissertations, and Problem Reports collection by an authorized administrator of The Research Repository @ WVU. \\ For more information, please contact researchrepository@mail.wvu.edu.}




\title{
Three Essays on Utilizing Spatial Econometrics in Natural Resource Economics related to Water, Health, and Energy
}

\author{
Zohreh Erfanian \\ Dissertation submitted to the Davis College of Agriculture, Natural \\ Resources and Design, \\ At West Virginia University \\ In partial fulfillment of the requirements \\ For the degree of \\ Doctor of Philosophy \\ In Natural Resource Economics
}

\author{
Alan R. Collins, Ph.D., Committee Chairperson \\ Randall W. Jackson, Ph.D. \\ Daniel S. Grossman, Ph.D. \\ Donald J. Lacombe, Ph.D. \\ Michael P. Strager, Ph.D.
}

Division of Resource Economics and Management

Morgantown, West Virginia

2019

Keywords: Municipal water utility charges, Opioid overdose deaths, Naloxone, $P M_{2.5}$ Concentrations, Asthma hospitalization, Spillover effects, Spatial Econometrics

Copyright 2019 Zohreh Erfanian 


\title{
ABSTRACT
}

\section{THREE ESSAYS ON UTILIZING SPATIAL ECONOMETRICS IN NATURAL RESOURCE ECONOMICS RELATED TO WATER, HEALTH, AND ENERGY}

\author{
Zohreh Erfanian
}

Spatial interaction and the locational structure between observations have recently gained more attention in the field of econometrics for both cross-sectional and panel data analyses. Compared to a non-spatial economic model, a spatial model relaxes the assumption of independency in observations. This research will apply spatial econometrics modeling in three different fields in applied economics: 1) water charge and minimum monthly access charge in West Virginia municipalities, 2) Naloxone access law and opioid overdose deaths among the U.S. states, and 3) $P M_{2.5}$ concentrations and asthma hospitalizations in Pennsylvania counties. Based on the nature of water resource imposing spillovers in water charge model is inevitable, likewise Naloxone law and $P M_{2.5}$ concentrations. We expect to see a significant spillover effects in water charge and minimum water access charge as well as Naloxone law and asthma prevalence among observations.

In Chapter 2, we apply linear and log-log functional forms plus spatial econometric analyses to a 2014 dataset of 125 municipal water utilities in West Virginia to investigate the determinants of charges for water use and access. The water charges models are consistent with the theory of water cost determination as water source, debt, and economies of size and scale influence what consumers pay for water. Based on model results, groundwater use by utilities is estimated to save household customers in West Virginia over $\$ 12.6$ million annually. The results for the spatial model indicate that there are moderate spillover effects for both water and minimum access charges among utilities. West Virginia households using municipal water typically pay far below the OECD standard of $3 \%$ to $5 \%$ of household income which may explain why socioeconomic factors do not influence monthly minimum charges. A manuscript based on this essay is accepted for the publication for in the journal, Water Economics \& Policy.

Chapter 3 contains an essay examining naloxone access laws. Opioid overdose is the leading cause of unintentional death in the U.S. Naloxone is a medicine that reverses the overdose. The second essay investigates the effects of Naloxone access laws on opioid overdose death rates. Analyses reveal that when broken down by access law provisions, there exist positive effects on overdose death rates depending upon the provision. The results indicate that Naloxone access provisions have regional impacts by influencing 
overdose death rates neighboring states. Looking across multiple provisions, our findings provide no statistical evidence that these laws reduce opioid overdose death rates. This essay has been published in Review of Regional Studies.

Finally, Chapter 4 is an essay relating $P M_{2.5}$ concentrations and asthma hospitalization across Pennsylvania counties. Ambient air pollution adversely impacts human health. According to the World Health Organization, 235 million people around the world currently suffer from asthma, which includes approximately 25 million in the United States. There is substantial epidemiological evidence linking outdoor air pollution and asthma symptoms, more specifically particulate matter concentrations and asthma. Based upon county level data from 2001-2014, a spatial panel framework based upon prevailing wind patterns is used to investigate the direct and indirect impacts of $\mathrm{PM}_{2.5}$ concentration levels on asthma hospitalization rates in Pennsylvania. This model controls for population density, precipitation, per capita income, and smoking rate. Results show that $\mathrm{PM}_{2.5}$ concentrations have both positive direct and indirect effects on asthma hospitalization rates. Varying with county population size, a one $\mu \mathrm{g} / \mathrm{m}^{3}$ increase in $\mathrm{PM}_{2.5}$ will add asthma hospitalization costs between \$3.1M (Philadelphia County) and \$37,732 (Cameron County). This study highlights the need for a more accurate impact analysis of ambient air pollution on asthma that reflects the impacts on neighboring regions as well. A one $\mu \mathrm{g} / \mathrm{m}^{3}$ increase in $\mathrm{PM}_{2.5}$ concentrations throughout all counties in Pennsylvania raises the number of annual asthma hospitalizations by over 1,200 , with $26.8 \%$ of this increase occurring due to spillover effects. In the case of asthma hospitalization rates from $\mathrm{PM}_{2.5}$ pollution, an appropriate wind direction algorithm is important to identify spillover effects across counties. This essay has been under review in Journal of Regional Analysis and Policies. 


\section{DEDICATION}

For my family,

This dissertation is dedicated to the memory of my father. Although he was my inspiration to pursue my doctoral degree, he was unable to see my graduation. This is for him and all he taught me.

For my mother, who has supported me and helped throughout my entire life.

For my aunts, who were always there for me, no matter how far we were apart.

For my sister, who is my inspiration to always be strong.

For my older brother, who taught me to follow my heart, do what I like to do, and work hard.

For my younger brother, who is the best brother I could ever have asked for, words alone cannot describe how grateful I am to have him. 


\section{ACKNOWLEDGMENTS}

Firstly, I would like to express my sincere gratitude to my advisor Professor. Alan Collins for his continued support of my Ph.D. study and related research, for his patience, motivation, and immense knowledge. His guidance helped me in my researching and writing of this dissertation. I could not imagine having had a better advisor and mentor for my Ph.D. study.

My sincere thanks also go to my supervisor, my committee members, and my mentor Professor Randall Jackson, who provided me with the opportunity to join the Regional Research Institute (RRI) team as a graduate research assistant - the best environment in which to work. Aside from his continual guidance to be a better researcher and a better person, he helped me benefit from attending different conferences, to learn more, and to become acquainted with multidisciplinary researchers to build and expand my professional network. Without his precious support, it would not be possible to be who I am.

Besides my advisor and my supervisor, I would like to thank the rest of my dissertation committee: Professor Donald Lacombe, Professor Michael Strager, and Professor Daniel Grossman, not only for their insightful comments and encouragement but also for their questions, which incented me to widen my research from various perspectives.

I thank my fellow classmates, officemates, and my friend Caleb Stair for all the support he and his family provided to me during my Ph.D. I thank Juan Tomas Sayago, Christa Court, Amir Neto, Jing Chen, Xueting Zhao, Zheng Tian, Péter Járosi, Peter Schaeffer, Alexandre Scarcioffolo, Shishir Shakya and the rest of the RRI family for all the insightful comments and encouragement.

Special thanks to Caigan McKenzie and Doris Berns who are the ones that make the RRI the best place to do research. I have been fortunate enough to have their support from the first day of my work. I would like to thank Lisa Lewis for all her support at the division of Resource Economics and Management. Caigan, Doris and Lisa are the ones who made me feel as though the RRI and the Agricultural and Resource Economics department were home. 


\section{TABLE OF CONTENTS}

\section{Contents}

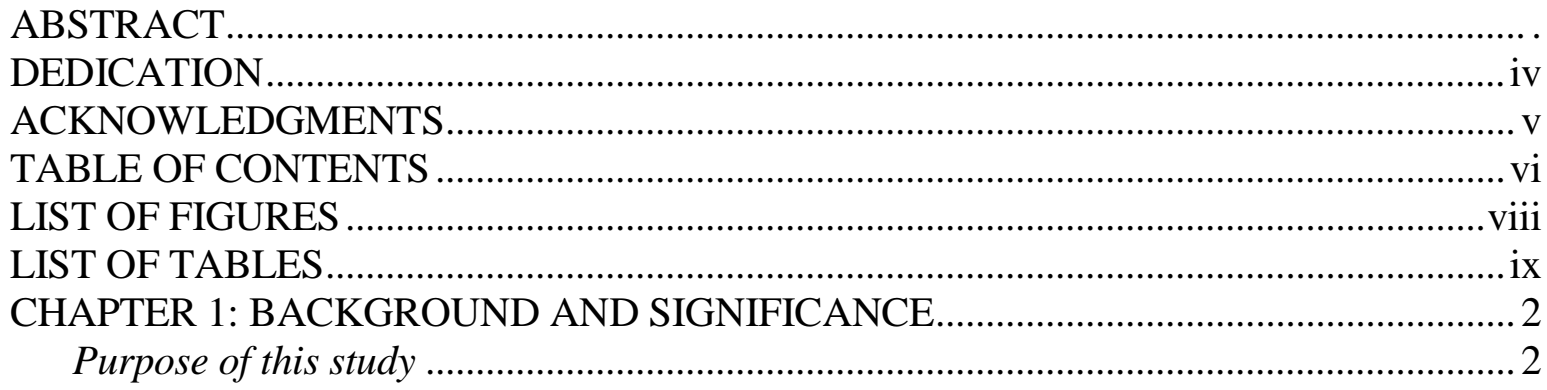

Aim of Essay 1: Examine the factors impact the water charges and access in West Virginia municipalities applying a spatial model ........................................................................ 2 Aim of Essay 2: Examine state-level variations in opioid overdose deaths as a result of the Naloxone access law with an application of spatial regression ......................................... 3 Aim of Essay 3: Examine county-level asthma hospitalization and PM2.5 concentrations: An application of spatial Durbin panel approach ......................................................... 4

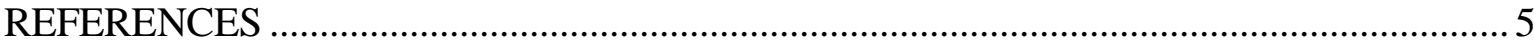

CHAPTER 2: CHARGES FOR WATER AND ACCESS: WHAT EXPLAINS THE DIFFERENCES AMONG WEST VIRGINIA MUNICIPALITIES? ……………………….. 7

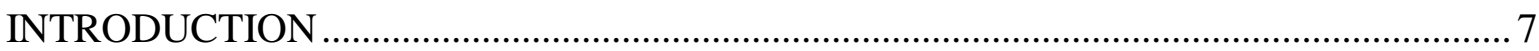

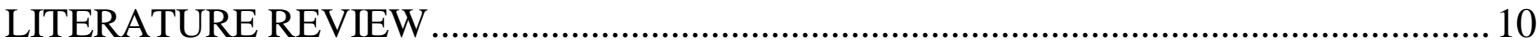

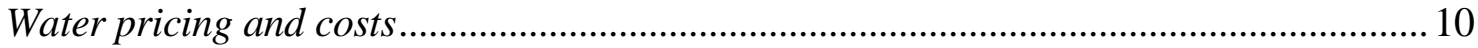

Water efficiency, ownership, and utility regulation ………............................................. 12

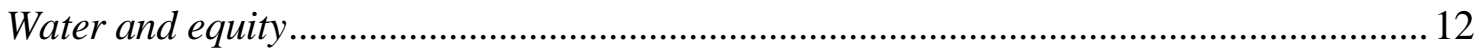

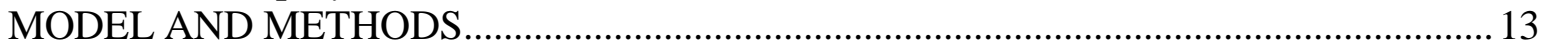

DATA

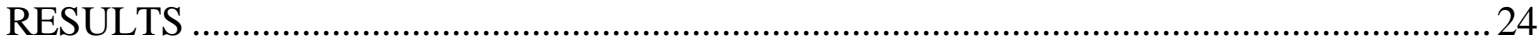

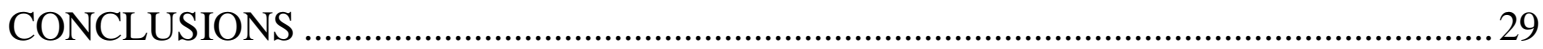



CHAPTER 3: THE IMPACTS OF NALOXONE ACCESS LAWS ON OPIOID OVERDOSE

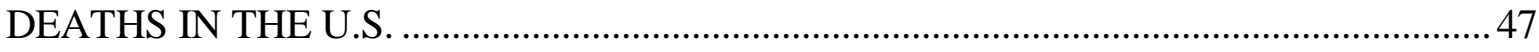

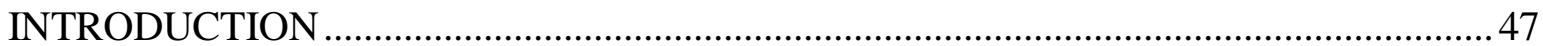

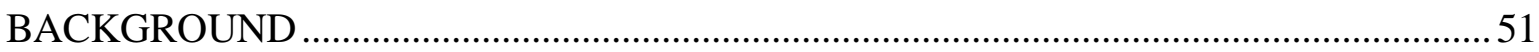

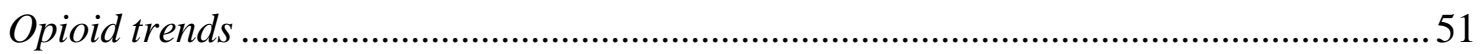

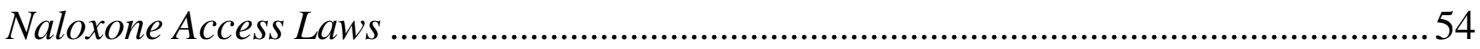

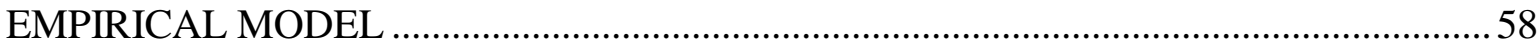

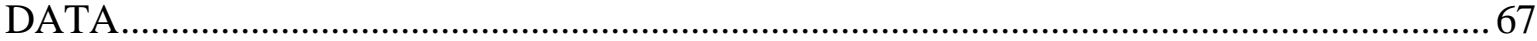

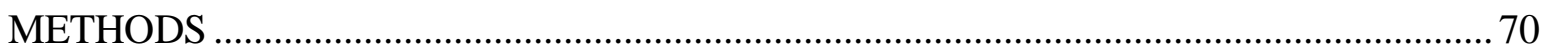

Exploring spatial dependency in opioid overdose death rates across states ....................70

Spatial econometric analysis .................................................................................... 74

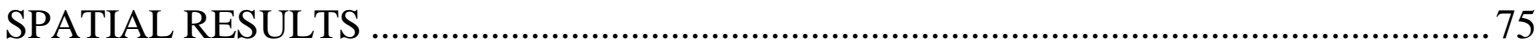

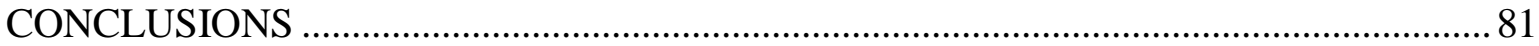

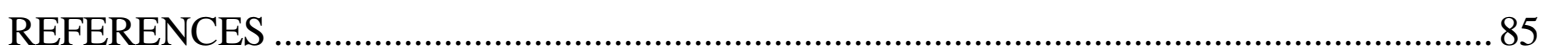


CHAPTER 4: AIR QUALITY AND ASTHMA HOSPITALIZATION: EVIDENCE OF PM2.5 CONCENTRATION IN PENNSYLVANIA COUNTIES..................................... 93

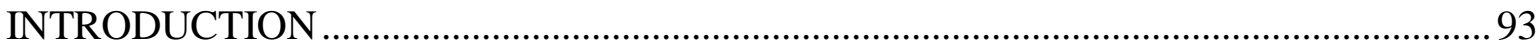

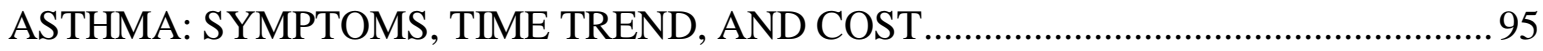

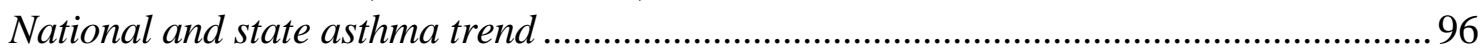

The burdensome cost of asthma on society ..................................................................... 97



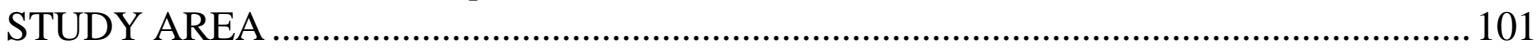

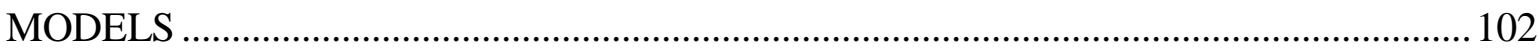

DATA

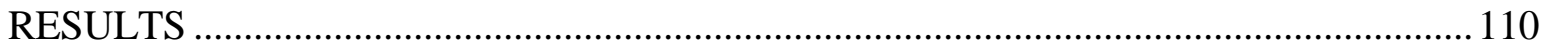

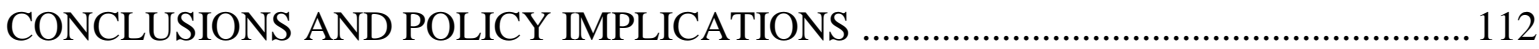

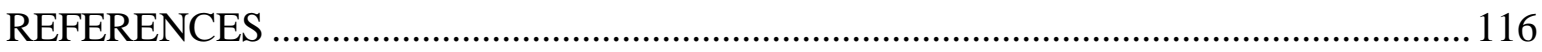



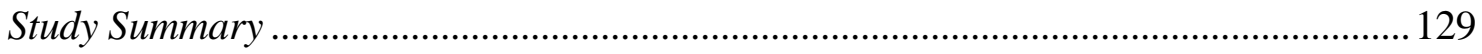

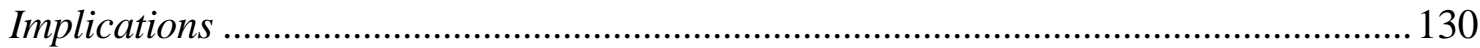

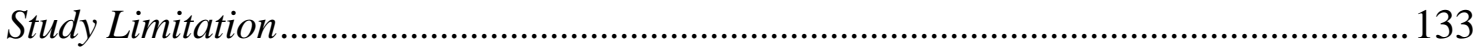




\section{LIST OF FIGURES}

Figure 1. Map of West Virginia municipal utilities and their 2014 water charges................. 45

Figure 2. Opioid overdose death per 100,000 population by state, 1999 and 2016 ..............52

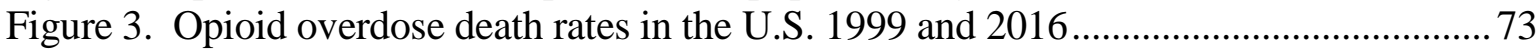

Figure 4. Moran's scatter plot of state Level Opioid Overdose Death Rates (1999 and

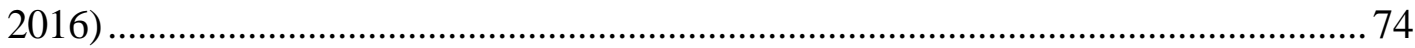

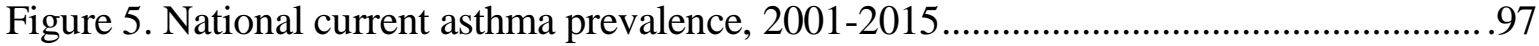

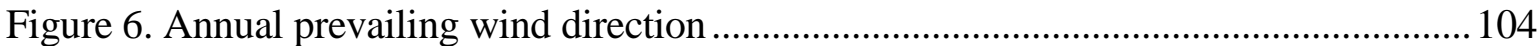

Figure 7. Asthma hospitalization in Pennsylvania counties 2014 ...................................... 109

Figure 8. Attainment vs. nonattainment designation status in Pennsylvania counties based on $\mathrm{PM}_{2.5}$ concentrations criteria. 126 


\section{LIST OF TABLES}

Table 1. Categorization of explanatory variables

Table 2. Summary statistics of variables used in the water charge model $(n=125)$

Table 3. Summary statistics of variables used in the minimum monthly access charge model $(\mathrm{n}=125)$

Table 4. Water charges model results for OLS and SAR estimations $(n=125)$

Table 5. Minimum monthly access charge model results for OLS, SAR, and SEM estimates $(n=125)$

Table 6. Estimation results for water charges SEM, SDM, SLX, and SDEM models

Table 7. Estimation results for minimum water charge SEM, SDM, SLX, and SDEM models....

Table 8. Estimation results for water charge spatial model with the coal production variable

Table 9. Estimation results for water charge spatial model with the distance from the river variable

Table 10. Estimation results for water charge spatial model with the possibility to have a private water well variable

Table 11. Estimation results for water charge spatial model with the water utility age variable

Table 12. Effective Dates of Naloxone Access Laws, 1999-2016.

Table 13. Effective Dates of Naloxone Access Law Provisions, 1999-2016

Table 14. List of the Variables Utilized in Overdose Death Research 64

Table 15. Descriptive Statistics 72

Table 16. Moran's I index for State Level Opioid Overdose Death Rates .72

Table 17. Estimation Results for Model 1 (dummy of access law NAL 1) and Model 2 (days after effective date of access law)....

Table 18. Direct, Indirect, and Total Effects of SDM Model (Based on Model 3) ...............80

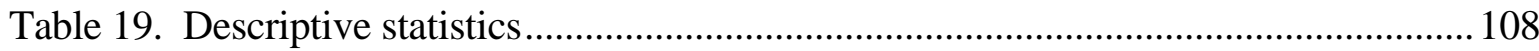

Table 20. 1st-order spatial autoregressive Rho for Pennsylvania asthma hospitalization.... 110

Table 21. Asthma hospitalization estimation results for the SLX model 
CHAPTER 1 


\section{CHAPTER 1: BACKGROUND AND SIGNIFICANCE}

Spatial interaction and the locational structure between observations have recently gained more attention in the field of econometrics for both cross-sectional and panel data analyses. Given a location to any observation in the system, spatial econometrics specifies, estimates, and tests how the magnitude of a variable of interest would be determined by the value of the same variable at other locations in the system (Anselin, 2001). Compared to a non-spatial economic model, a spatial model relaxes the assumption of independency in observations. Spatially correlated observations could be zip codes, cities, municipalities, counties, states, and countries (Elhorst, 2014). In this study, applying different level of spatially correlated observations I model spatial spillovers in topics related to water, health and environment.

\section{Purpose of this study}

The overall aim of this study is to empirically demonstrate, at the municipal, county and a state level, how the spatial analysis may help to find a more accurate results while evaluating the impacts of exogenous variables, shocks and policies in different fields. This study is composed of three essays.

\section{Aim of Essay 1: Examine the factors impact the water charges and access in West}

\section{Virginia municipalities applying a spatial model}

The first essay describes the factors that explain water charges and access in West Virginia municipalities.

The specific objectives for this essay are listed below: 
1. Given the dramatic differences in water charges observed for municipal utilities throughout the state of West Virginia, the main objective of this research is to investigate the factors that explain water charge differences.

2. The next question addressed in this research is about how minimum access charges for water provision (independent from the water volume consumption) account for social equity concerns across municipalities.

3. Explore whether there are any spillover effects in water charges and the minimum water access across municipalities.

\section{Aim of Essay 2: Examine state-level variations in opioid overdose deaths as a result of the Naloxone access law with an application of spatial regression}

The second essay focuses on one of the most important recent national challenges, opioid crisis. Opioid overdose is the leading cause of unintentional death in the U.S. (Visconti et al., 2015). While opioid epidemic is a phenomenon that all the states are suffering from, there are regions consist of a cluster of states that experience a higher rate of opioid overdoses. It is plausible that the opioid related Naloxone access law state level policy in one state can affect the opioid overdose deaths of the neighboring states because of cross bordering the drugs. Therefore, using a spatial econometrics model this study aims to:

1. Evaluate the effectiveness of state level Naloxone overdose prevention laws on overdose deaths in the U.S.

2. Explore whether there are any spillover effects in the Naloxone access law and the overdose deaths across states. 


\section{Aim of Essay 3: Examine county-level asthma hospitalization rate and $P M_{2.5}$ concentrations: An application of spatial Durbin panel approach}

The third essay examines the complex relationship between $P M_{2.5}$ concentrations and asthma hospitalization outcome. Over the last decades, air pollution has changed from less concentrations of $\mathrm{SO}_{2}$ and coarse particles toward more traffic-related air pollutants (TAP) (i.e., nitrogen oxides (NOx), small particles and organic compounds) (Pénard-Morand et al., 2010). While many researchers investigate the effects of shortterm and long-term exposure to PM and resulting asthma symptoms (Silverman and Ito, 2010; Samoli et al., 2011; Iskandar et al., 2012; Zhang et al., 2015), further research is needed to investigate the presence of "uncompensated spillovers" of $P M_{2.5}$ concentrations on asthma hospitalization. Therefore, using a Spatial Durbin Model, the objectives are to:

1. Identify and estimate the impacts of $P M_{2.5}$ concentrations on asthma prevalence across counties in the state of Pennsylvania.

2. Check whether or not there is any spillover effects from $P M_{2.5}$ concentrations and asthma prevalence across counties in Pennsylvania. 


\section{REFERENCES}

Anselin, L. (2001). Spatial econometrics. A companion to theoretical econometrics, 310330 .

Elhorst, J. P. (2014). Spatial econometrics: from cross-sectional data to spatial panels (pp. 20-25). Heidelberg: Springer.

Visconti, A. J., Santos, G. M., Lemos, N. P., Burke, C., \& Coffin, P. O. (2015). Opioid overdose deaths in the city and county of San Francisco: prevalence, distribution, and disparities. Journal of Urban Health, 92(4), 758-772.

Pénard-Morand, C., Raherison, C., Charpin, D., Kopferschmitt, C., Lavaud, F., Caillaud, D., \& Annesi-Maesano, I. (2010). Long-term exposure to close-proximity air pollution and asthma and allergies in urban children. European Respiratory Journal, 36(1), 33-40.

Silverman, R. A., \& Ito, K. (2010). Age-related association of fine particles and ozone with severe acute asthma in New York City. Journal of Allergy and Clinical Immunology, 125(2), 367-373.

Samoli, E., Nastos, P. T., Paliatsos, A. G., Katsouyanni, K., \& Priftis, K. N. (2011). Acute effects of air pollution on pediatric asthma exacerbation: evidence of association and effect modification. Environmental research, 111(3), 418-424.

Iskandar, A., Andersen, Z. J., Bønnelykke, K., Ellermann, T., Andersen, K. K., \& Bisgaard, H. (2011). Coarse and fine particles but not ultrafine particles in urban air trigger hospital admission for asthma in children. Thorax, thoraxjnl-2011.

Zhang, Q., Qiu, Z., Chung, K. F., \& Huang, S. K. (2015). Link between environmental air pollution and allergic asthma: East meets West. Journal of thoracic disease, 7(1), 14. 
CHAPTER 2 


\section{CHAPTER 2: CHARGES FOR WATER AND ACCESS: WHAT EXPLAINS THE DIFFERENCES AMONG WEST VIRGINIA MUNICIPALITIES?}

\section{INTRODUCTION}

Water is a basic resource that is vital to the existence of life. Because of this, provision of potable water is often discussed as a basic human right (United Nations, 2010). While a renewable resource, the global water cycle implies essentially a fixed water supply (Renzetti, 2012). Increasing demands for water strain the ability of communities to achieve sustainable management. One of the main goals in a sustainable water planning system is providing adequate supplies of clean water for all users at a reasonable cost (Gleick, 1998). According to the World Bank (2015), 99\% of Americans have access to an improved water source; however, consumers pay vastly different amounts for the same volume of water. For instance, Walton (2015) provides water price data for 30 major U.S. cities with a range for the same volume of water from $\$ 23.26$ (in Fresno, CA) to $\$ 153.78$ (in Santa Fe, NM). These price data were calculated as a monthly bill for a family of four using 100 gallons per person per day.

Provision of clean and reliable water is a key element of any developed society. Water markets are mostly dominated by monopolists or at least contains monopoly elements (Klein, 1996). The lack of any feasible and realistic competition makes it necessary to have a regulatory mechanism in place to deal with the loss of social welfare imposed by a monopoly market. In West Virginia, the provision of water services occurs as a regulated monopoly. The West Virginia Public Service Commission (WV PSC) provides oversight for this necessary government function to ensure that consumers have access to safe and reliable water supplies at reasonable rates. Through 
the WV PSC, municipal utilities operate as monopolies within their communities because of the capital intensive structure of operating a water utility.

Pricing regulation by the WV PSC is based on the costs faced by water providers. However, when water charges across West Virginia municipalities are examined on the basis of cost to residential customer for 4,500 gallons, a more than five-fold difference is observed (from $\$ 13.26$ in Vienna to $\$ 71.89$ in Matoaka) (WV PSC, 2014). This range is comparable to that found at a national level even with a much more homogenous climate in West Virginia. Figure 1 demonstrates the spatial distribution of charges across West Virginia municipal utilities.

Given these dramatic differences in water charges and a growing concern for the municipal agencies' actions for supplying drinking water (Renzetti, 1999; Rijsberman, 2006; Ercin and Hoekstra, (2014); World Economic Forum, 2015; Mekonnen and Hoekstra, 2016), our main objective in this research is to examine what factors explain the cost differences among municipal water utilities across the state of West Virginia. We use a cost-based approach to determine what factors explain water pricing differences.

In this research, we use the term water charge as the concept to be examined. Price and charge both involve the element of money, but price describes how a consumer must pay to gain an additional unit of product or service, while charge is the total amount paid to acquire a certain quantity of a product or service. In terms of water supply in the United States, water charge is a way to standardize the acquisition of water across a multitude of pricing structures. Water utility pricing structures often include a minimum charge and either fixed or variable unit charges (usually on a per 1,000-gallon basis). This argument, as first stated by Coase (1946), notes that the efficient price in a regulated market needs to be expressed as a two-part tariff. The volumetric charge equals to marginal cost and the fixed fees equal to each customer's share of fixed costs. 
Besides this main objective, we ask another question about whether social equity concerns are linked to minimum charges for access to water provision (independent from the water volume consumption) among water utilities. We will investigate whether minimum charges by utilities vary based upon socioeconomic circumstances within a community. Similar to water charges, minimum charges differ across municipal utilities. For example, there are 30 municipalities in West Virginia whose minimum charge to consumers is zero, while the highest minimum charge in our sample is at the municipality of Sistersville where households have $\$ 39$ per bill as the minimum charge.

Kanakoudis and Tsitsifli (2014) point out that assessment of minimum charges is not socially fair. Fairness matters to consumers, especially fairness in distribution is a concern in political philosophy. Regardless of income level, all individuals should have access to water. In the scope of fairness literature, consumers need to pay for water based on their ability to pay. This is an issue that we address in this study by examining minimum charges by water utilities as the amount that households are obliged to pay per month to have access to water. These charges generate a secure source of revenue for the local water utilities that enable them to cover, for example, water losses in their network.

Finally, we introduce a spatial aspect to models that explain water and minimum access charges. We add geographic variables to investigate the spatial implications of water charges. Commonly, municipal utilities located in the same county or region will have similarities in their primary source of water, topography, cost of living, etc. These similarities among municipalities in a region may have effects on either water charges or minimum charge determinants within a spatial framework. 
Thus, this study contributes to the literature in three ways. First, we introduce spatial characteristics to the model to determine the extent to which neighboring municipal utilities influence the municipal water charges. Second, we consider geography and morphology attributes in the water charges model. Lastly, we test to see whether social equity considerations explain minimum access charges to water provision. The next four sections cover: previous literature related to the economy of water, conceptual and empirical models along with methods, and data utilized in this research. In the last two sections, we provide the results and then conclude with a discussion of the implications from this research.

\section{LITERATURE REVIEW}

Among the studies on water issues include: pricing and costs, utility ownership and efficiency, utility regulatory policies, and social equity. We will focus on these issues in separate sub-sections below.

\section{Water pricing and costs}

Goldstein (1986) argued that potable water is an inexpensive, virtually limit-less resource in many areas of the United States. According to Goldstein, accessibility and availability of the water supply is the reason why water cost is not a substantial concern in the U.S. After 30 years of changes in availability of water resources, the Goldstein argument of limit-less water supplies is questionable (e.g. Boyer et al. (2015) note examples in the western U.S.), but his main recommendation of setting water charges in a way that reflects the full cost of providing water is still accurate and valuable. From Feigenbaum and Teeples (1983), who recommend a hedonic cost function for water provided by public versus private, to Bae (2007), who investigates institutional factors influencing the water pricing system, there is a considerable amount of research evaluating 
water pricing in the U.S. These pricing structures involve different systems of either a uniform block rate, decreasing block rate, increasing block rate, or increasing and declining block rate.

While Renwick and Archibald (1998) find that price-based policies are as effective as nonprice policies, there is a clear trend in water conservation policies towards volumetric charging (Inman and Jeffery, 2006; Randolph and Troy, 2008; Millock and Nauges, 2010; Polycarpou and Zacharizdis, 2013). Baerenklau et al. (2014) is an example of investigating a new water rate mechanism (increasing block rate water budgets), which considers household-specific characteristics and environmental conditions in setting a more efficient block rate. SanchezMartinez and Rodriguez-Ferrero (2016) argue that natural hydrological conditions require application of a complex, integrated and highly developed water management and pricing systems.

Finally, two influential studies for this research include Bae (2007) and Antonioli and Filippini (2001). Bae (2007) examines factors influencing the cost of water provision. He separates the influential factors into four major categories: (1) institutional arrangements and characteristics, (2) government regulations, (3) supply factors and characteristics, and (4) natural environment and local characteristics. The maximum capacity of water production and treatment, water sources, water loss during water production, and rate structures are the explanatory variables that Bae uses to explain cost variation over a sample of 259 utilities across the U.S. For monthly residential water charges, positive impacts on cost are found for variables concerning the volume of water sold, use of increasing block rates, long-term utility debt, water loss, implementation of prior appropriation doctrine, and providing other infrastructure services. Variables with negative impacts include ground water as a source, water treatment capacity, daily water production, and a combined bill with other services. Antonioli and Filippini (2001) recommend controlling for geographical and morphological variables in cost model in order to achieve more accurate results. 


\section{Water efficiency, ownership, and utility regulation}

Among water efficiency and ownership studies, Teeples and Glyer (1987) estimate three cost models examining water delivery systems to compare ownership efficiency. The authors find that as specification improves, differences between public and private water supplies reduce to insignificance. Renzetti and Dupont (2004) find the same results in their study. They emphasize a lack of evidence for differences in performance of public versus private utilities. Also Bel et al. (2010) find there is no empirical evidence that private ownership is more efficient than public ownership utilities and Carvalho (2012) points out that this result is not surprising because of a wide range of different circumstances in each case study.

As mentioned by other water economists, Savenije (2002) argues that because a large investment (high fixed cost) is needed to supply water at an economy of scale, water provision is a natural monopoly market. In particular, residential water supply is also considered a natural monopoly (Müller, 2015). As Holland (2006) points out, the owner of a water supply system is interested in shrinking the deliveries in order to increase the profit by a higher cost of water provided to customers. To deal with derived market failure, governmental regulation is required to control the monopoly structure of the water market (Guerrini et al, 2011; Pahl-Wostl, 2015; Suárez-Varela et al., 2017; Araral et al., 2017).

\section{Water and equity}

Efficiency and equity tradeoffs are a well-defined topic within the foundations of welfare economics (Boadway, 1976; Zajac, 1978; Le Grand, 1990; Kritikos and Bolle, 2001). The tradeoff between efficiency and equity is considerable when there is a high level of fixed cost of providing services in markets such as energy, water, and transportation (Borenstein and Davis, 2012). Studies that investigate equity and efficiency in water supply include Bakker (2001), 
Garcia-Valinas (2005), and Porcher (2014). Bakker (2001) discusses economic equity versus equalization in water policy. Distinguishing between these two concepts, he explains that based on the equity principle, users should be charged according to their ability to pay. Following Bakker, Garcia-Valinas (2005) uses the same equity argument to propose a tariff rate which achieves efficiency, equity, financial aspects and/or public acceptability and transparency. The author controls for water supplied, labor and capital cost, and the length of the pipeline. Porcher (2014) discusses the effects of rebalancing water rates from current tariff to Coasian tariffs in France. The result is a lower bill for consumers and strong distributional consequences.

Water affordability gains growing attention in recent years (Mack and Wrase, 2017); Komarulzaman, 2017; Teodoro, 2018; Vanhille et al., 2018; Wutich et al., 2017). The Organization for Economic Co-operation and Development recommends that water bills not exceed 3-5\% of annual household income (OECD, 2003; OECD, 2010). Bithas (2008) argues that increasing block rates do not promote social equity and recommends the number of members in each household to be considered in setting water cost. Finally, the Consumer Utilities Advocacy Centre (2012) contends that social equity was traditionally an important concern in the urban water pricing system, while nowadays policies focus on different aspects such as water efficiency, financial sustainability, and cost recovery. He recommends a two-part tariff: a fixed supply charge and a variable charge. Based on household income or other economic circumstances, the requisite social support policy should be considered in a fixed charge.

\section{MODEL AND METHODS}

As motivated by Bae (2007), the general form of a model that explains variations in water charges to customers from a municipal water utility includes four categories of variables that influence the cost of water provision: 


$$
W C_{i}=f\left(Q_{i}, I n_{i}, E n_{i}, G e_{i}\right)
$$

where $(W C)$ is the water charges for a fixed volume of water that customers pay in return for provision of water; $(Q)$ is the quantity of water sold by the water utility; $(I n)$ is a vector of institutional and cost of providing service characteristics of water utilities; $(E n)$ is the index of water quality provided by the utility; and $(\mathrm{Ge})$ is geographical characteristics of the area served by the utility.

As described in the introduction, the $W C$ variable reflects the cost to a residential consumer from consumption of 4,500 gallons of water. This charge is for a consistent water quantity across municipal water utilities and represents an average cost faced by residential customers. Following Kim (1987), Kim and Clark (1988), Fabbri and Fraquelli (2000), Mizutani and Urakami (2001), Filippini (2008), and Ansink and Houba (2012), we control for both economies of size and scale to account for quantity of water sold. Each of these studies distinguish between output scale and network scale effects (economies of size and scale). Sold water and sold water per capita reflect different (although related) issues of economies of size and scale aspects for municipal water utilities. Also, inclusion of sold water better accounts for water purchases by surrounding communities and public service districts that impact the volume of water produced by the utility.

In the institutional category, we utilize variables of primary water source (i.e. ground water, surface water, or purchased water), network line length, long term debt, and volume of water loss in water production cycles. Bae (2007) controlled for different water right doctrines (i.e. riparian rights versus prior appropriation), different ownerships for water supply (i.e., public water versus private water systems), and different pricing mechanisms (i.e. uniform rates, increasing block rate, or decreasing block rates). Our observations are within a single state where 
more than $80 \%$ of all municipal water utilities follow a declining block rate structure. Since there is no significant heterogeneity in block rates, our final estimation does not control for this variable.

The water quality category includes a variable that reflects water quality violations experienced by utilities. For the geography category, we include variables reflecting elevation changes and differences in slope within a municipality's boundary along with population density. Table 1 shows the explanatory variables considered in each category.

Table 1. Categorization of explanatory variables

\begin{tabular}{ll}
\hline Variable & Category \\
\hline Sold water (million gallons) & Quantity \\
\hline Sold water per customer (million gallons) & Quantity \\
\hline Network length (miles/customer) & Institutional \\
\hline Debt $(\$ 1,000 /$ customer) & Institutional \\
\hline Water loss $(\%)$ & Institutional \\
\hline Ground water as source & Institutional \\
\hline Violations (number in 2014$)$ & Water quality \\
\hline Elevation difference (ft.) & Geographical \\
\hline Average slope $(\%)$ & Geographical \\
\hline Population density (person/sq. mile) & Geographical \\
\hline
\end{tabular}

Based on equation (1) and the variables described above, an empirical equation for water charges is written as:

$$
\begin{aligned}
& W C_{i}=\beta_{0}+\beta_{1} \text { Line }_{i}+\beta_{2} \text { Sold }_{i}+\beta_{3} \text { Sold }_{i}^{2}+\beta_{4} \text { SoldPC }_{i}+\beta_{5} \text { SoldPC }_{i}^{2}+\beta_{6} \text { Debt }_{i}+ \\
& \beta_{7} \text { Loss }_{i}+\beta_{8} \text { Ground }_{i}+\beta_{9} \text { Population }_{i}+\beta_{10} \text { Populationd }_{i}^{2}+\beta_{11} \text { Violation }_{i}+ \\
& \beta_{12} \text { ElevationDif }_{i}+\varepsilon_{i}
\end{aligned}
$$

The error term $\left(\varepsilon_{i}\right)$ is assumed to comply with the BLUE standard assumptions of expected value equal to zero, homoscedasticity, independently distributed and not correlated with other error terms or the independent variables. However, as pointed out by Guyomard and Vermersch (1989) and Filippini (1996), estimation of a translog variable cost function with a high number of explanatory variables can lead to multicollinearity problems. Thus, we evaluate three 
functional forms for the water charges model: a linear with quadratic variables, a Cobb-Douglas (log of dependent and independent variables), and a spatial model. A total of ten different specifications are estimated and evaluated with adjusted $\mathrm{R}^{2}$, Akaike Information Criterion (AIC), Schwarz Information Criterion (SIC), and Hannan-Quinn criteria to select the best specification. The first six models have a linear functional form and the remaining four are log-log form. A Davidson-MacKinnon $\mathrm{J}$ test is applied to choose between linear and log-log model specifications.

Our approach here is to initially estimate a non-spatial water charges model and then control for spatial spillovers by estimating another model in a spatial framework. According to the LeSage and Pace (2009) and Elhorst (2014), non-spatial econometric estimation is based upon observed values being independent of location with no correlation between neighbors. In nonspatial models, each observation has a mean of $x_{i} \beta$ and a random component $\varepsilon_{i}$ where the observation $i$ represents a region or point in space at one location and is considered to be independent of observations in other locations, i.e. $E\left(\varepsilon_{i} \varepsilon_{j}\right)=E\left(\varepsilon_{i}\right) E\left(\varepsilon_{l}\right)=0$.

However, in many cases, this independence assumption is not applicable so that observations at different points or regions are dependent (LeSage and Pace 2009). Suppose we have two neighbors (regions) $i$ and $j$. If these two regions are spatially correlated and normality for error terms is assumed, then:

$$
\begin{aligned}
& y_{i}=\rho_{i} y_{j}+x_{i} \beta+\varepsilon_{i} \\
& y_{j}=\rho_{j} y_{i}+x_{j} \beta+\varepsilon_{j}
\end{aligned}
$$

where the dependent variable in neighbor $j$ influences the dependent variable in neighbor $i$ and vice versa. When the spatial component (whether this component is from the dependent variable, control variables or the error term) is statistically significant, the coefficients estimated by nonspatial model may be biased. Also, variances may be non-efficient (Griffith, 2005; LeSage and 
Pace, 2009). Accordingly, statistical tests (t-test and F-test) may be invalid, leading researchers to interpret their results improperly.

After examining spatial dependency of our dependent variable with a Moran's I test ${ }^{1}$ (Moran's i index $=0.113$, P-value $=0.030$ ), this result show spatial dependency and the need to apply spatial econometrics modeling. There are five different spatial models. The first is the spatial autoregressive lag model (SAR) as shown in equations 3 and 4. Spatial Error Model (SEM) assumes dependency in error term. A SLX model or spatial lag of explanatory variable assumes that only explanatory variables play a direct role in determining dependent variables. Lastly, the Spatial Durbin Model (SDM) and Spatial Error Durbin Model (SDEM) include spatial lags of the explanatory variables as well as the dependent variable and a spatial lag of the explanatory variables (WX) along with spatially dependent disturbances.

To observe dependence between neighboring municipal water utility observations, spatial econometrics models differentiate between direct and indirect effects. Direct effects show how changes in an explanatory variable for the $i^{\text {th }}$ utility influences the $i^{\text {th }}$ utility's dependent variable. Indirect effects illustrate the effects of an explanatory variable in $j^{\text {th }}$ utility on $i^{\text {th }}$ utility's dependent variable $^{2}$. LeSage (2008) argues that since the impacts of the explanatory variable are different among observations, it is desirable to have a measurement of overall and average impacts. He introduces the concepts of average direct, indirect, total effects, and also feedback effects. LeSage and Pace (2014) explain "Feedback effects arise when changes to own region/entity characteristics exert an impact on outcomes in the own and neighboring regions/entities, which produce additional changes or feedback effects on outcomes in the own region."

\footnotetext{
${ }^{1}$ For more information, please see Li et al. (2007).

${ }^{2}$ For more information, see LeSage and Pace (2014) and LeSage (2008).
} 
Parameters in a general linear regression interpret as partial derivative of the dependent variable respect to the explanatory variable. Independent assumption is the base for the estimation of partial derivatives in a linear regression.

In a spatial model, interpretation of the parameters become more complicated. LeSage and Pace, 2009; Anselin and LeGallo, 2006; Kelejian, Tavlas and Hondronyiannis, 2006; Kim, Phipps, and Anselin, 2003; LeGallo, Ertur, and Baumont, 2003 argue that the model with a spatial lag of the dependent variable require special interpretation of the parameters.

Elhorst (2014) calculated the direct, indirect and the total effect in a general nesting spatial (GNS) model as

$$
Y=(I-\delta W)^{-1}(X \beta+W X \theta)+R
$$

where $\mathrm{R}$ is a rest term containing the intercept and the error terms.

The matrix of partial derivatives of expected dependent variable with respect to explanatory variables can be seen as

$$
\begin{aligned}
& {\left[\frac{\partial E(Y)}{\partial x_{1 k}} \cdot \frac{\partial E(Y)}{\partial x_{N k}}\right]=\left[\begin{array}{ccc}
\frac{\partial E\left(y_{1}\right)}{\partial x_{1 k}} & \cdot & \frac{\partial E\left(y_{1}\right)}{\partial x_{N k}} \\
\frac{\partial E\left(y_{N}\right)}{\partial x_{1 k}} & \cdot & \frac{\partial E\left(y_{N}\right)}{\partial x_{N k}}
\end{array}\right]} \\
& =(1-\delta W)^{-1}\left[\begin{array}{cccc}
\beta_{k} & w_{12} \theta_{k} & \cdot & w_{1 N} \theta_{k} \\
w_{21} \theta_{k} & \beta_{k} & \cdot & w_{2 N} \theta_{k} \\
\cdot & \cdot & \cdot & \cdot \\
w_{N 1} \theta_{k} & w_{N 2} \theta_{k} & \cdot & \beta_{k}
\end{array}\right]
\end{aligned}
$$

where $w_{i j}$ is the $(\mathrm{i}, \mathrm{j})$ th element of $\mathrm{W}$. Every diagonal element of the partial derivative matrix shows the direct effect while the indirect effects show by every off-diagonal element. Since the direct and indirect effects are unique for each observation, Lesage and Pace (2009) propose to report the summary indicators (the average of the diagonal elements for the direct effect and the 
average of either the row sums or the column sums of the off-diagonal elements for indirect effects). $\theta$ in a SAR model is equal to zero, indirect effect would be equal to the off-diagonal elements of $(1-\delta W)^{-1} \beta_{k}$.

All spatial models have a weight matrix (W), which quantifies the connections between regions. Elhorst (2014) names the weight matrix as a tool to describe the spatial arrangement of the geographical units in the sample. There are variety of units of measurement for spatial dependency such as neighbors, distance, and links (Getis, 2007). The spatial weight matrix is based on the distance between municipalities. In this study, we applied seven nearest-neighbors weight matrix. ${ }^{3}$ Spatial econometric models are estimated using software codes provided by Donald Lacombe. $^{4}$

For the minimum monthly access charge model, we include variables reflecting cost, social equity, municipal governance, city size, and fixed cost considerations. Brown (2007) explains that minimum charges are established to provide an essentially guaranteed base revenue stream for the utility. Kanakoudis and Tsitsifli (2014) argue that the determination of the fixed charge has to be based on the actual water charge. Besides water charge, we introduce social demographics of a municipality such as percentage of elderly population, median household income, and percentage of population below the poverty level to the minimum charge equation to see whether these socioeconomic characteristics influence the minimum monthly charge for access to water provision.

The general form for a minimum access charge equation for water provision is:

$$
M M C_{i}=f\left(W C_{i}, S E_{i}, S M_{i}, C S_{i}, W L_{i}\right)
$$

\footnotetext{
${ }^{3}$ Lesage and Pace (2010) argue that the configuration of the spatial weight matrix matters very little

${ }^{4}$ Available at: http://myweb.ttu.edu/dolacomb/matlab.html
} 
where $(M M C)$ stands for the minimum monthly charge set by the municipal water utility $i,(W C)$ is the water charge, and $(S E)$ shows the socioeconomic factors as indicators of social equity concerns influencing minimum charges.

$S M$ is a dummy variable to describe municipality governance. This variable is included in the minimum monthly access charge model to examine whether local politics influenced this charge. A "strong" mayor-council type of government is compared to a "weak" mayor-council and council-manager. Under a "strong" mayor-council government, a mayor is elected separately and has substantial administrative and budgetary authority above the council (National League of Cities, 2013). It is hypothesized that a "strong" mayor type of government would result in more political pressure to keep minimum charges low relative to a "weak" mayor or council-manager. There is some evidence in the literature that the existence of a "strong" mayor inhibits the implementation of policies such as market-based ideas within municipalities (Krebs and Pelissero, 2010, Bae et al., 2013).

The $C S$ variable measures the effect of city size on minimum monthly water charge. As we explained earlier, minimum charge represents a fixed proportion of the water charge that each residential customer must pay regardless of their water consumption. Since West Virginia is a small, mostly rural state, there are few large cities (only one over 50,000 in population). Thus, the size variable utilized was a distinction between class II municipalities $(10,000$ to 50,000 in population) versus class III and IV municipalities (less than 10,000). The logic for this variable is that larger municipalities imply a greater tax base from which there may be an increased ability of the municipality to absorb losses that might be incurred from lower minimum monthly access charges. Lastly, we include a variable to measure water loss (WL). The WL variable examines whether fixed costs like water losses influence the minimum water charge. 
The empirical model for minimum monthly access charges is:

$$
M M C_{i}=\beta_{0}+\beta_{1} W C_{i}+\beta_{2} P C I_{i}+\beta_{3} S R_{i}+\beta_{4} H O_{i}+\beta_{5} S M_{i}+\beta_{6} C S_{i}+\beta_{7} L_{i}+\varepsilon_{i}
$$

where $(P C I)$ is average per capita income; $(S R)$ is the percentage of households with one or more above 65-year-old; and $(\mathrm{HO})$ is the percentage of households own a house unit. To avoid a simultaneity issue, predicted water charges from equation 2 are utilized for $M C$ since both water charges and minimum charges are proposed simultaneously by water utilities to the WV PSC.

Since education, percent below poverty, and income variables are highly correlated, we conducted robustness checks by examining different combinations of these variables in models. We examine four different regression models and based on adjusted $\mathrm{R}^{2}$, AIC, SIC, and HannanQuinn criteria, the best model specification is chosen.

\section{DATA}

Data for this research are primarily based on the annual reports submitted to the WV PSC by municipal water utilities in West Virginia. These annual reports for water utilities are available through WV PSC website ${ }^{5}$ and data were collected for 2014. These reports contained numerous missing values - mostly for total treatment capacity, total main line, total long term debt, and water source. According to the WV PSC, there is no obligation for utilities to provide the information in their annual report. Thus, additional information was gathered through email and phone calls to utility personnel about missing data or when information in a report seems questionable.

Although regulated by the West Virginia Bureau of Public Health (WVBPH), the quality of water provided by each municipal utility differs depending upon the number of violations to drinking water standards. We introduce two variables to reflect violations during 2014 obtained

\footnotetext{
${ }^{5}$ Available at: http://www.psc.state.wv.us/Annual_Reports/default.htm
} 
from an annual report of environmental engineering division of the WVBPH: 1) the number of violations reported for each water utility, and 2) a dummy variable as an indicator of having a water violation or not. Out of 125 observations, 72 municipalities did not have any reported violations in 2014. The Natural Resource Analysis Center at West Virginia University provided the necessary topography data within municipality boundaries, maximum elevation, minimum elevation, elevation difference, and the average slope. Municipal population size is derived from the 2014 population estimates of the U.S. Census Bureau (2015).

A total of 14 cities in West Virginia have a population greater than 10,000, nine of these municipalities are in our data base. For local governance, historically, most municipalities in West Virginia have implemented a mayor-council type of government (Brisbin et al., 1996). This type of government was selected as the base and compared to a strong mayor type. Municipalities with a strong mayor were determined from an on-line search of municipal government web pages and a description of their governing structure. Of the 125 municipalities in the database, only nine have a strong mayor type.

Tables 2 and 3 show the data summary statistics ${ }^{6}$ and expected coefficient signs for the independent variables in the water charge and the minimum monthly access charge models. Due to considerations of economies of size and scale, negative coefficients are expected for population density, water sold, and the water sold per customer. We expect a positive coefficient for main line length due to added infrastructure costs. Since ground water typically requires less treatment than surface water, we expect a negative coefficient for the ground water source variable. Also, the

\footnotetext{
${ }^{6}$ For the log-log models, a value of 0.1 is used to replace zeros in all variable observations of zero with the exception of the violations variable. This allowed for conversion of variables to $\log$ values at a small value close to zero. Since the violations variable is expressed as integers only, we added +1 to the current values.
} 
violation coefficient is expected to be negative as the number of violations stem from lower quality source water and less treatment. To control for the degree of elevation changes within the utility service area, we introduce two topographic variables: difference between maximum and minimum elevation and average percent slope (Reznik et al. 2016). We expect both to have negative coefficients - the more changes in topography, the higher the cost of providing water due to higher costs of water transmission. In addition, we tried to control for other explanatory variables such as coal production, distance from the river, possibility to have access to private well, and water utility age. None of these variables had a statistically significant coefficient when included in regressions, therefore we report these results in Appendices III-IV.

For the minimum monthly access charge equation, we expect a positive sign for water charge. If social equity matters in setting minimum water charges, then income, education, and home ownership variables are expected to have positive coefficients. Also with social equity concerns, the percent of residents who are below the poverty line and the percentage of elderly households both should have negative impacts on minimum charges.

Table 2. Summary statistics of variables used in the water charge model $(n=125)$

\begin{tabular}{lllllc}
\hline Variable & Mean & $\begin{array}{c}\text { Standard } \\
\text { Deviation }\end{array}$ & Min & Max & $\begin{array}{c}\text { Expected } \\
\text { sign of } \\
\text { coefficient }\end{array}$ \\
\hline Water charges (\$) & 38.71 & 11.88 & 13.26 & 71.89 & \\
\hline Network length (miles/customer) & 0.04 & 0.27 & 0.001 & 3.10 & + \\
\hline Sold water (million gallons) & 137.34 & 295.26 & 13 & 11,374 & - \\
\hline $\begin{array}{l}\text { Sold water per customer (million } \\
\text { gallons) }\end{array}$ & 0.06 & 0.08 & 0.002 & 0.83 & - \\
\hline Debt (\$1,000/customer) & 1.52 & 1.42 & 0 & 6.03 & + \\
\hline Water loss (\%) & 24.59 & 17.23 & 0 & 92.32 & + \\
\hline Ground water as source & 0.26 & N/A & 0 & 1.00 & - \\
\hline $\begin{array}{l}\text { Population density (person/sq. } \\
\text { mile) }\end{array}$ & $1,316.60$ & 786.37 & 125.94 & $5,778.89$ & - \\
\hline Violations (number in 2014) & 2.46 & 5.15 & 0 & 34 & - \\
\hline Elevation difference (ft.) & 452.92 & 234.11 & 71.99 & 1285.03 & + \\
\hline Average slope (\%) & 18.834 & 11.175 & 4.62 & 55.82 & + \\
\hline
\end{tabular}


Table 3. Summary statistics of variables used in the minimum monthly access charge model $(n=125)$

\begin{tabular}{lccccc}
\hline Variable & Mean & $\begin{array}{c}\text { Standard } \\
\text { Deviation }\end{array}$ & Min & Max & $\begin{array}{c}\text { Expected } \\
\text { sign of } \\
\text { coefficient }\end{array}$ \\
\hline Minimum monthly charge $(\$)$ & 20.99 & 7.11 & 3.87 & 39 & \\
\hline $\begin{array}{l}\% \text { HHs with 1 and }>\text { 1 older than } \\
65(\%)\end{array}$ & 31.32 & 7.99 & 10.34 & 49.53 & - \\
\hline $\begin{array}{l}\text { Percentage of population older } \\
\text { than 65 (\%) }\end{array}$ & 17.62 & 5.82 & 4.60 & 37.50 & - \\
\hline Median Income $(\$)$ & $34,892.09$ & $12,263.78$ & 12,344 & 106,250 & + \\
\hline Per capita Income $(\$)$ & $19,719.85$ & $6,473.85$ & 4,472 & 64,099 & + \\
\hline $\begin{array}{l}\text { Percentage below poverty rate } \\
(\%)\end{array}$ & 22.61 & 9.96 & 0.1 & 55.3 & - \\
\hline $\begin{array}{l}\text { Percentage of home ownership } \\
(\%)\end{array}$ & 67.44 & 12.96 & 29.90 & 92.70 & + \\
\hline $\begin{array}{l}\text { Percentage of bachelor degree or } \\
\text { higher }(\%)\end{array}$ & 14.64 & 10.32 & 0.1 & 65.80 & + \\
\hline $\begin{array}{l}\text { Class II municipalities } \\
\text { Strong Mayor }\end{array}$ & 0.06 & N/A & 0 & 1 & - \\
\hline Water loss $(\%)$ & 0.04 & N/A & 0 & 1 & - \\
\hline
\end{tabular}

\section{RESULTS}

We estimate regressions using $W C$ and $M M C$ as dependent variables with institutional, governmental, geographical, environmental, and socioeconomic factors serving as independent variables. Variables that are highly correlated with the number of customers (network length, sold water, debt) are converted to per capita to avoid multicollinearity. For the water charges model, all specification criteria (adjusted $\mathrm{R}^{2}$, AIC, SIC, and Hannan-Quinn criteria) show models with Violations and Elevation difference variables as the best for both linear and log-log specifications. The Davidson-MacKinnon $\mathbf{J}$ test resulted in selection of a linear specification with variables not transformed into log values ${ }^{7}$.

\footnotetext{
${ }^{7}$ The estimated coefficient for predicted value from the log-log model in the linear model is $0.10(\mathrm{p}$-value $=0.717)$ while the estimated coefficient for the predicted value from the linear model in the log-log model is 1.04 ( $p$-value $=0.000$ ).
} 
For the spatial model, we choose the most representative weight matrix for the data by testing for different sets of nearest neighbor relationships. The seven nearest neighbors' weight matrix has the highest log likelihood value among the eight matrices examined. Since loglikelihood has the power to compare the models, this statistic guides us to our particular specification (Kalenkoski and Lacombe, 2013).

To examine spatial correlation among observations, we utilize five different spatial models (i.e. SAR, SEM, SDM, SDEM, and SLX). Table 4 shows the results for the SAR model since this model is the only one with a significant spatial component. We report the other specifications in Appendix I. Model 1 specification is used in a spatial framework because among all the linear and $\log -\log$ functional forms, this model has the highest adjusted $\mathrm{R}^{2}$. In the SAR model, there is a positive and statistically significant spillover effect. This result means that water charges in neighboring municipal utilities have positive spillover effects on the water charge of a particular municipal utility. In other words, since water charges are spatially dependent, if charges increase in a neighboring municipal $j$, then water charges in municipal $i$ will increase as well.

With a statistically significant $\rho$ value in the SAR model, the OLS coefficient estimates are likely biased and presented in Table 4 only for a comparison with the magnitude of the direct effects from the SAR model. The water charges model has direct effect with p-values below 0.05 for the variables: sold water per capita; total debt; ground water as a water source, and population density. The network length variable has a direct effect with a p-value under 0.10 , while water loss, elevation difference and violation variable coefficients have p-values much above 0.05 (Table 4). Our expectations for the elevation difference and violation variables are not met by this model, however, their p-values are all above 0.10. 
To interpret the direct effect results, a one person increase per square mile will decrease the water charge by $\$ 0.01$. Although based on the quadratic form of population density, this is true up to a certain point (5000 people/square mile), after this point, population density will actually start to increase water charges. Other interpretations of 4,500 gallon charges include: increasing the total long-term debt by one thousand dollars per customer will increase this charge by $\$ 1.84$, use of ground water as a primary water source reduces this charge by $\$ 4.83$, and an increase of one mile in main line length per customer will increase this charge by $\$ 5.15$.

While none of the indirect effects have p-values even close to 0.10 , the total effect impacts in the SAR model increase the overall magnitude of impact on water charges. For example, ground water as a water source has an estimated total impact of reducing water charges by $\$ 6.45$ in the SAR model compared to the linear model estimate of $\$ 5.11$. 
Table 4. Water charges model results for OLS and SAR estimations $(n=125)$

\begin{tabular}{|c|c|c|c|c|}
\hline & OLS & & SAR & \\
\hline Variable & Coefficients & Direct effect & Indirect effect & Total effect \\
\hline \multirow{2}{*}{ Network length pc } & 5.20 & 5.15 & 1.87 & 7.03 \\
\hline & $(0.096)$ & $(0.087)$ & $(0.442)$ & $(0.131)$ \\
\hline \multirow{2}{*}{ Sold water (000) } & -8.82 & -8.33 & -2.15 & -10.48 \\
\hline & $(0.282)$ & $(0.285)$ & $(0.544)$ & $(0.315)$ \\
\hline \multirow{2}{*}{ Sold water ${ }^{2}(000)$} & 0.0007 & 0.0004 & 0.00007 & 0.0005 \\
\hline & $(0.859)$ & $(0.915)$ & $(0.992)$ & $(0.936)$ \\
\hline \multirow{2}{*}{ Sold water pc } & -126.40 & -125.33 & -44.37 & -169.71 \\
\hline & $(0.006)$ & $(0.004)$ & $(0.368)$ & $(0.026)$ \\
\hline \multirow{2}{*}{ Sold water $\mathrm{pc}^{2}$} & 147.79 & 146.86 & 51.88 & 198.75 \\
\hline & $(0.006)$ & $(0.004)$ & $(0.366)$ & $(0.025)$ \\
\hline \multirow{2}{*}{ Debt pc } & 1.84 & 1.84 & 0.65 & 2.50 \\
\hline & $(0.002)$ & $(0.001)$ & $(0.347)$ & $(0.015)$ \\
\hline \multirow{2}{*}{ Water loss } & 0.05 & 0.05 & 0.02 & 0.07 \\
\hline & $(0.281)$ & $(0.234)$ & $(0.511)$ & $(0.273)$ \\
\hline \multirow{2}{*}{ Ground water } & -5.11 & -4.83 & -1.61 & -6.45 \\
\hline & $(0.008)$ & $(0.008)$ & $(0.339)$ & $(0.020)$ \\
\hline \multirow{2}{*}{ Population density (000) } & -10.01 & -9.87 & -2.59 & -12.46 \\
\hline & $(0.000)$ & $(0.000)$ & $(0.336)$ & $(0.009)$ \\
\hline \multirow{2}{*}{ Population density $^{2}(000)$} & 0.002 & 0.002 & 0.0004 & 0.0022 \\
\hline & $(0.002)$ & $(0.001)$ & $(0.346)$ & $(0.015)$ \\
\hline \multirow{2}{*}{ Violation } & 0.17 & 0.15 & 0.04 & 0.20 \\
\hline & $(0.323)$ & $(0.346)$ & $(0.590)$ & $(0.378)$ \\
\hline \multirow{2}{*}{ Elevation difference } & -0.006 & -0.005 & -0.001 & -0.007 \\
\hline & $(0.110)$ & $(0.126)$ & $(0.432)$ & $(0.157)$ \\
\hline \multirow{5}{*}{ Constant } & 55.54 & - & - & 45.45 \\
\hline & $(0.000)$ & & & $(0.000)$ \\
\hline & $\mathrm{R}^{2}=0.32$ & \multirow{2}{*}{\multicolumn{2}{|c|}{ Adj. $R^{2}=0.34$}} & \\
\hline & $12=5.91$ & & & \\
\hline & & \multicolumn{2}{|c|}{$\begin{array}{c}\rho=0.23 \\
\text { p-value }=0.001\end{array}$} & \\
\hline
\end{tabular}

Note: P-values in parenthesis

$\mathrm{pc}=$ per customer

Finally, the best model specified for minimum monthly access charges includes variables for households with one or more residents over 65 and per capita income (Table 5). This model also is examined for spatial impacts. We repeat the same procedure as the water charge model in order to choose the most appropriate weight matrix. The seventh nearest neighbor weight matrix has the highest log-likelihood, so that we continue the rest of spatial econometric estimations based upon influences from the seventh nearest neighbors. The results of the SAR and 
SEM estimations (the only two spatial models with statistically significant spatial components) are presented in Table 5. The results for the other three spatial models are presented in Appendix II. Interpreting the spatial model impacts, only predicted water charges impact minimum monthly access charges with p-values below 0.05 . These minimum monthly access charges incorporate from between $33 \%$ and $40 \%$ of the municipal utility's 4,500-gallon charge. All other variables, including the socioeconomic variables, have impacts with p-values well above 0.10 . Overall, the results of these models show that socioeconomic factors within municipal populations do not contribute to equity considerations explaining variations in municipal utility minimum charges.

Water charges have positive indirect effects on the minimum monthly access charges so that predicted water charges in municipal $i$ influence not only the minimum water charge in municipal $i$, but also influence the minimum water charge in neighboring $j$ municipalities. This spillover effect from water charges is about $1 / 3$ the size of the direct effect. Also, the SEM model result shows that there are some significant spillover effects of variables that are not explicitly modeled (error term). Except for the negative total effect by strong mayor in the SAR model, none of the variable coefficients other than predicted water charge in Table 5 show evidence of statistical significance. 
Table 5. Minimum monthly access charge model results for OLS, SAR, and SEM estimates $(n=125)$

\begin{tabular}{|c|c|c|c|c|c|}
\hline & OLS & & SAR & & SEM \\
\hline Variable & Coefficients & Direct effect & Indirect effect & Total effect & Coefficients \\
\hline $\begin{array}{l}\text { Predicted Water } \\
\text { Charge }\end{array}$ & $\begin{array}{c}0.39 \\
(0.000)\end{array}$ & $\begin{array}{c}0.33 \\
(0.000)\end{array}$ & $\begin{array}{c}0.11 \\
(0.077)\end{array}$ & $\begin{array}{c}0.44 \\
(0.000)\end{array}$ & $\begin{array}{c}0.39 \\
(0.000)\end{array}$ \\
\hline $\begin{array}{l}\text { Household with one } \\
\text { or more older than } \\
65\end{array}$ & $\begin{array}{c}0.04 \\
(0.638)\end{array}$ & $\begin{array}{c}0.03 \\
(0.524)\end{array}$ & $\begin{array}{c}0.01 \\
(0.589)\end{array}$ & $\begin{array}{c}0.04 \\
(0.534)\end{array}$ & $\begin{array}{c}0.04 \\
(0.649)\end{array}$ \\
\hline Per capita income & $\begin{array}{c}-0.04 \\
(0.658)\end{array}$ & $\begin{array}{c}-0.04 \\
(0.710)\end{array}$ & $\begin{array}{c}-0.02 \\
(0.759)\end{array}$ & $\begin{array}{c}-0.06 \\
(0.720)\end{array}$ & $\begin{array}{l}-0.028 \\
(0.746)\end{array}$ \\
\hline $\begin{array}{l}\text { Home ownership } \\
\text { rate }\end{array}$ & $\begin{array}{c}0.06 \\
(0.264)\end{array}$ & $\begin{array}{c}0.04 \\
(0.238)\end{array}$ & $\begin{array}{c}0.01 \\
(0.368)\end{array}$ & $\begin{array}{c}0.05 \\
(0.259)\end{array}$ & $\begin{array}{c}0.06 \\
(0.230)\end{array}$ \\
\hline $\begin{array}{l}\text { Class II } \\
\text { municipalities }\end{array}$ & $\begin{array}{l}-1.20 \\
(0.645)\end{array}$ & $\begin{array}{l}-1.68 \\
(0.647)\end{array}$ & $\begin{array}{c}-0.68 \\
(0.708)\end{array}$ & $\begin{array}{c}-2.37 \\
(0.659)\end{array}$ & $\begin{array}{c}-0.38 \\
(0.824)\end{array}$ \\
\hline Strong Mayor & $\begin{array}{c}-4.55 \\
(0.095)\end{array}$ & $\begin{array}{c}-4.62 \\
(0.118)\end{array}$ & $\begin{array}{c}-1.70 \\
(0.276)\end{array}$ & $\begin{array}{c}-6.33 \\
(0.099)\end{array}$ & $\begin{array}{c}-4.04 \\
(0.115)\end{array}$ \\
\hline Water loss & $\begin{array}{c}0.01 \\
(0.100)\end{array}$ & $\begin{array}{c}0.006 \\
(0.855)\end{array}$ & $\begin{array}{c}0.001 \\
(0.898)\end{array}$ & $\begin{array}{c}0.007 \\
(0.864)\end{array}$ & $\begin{array}{c}0.001 \\
(0.959)\end{array}$ \\
\hline Constant & $\begin{array}{c}1.02 \\
(0.823)\end{array}$ & - & - & $\begin{array}{l}-5.25 \\
(0.31)\end{array}$ & $\begin{array}{c}1.51 \\
(0.736)\end{array}$ \\
\hline & $\begin{array}{l}R^{2}=0.19 \\
17=5.19\end{array}$ & \multicolumn{3}{|c|}{ Adj. $R^{2}=0.20$} & Adj. $\mathrm{R}^{2}=0.23$ \\
\hline & & \multicolumn{2}{|c|}{$\begin{array}{c}\rho=0.34 \\
\text { p-value }=0.007\end{array}$} & & $\begin{array}{c}\lambda=0.31 \\
\text { p-value }=0.022\end{array}$ \\
\hline
\end{tabular}

Note: P-values in parenthesis

\section{CONCLUSIONS}

Previous studies on water cost estimation have neglected both geography and spillover aspects regarding factors explaining the cost of providing water, although some researchers explicitly recommend controlling for these variables (Antonioli and Filippini, 2001). As discussed earlier, the main goal of this study is first to estimate the influences of primary factors on water charges and secondly, to estimate the determinants of minimum monthly access charges across municipalities in West Virginia. Our estimation of the water charge model shows that the quantity of water sold per customer, population density, ground water as a primary source of water, and utility debt source are the most important explanatory factors for residential water charges. In addition, main line length is an influential factor to explaining water charges. The addition of a 
geographic variable did not explain variations in water charges and did have its expected impact on water charges.

From our model results, ground water as a water source lowers water charges by about $\$ 5$ to $\$ 6$ per 4,500 gallons (approximately a $15 \%$ reduction in customer cost). This result demonstrates the importance of protecting ground water quality with source water protection programs. According to the U.S. Environmental Protection Agency, states, local governments, and utilities all play important roles in water protection programs. In West Virginia, implementation of wellhead protection programs began in the early 1990's as a part of ground water protection strategy to encourage utilities to develop protection and management plans. The WVBPH assesses all of West Virginia's public water systems and creates polices to provide clean and safe drinking water. Our water charge model results provide the basis for a rough estimate of the benefits from this ground water protection. Allowing for a \$5 saving for each 4,500 gallons of use, the over 240,000 households in West Virginia served by municipalities using ground water have an annual cost savings of $\$ 3.6$ million in their water charges compared to other water sources.

Similar to Bae (2007), we find that utility debt also impacts water charges. For every $\$ 1,000$ of utility debt, water charges increase by about $\$ 2$ per 4,500 gallons. Given the mean of debt per customer and 4,500 gal of water use monthly, utility debt adds about $\$ 36$ to the annual household water bill (about an $8 \%$ increase). This result demonstrates the importance of grant versus loan financing to utilities. As reported by the Environmental Finance System ${ }^{8}$, different organizations provide long term fixed low-interest loans to rural areas and low-income communities to help them to increase the water quality. Prior to the 1987 amendments to the Clean Water Act, municipal utility assistance was provided through grants with the federal

\footnotetext{
${ }^{8}$ http://efcnetwork.org/wp-content/uploads/2016/07/WV-Water-Wastewater-Funds-2016.pdf
} 
government picking up 55\% of project cost. This amendment changed grants to low-interest rate loans. This change means that now local governments are responsible for $100 \%$ of projects' cost (Copeland, 1999). This societal change of replacing the federal government grants to municipal utilities with low-interest loans has increased long term utility debt, which has increased water charges to customers.

The population density variable has a negative effect on water charges in all model specifications, which means more dense areas have lower water charges. Given the quadratic specification, this negative impact occurs only up to a certain point (5,000 people/square mile). This is also true for the total water sold to customers. In other words, although municipalities in West Virginia are small, both size and scale impacts are still found in small municipalities.

In addition, there are modest, but statistically significant (evaluated at a $\mathrm{p}=0.05$ or lower) levels of spatial autocorrelation in both models among West Virginia municipal water utilities in terms of water charges and minimum monthly access charges. This result shows that both these pricing decisions are influenced by neighboring utilities. While none of the variables in the water charges model had statistically influential, indirect impacts, water charges in the minimum monthly access charge model had a positive indirect impact with a p-value below 0.10 . Thus, an increase in water charges in municipal utility $i$ leads not only to a higher minimum charge in municipality $i$, but also higher minimum charges in neighboring $j$ municipalities due to positive spillover effects.

When examining minimum charges, there is some evidence that utilities located in strong mayor governing system assess lower minimum charges than other municipalities. Overall, minimum charges are closely related to water charges - incorporating just over one-third of the water charge for 4,500 gallons into the minimum charge. To examine the share of household income taken up by water charges in West Virginia municipalities, we calculated the average water 
use for each household multiplied the water charge and divided by the average household income. On average, West Virginia households pay far below the OECD standard of $3 \%$ to $5 \%$ of household income for water. Our results indicate that the average share of water costs across West Virginia households with municipal water utilities is about $1.5 \%$ of household income devoted to water charges with a maximum share being $4 \%$. With such reasonable costs of water for households, this could be a factor explaining why our models find no significant effects from socioeconomic factors on monthly minimum charges for access to water.

Finally, this research raises few issues with affordability of current municipal water charges. However, Mack and Wrase (2017) project affordability issues that could occur with future water rate increases of $6 \%$ and $41 \%$. These projected increases are based upon observed water rate increases since 2010. If such water rate increases do occur, this will leave the state of West Virginia with the highest percentage of at-risk census tracts $(46 \%)$ of any state in the nation for households unable to afford water bills, primarily due to the prevalence of low-income and elderly households in southern and central parts of the state. Their research raises potential future concerns about the continued affordability of water and the financial viability of municipal utilities providing service to areas with numerous low income households. 


\section{REFERENCES}

Anselin, L., \& Le Gallo, J. (2006). Interpolation of air quality measures in hedonic house price models: spatial aspects. Spatial Economic Analysis, 1(1), 31-52.

Ansink, E., \& Houba, H. (2012). Market power in water markets. Journal of Environmental Economics and Management, 64(2), 237-252.

Antonioli, B., \& Filippini, M. (2001). The use of a variable cost function in the regulation of the Italian water industry. Utilities Policy, 10(3), 181-187.

Araral, E., Asquer, A., \& Wang, Y. (2017). Regulatory Constructivism: Application of Q Methodology in Italy and China. Water Resources Management, 31(8), 2497-2521.

Bae, S. (2007). Explaining Geographical Differences in Water Prices: Do Institutional Factors Really Matter? The Review of Regional Studies, 37(2), 207-250.

Bae, S., Moon, S. G., \& Hong, S. W. (2013). Institutional, Regulatory, and Municipality-Specific Factors Affecting Wastewater Prices: The Case of North Carolina Municipalities. Policy Analysis and Management, May 25-27, 2013 in Shanghai, China.

Baerenklau, K. A., Schwabe, K. A., \& Dinar, A. (2014). The residential water demand effect of increasing block rate water budgets. Land Economics, 90(4), 683-699.

Bakker, K. (2001). Paying for water: water pricing and equity in England and Wales. Transactions of the Institute of British Geographers, 26(2), 143-164.

Bel, G., Fageda, X., \& Warner, M. E. (2010). Is private production of public services cheaper than public production? A meta-regression analysis of solid waste and water services. Journal of Policy Analysis and Management, 29(3), 553-577.

Bithas, K. (2008). The sustainable residential water use: Sustainability, efficiency and social equity. The European experience. Ecological Economics, 68(1), 221-229.

Boadway, R. (1976). Integrating equity and efficiency in applied welfare economics. The Quarterly Journal of Economics, 541-556.

Borenstein, S., \& W. Davis, L. (2012). The equity and efficiency of two-part tariffs in US natural gas markets. The Journal of Law and Economics, 55(1), 75-128.

Boyer, T. A., Kanza, P., Ghimire, M., \& Moss, J. Q. (2015). Household adoption of water conservation and resilience under drought: The case of Oklahoma City. Water Economics and Policy, 1(02), 1550005.

Brisbin, R.A., Dilger R.J., Hammock A.S., \& Mooney C.Z. (1996). West Virginia Politics \& Government. University of Nebraska Press. 
Brown, C. (2007). Minimum charge concept for water and wastewater systems. The Kansas Lifeline. http://www.krwa.net/lifeline/currentissue/0711_032.pdf

Carvalho, P., Marques, R. C., \& Berg, S. (2012). A meta-regression analysis of benchmarking studies on water utilities market structure. Utilities Policy, 21, 40-49.

Coase, R. H. (1946). The marginal cost controversy. Economica, 13(51), 169-182.

Consumer Utilities Advocacy Centre. (2012). Social equity objectives in urban water pricing. http://www.cuac.org.au/consumer-a-community-resources/presentations/46-socialequity-objectives-in-urban-water-pricing/file [14 June 2016].

Copeland, C. (1999). Water infrastructure financing: History of EPA appropriations. Congressional Research Service, Library of Congress.

Elhorst, J. P. (2014). Spatial econometrics: from cross-sectional data to spatial panels (pp. 2025). New York: Springer.

Ercin, A. E., \& Hoekstra, A. Y. (2014). Water footprint scenarios for 2050: A global analysis. Environment international, 64, 71-82.

Fabbri, P., \& Fraquelli, G. (2000). Costs and structure of technology in the Italian water industry. Empirica, 27(1), 65-82.

Feigenbaum, S., \& Teeples, R. (1983). Public versus private water delivery: a hedonic cost approach. The review of Economics and Statistics, 672-678.

Filippini, M. (1996). Economies of scale and utilization in the Swiss electric power distribution industry. Applied Economics, 28(5), 543-550.

García-Valiñas, M. Á. (2005). Efficiency and equity in natural resources pricing: a proposal for urban water distribution service. Environmental and Resource Economics, 32(2), 183204.

Getis, A. (2007). Reflections on spatial autocorrelation. Regional Science and Urban Economics, 37(4), 491-496.

Gleick, P. H. (1998). Water in crisis: paths to sustainable water use. Ecological Applications, 8(3), 571-579.

Goldstein, J. (1986). Full-cost water pricing. Journal American Water Works Association, 52-61.

Griffith, D. A. (2005). Effective geographic sample size in the presence of spatial autocorrelation. Annals of the Association of American Geographers, 95(4), 740-760. 
Guerrini, A., Romano, G., \& Campedelli, B. (2011). Factors affecting the performance of water utility companies. International Journal of Public Sector Management, 24(6), 543-566.

Guyomard, H., \& Vermersch, D. (1989). Derivation of long-run factor demands from short-run responses. Agricultural Economics, 3(3), 213-230.

Holland, S. P. (2006). Privatization of water-resource development. Environmental and Resource Economics, 34(2), 291-315.

Inman, D., \& Jeffrey, P. (2006). A review of residential water conservation tool performance and influences on implementation effectiveness. Urban Water Journal, 3(3), 127-143.

Kalenkoski, C. M., \& Lacombe, D. J. (2013). Minimum wages and teen employment: A spatial panel approach. Papers in Regional Science, 92(2), 407-417.

Kanakoudis, V., \& Tsitsifli, S. (2014). Verifying the usefulness of the IWA Water Balance 2nd modification: Pinpointing the actual role of the fixed charge included in the water tariffs. In A. Liakopoulos, A. Kungolos, C. Christodoulatos, \& A. Koutsospyros Eds.), Proceedings of the 12th International Conference on Protection and Restoration of the Environment, Skiathos Island, Greece (Vol. 29).

Kelejian, H. H., Tavlas, G. S., \& Hondroyiannis, G. (2006). A spatial modelling approach to contagion among emerging economies. Open economies review, 17(4-5), 423-441.

Klein, M. W. (1996). Economic regulation of water companies. World Bank Publications.

Kim, H. Y. (1987). Economies of scale in multi-product firms: an empirical analysis. Economica, 185-206.

Kim, H. Y., \& Clark, R. M. (1988). Economies of scale and scope in water supply. Regional Science and Urban Economics, 18(4), 479-502.

Kim, C. W., Phipps, T. T., \& Anselin, L. (2003). Measuring the benefits of air quality improvement: a spatial hedonic approach. Journal of environmental economics and management, 45(1), 24-39.

Komarulzaman, A. (2017). Water Affordability, Water Quality and their Consequences for Health and Education in Indonesia (Doctoral dissertation, [Sl: sn]).

Krebs, T.B. \& Pelissero J.P. (2010). Urban managers and public policy: Do institutional arrangement influence decisions to initiate policy? Urban Affairs Review, 45(3): 391411.

Kritikos, A., \& Bolle, F. (2001). Distributional concerns: equity-or efficiencyoriented? Economics Letters, 73(3), 333-338. 
Le Gallo, J., Ertur, C., \& Baumont, C. (2003). A spatial econometric analysis of convergence across European regions, 1980-1995. In European regional growth (pp. 99-129). Springer, Berlin, Heidelberg.

Le Grand, J. (1990). Equity versus efficiency: the elusive trade-off. Ethics, 100(3), 554-568.

LeSage, J. P. (2008). An introduction to spatial econometrics. Revue d'économie industrielle, (3), $19-44$.

LeSage, J.P., \& Pace, K., (2009). Introduction to Spatial Econometrics. Taylor \& Francis Group, LLC.

LeSage J.P., \& Pace, K. (2010). The biggest myth in spatial econometrics. http://ssrn.com/abstract=1725503 [5 June 2016].

LeSage, J. P., \& Pace, R. K. (2014). Interpreting spatial econometric models. In Handbook of Regional Science (pp. 1535-1552). Springer Berlin Heidelberg.

Li, H., Calder, C. A., \& Cressie, N. (2007). Beyond Moran's I: testing for spatial dependence based on the spatial autoregressive model. Geographical Analysis, 39(4), 357-375.

Mack, E. A., \& Wrase, S. (2017). A burgeoning crisis? A nationwide assessment of the geography of water affordability in the United States. PloS one, 12(1), e0169488.

Mekonnen, M. M., \& Hoekstra, A. Y. (2016). Four billion people facing severe water scarcity. Science advances, 2(2), e1500323.

Millock K, \& Nauges C (2010) Household adoption of water-efficient equipment: the role of socio-economic factors, environmental attitudes and policy. Environ Resour Econ 46:539-565.

Mizutani, F., \& Urakami, T. (2001). Identifying network density and scale economies for Japanese water supply organizations. Papers in Regional Science, 80(2), 211-230.

Müller, C. (2015). Welfare Effects of Water Pricing in Germany. Water Economics and Policy, 1(04), 1550019.

National League of Cities. (2013). Forms of municipal government. http://www.nlc.org/buildskills-and-networks/resources/cities-101/city-structures/forms-of-municipal-government. [7 March 2016].

Organization for Economic Co-operation and Development (OECD). (2003). Social Issues in the Provision and Pricing of Water Services, OECD Publishing, Paris. http://dx.doi.org/10.1787/9789264099890-en. [4 July 2016]. 
OECD. (2010). Pricing Water Resources and Water and Sanitation Services, OECD Publishing, Paris. http://www.oecdbookshop.org/browse.asp?pid=titledetail\&lang=en\&ds=\&ISB=9789264083608 [23 April 2016].

Pahl-Wostl, C. (2015). Water Policy—From Panaceas towards Embracing Complexity. In Water Governance in the Face of Global Change (pp. 11-24). Springer International Publishing.

Polycarpou, A., \& Zachariadis, T. (2013). An econometric analysis of residential water demand in Cyprus. Water resources management, 27(1), 309-317.

Porcher, S. (2014). Efficiency and equity in two-part tariffs: the case of residential water rates. Applied Economics, 46(5), 539-555.

Randolph B, Troy P (2008) Attitudes to conservation and water consumption. Environ Sci Policy 11:441-455.

Renzetti, S. (1999). Municipal water supply and sewage treatment: costs, prices, and distortions. Canadian Journal of Economics, 688-704.

Renzetti, S., \& Dupont, D. (2004). The performance of municipal water utilities: Evidence on the role of ownership. Journal of toxicology and environmental health, Part A, 67(20-22), 1861-1878.

Renzetti, S. (2012). The economics of water demands (Vol. 22). Springer Science \& Business Media.

Renwick, M. E., \& Archibald, S. O. (1998). Demand side management policies for residential water use: who bears the conservation burden? Land economics, 343-359.

Reznik, A., Feinerman, E., Finkelshtain, I., Kan, I., Fisher, F., Huber-Lee, A., \& Joyce, B. (2016). The Cost of Covering Costs: A Nationwide Model for Water Pricing. Water Economics and Policy, 2(04), 1650024.

Rijsberman, F. R. (2006). Water scarcity: fact or fiction? Agricultural water management, 80(1), $5-22$.

Sanchez-Martinez, T., \& Rodriguez-Ferrero, N. (2016). Ramsey Pricing for Cost Recovery Applied to Reservoir Infrastructure in Andalucía (Spain). Water Economics and Policy, 1650029.

Savenije, H. H. (2002). Why water is not an ordinary economic good, or why the girl is special. Physics and Chemistry of the Earth, Parts A/B/C, 27(11), 741-744.

Suárez-Varela, M., de los Ángeles García-Valiñas, M., González-Gómez, F., \& Picazo-Tadeo, A. J. (2017). Ownership and performance in water services revisited: Does private management really outperform public? Water Resources Management, 31(8), 2355-2373. 
Teeples, R., \& Glyer, D. (1987). Cost of water delivery systems: specification and ownership effects. The Review of Economics and Statistics, 399-408.

Teodoro, M. P. (2018). Measuring Household Affordability for Water and Sewer Utilities. Journal-American Water Works Association, 110(1), 13-24.

United Nations. (2010). The human right to water and sanitation. Resolution adopted by the General Assembly on 28 July 2010. http://www.un.org/waterforlifedecade/human_right_to_water.shtml [10 June 2016].

U.S. Census Bureau. (2015). Population estimates: Annual estimates of the resident population for incorporated places: April 1, 2010 to July 1, 2014. http://www.census.gov/popest/data/cities/totals/2014/SUB-EST2014-3.html [12 July 2015].

Vanhille, J., Goedemé, T., Penne, T., Van Thielen, L., \& Storms, B. (2018). Measuring water affordability in developed economies. The added value of a needs-based approach. Journal of environmental management, 217, 611-620.

West Virginia Public Service Commission. (2014). Water utility rankings in WV - 4500 gallons. http://www.psc.state.wv.us/scripts/Utilities/rptWaterRankings4500.cfm [1 June 2015].

Walton, B. (2015). Price of Water 2015: Up 6 percent in 30 Major U.S. Cities; 41 Percent Rise Since 2010. Circle of Blue. http://www.circleofblue.org/2015/world/price-of-water-2015up-6-percent-in-30-major-u-s-cities-41-percent-rise-since-2010/ [5 September 2015].

World Bank. (2015). Improved water source (\% of population with access). http://data.worldbank.org/indicator/SH.H2O.SAFE.ZS. [26 September 2015].

World Economic Forum, Global Risks 2015, 10th Edition (World Economic Forum, Geneva, Switzerland, 2015).

Wutich, A., Budds, J., Eichelberger, L., Geere, J., Harris, L. M., Horney, J. A., ... \& Shah, S. H. (2017). Advancing methods for research on household water insecurity: Studying entitlements and capabilities, socio-cultural dynamics, and political processes, institutions and governance. Water Security.

Zajac, E. E. (1978). Fairness or efficiency: An introduction to public utility pricing. Ballinger Pub. Co. 


\section{Appendix I.}

Table 6. Estimation results for water charges SEM, SDM, SLX, and SDEM models

\begin{tabular}{|c|c|c|c|c|}
\hline Variable & SEM & SDM & SLX & SDEM \\
\hline \multirow{2}{*}{ Network length pc } & 5.34 & 4.64 & 4.64 & 4.7 \\
\hline & $(0.064)$ & $(0.000)$ & $(0.161)$ & 0.10 \\
\hline \multirow{2}{*}{ Sold water (000) } & -6.86 & -6.96 & -6.92 & -6.78 \\
\hline & $(0.219)$ & $(0.325)$ & $(0.451)$ & $(0.395)$ \\
\hline \multirow{2}{*}{ Sold water square $(000)$} & 0.0006 & -0.0006 & -0.0006 & -0.0007 \\
\hline & $(0.843)$ & $(0.863)$ & $(0.889)$ & $(0.852)$ \\
\hline \multirow{2}{*}{ Sold water pc } & -123.33 & -157.10 & -156.98 & -157.57 \\
\hline & $(0.000)$ & $(0.000)$ & $(0.001)$ & $(0.000)$ \\
\hline \multirow{2}{*}{ Sold water pc square } & 145.40 & 187.19 & 178.11 & 178.11 \\
\hline & $(0.000)$ & $(0.000)$ & $(0.002)$ & $(0.000)$ \\
\hline \multirow{2}{*}{ Debt pc } & 1.81 & 2.01 & 2.01 & 2.00 \\
\hline & $(0.001)$ & $(0.000)$ & $(0.002)$ & $(0.000)$ \\
\hline \multirow{2}{*}{ Water loss } & 0.08 & -0.03 & 0.04 & 0.03 \\
\hline & $(0.222)$ & $(0.398)$ & $(0.478)$ & $(0.424)$ \\
\hline \multirow{2}{*}{ Ground water } & -5.13 & -5.004 & -5.005 & -4.96 \\
\hline & $(0.005)$ & $(0.004)$ & $(0.022)$ & $(0.009)$ \\
\hline \multirow{2}{*}{ Population density (000) } & -9.15 & -9.15 & -9.16 & -9.18 \\
\hline & $(0.000)$ & $(0.000)$ & $(0.001)$ & $(0.000)$ \\
\hline \multirow{2}{*}{ Population density square (000) } & 0.002 & 0.002 & 0.016 & 0.016 \\
\hline & $(0.001)$ & $(0.002)$ & $(0.009)$ & $(0.002)$ \\
\hline \multirow{2}{*}{ Violation } & 0.14 & 0.09 & 0.09 & 0.095 \\
\hline & $(0.357)$ & $(0.554)$ & $(0.607)$ & $(0.563)$ \\
\hline \multirow{2}{*}{ Elevation difference } & -0.005 & -0.004 & -0.004 & -0.004 \\
\hline & $(0.136)$ & $(0.311)$ & $(0.381)$ & $(0.328)$ \\
\hline \multirow{2}{*}{ Constant } & 54.70 & 70.94 & 70.54 & 71.00 \\
\hline & $(0.000)$ & $(0.000)$ & $(0.000)$ & $(0.000)$ \\
\hline rho & - & $\begin{array}{c}0.005 \\
(0.962)\end{array}$ & - & - \\
\hline Lambda & $\begin{array}{c}0.18 \\
(0.221)\end{array}$ & - & - & $\begin{array}{c}-0.05 \\
(0.767)\end{array}$ \\
\hline \multirow{2}{*}{$\mathrm{W}^{*}$ Network length pc } & & -4.82 & -4.85 & -4.47 \\
\hline & - & $(0.000)$ & $(0.567)$ & $(0.529)$ \\
\hline \multirow{2}{*}{ W* Sold water $(000)$} & & 4.08 & 4.6 & 4.92 \\
\hline & - & $(0.856)$ & $(0.882)$ & $(0.823)$ \\
\hline \multirow{2}{*}{$\mathrm{W}^{*}$ Sold water square $(000)$} & & -0.01 & -0.01 & -0.01 \\
\hline & - & $(0.349)$ & $(0.445)$ & $(0.320)$ \\
\hline \multirow{2}{*}{$\mathrm{W}^{*}$ Sold water pc } & & -197.44 & -196.18 & -203.04 \\
\hline & - & $(0.000)$ & $(0.253)$ & $(0.000)$ \\
\hline & & 186.88 & 185.58 & 191.23 \\
\hline W" sold water pc square & - & $(0.000)$ & $(0.326)$ & $(0.000)$ \\
\hline & & 1.97 & 1.95 & 2.03 \\
\hline$W^{*}$ Debt pc & - & $(0.200)$ & $(0.296)$ & $(0.190)$ \\
\hline & & -0.07 & -0.07 & -0.06 \\
\hline W* Water loss & - & $(0.536)$ & $(0.643)$ & $(0.620)$ \\
\hline & & 0.68 & 0.72 & -0.36 \\
\hline W* Ground water & - & $(0.014)$ & $(0.88)$ & $(0.927)$ \\
\hline & & -5.57 & -5.44 & -5.78 \\
\hline W* Population density (000) & - & $(0.274)$ & $(0.506)$ & $(0.421)$ \\
\hline $\mathrm{W}^{*}$ Population density square & - & 0.001 & 0.01 & 0.001 \\
\hline$(000)$ & - & $(0.453)$ & $(0.553)$ & $(0.472)$ \\
\hline & & 0.58 & 0.58 & 0.57 \\
\hline W*Violation & - & $(0.332)$ & $(0.426)$ & $(0.342)$ \\
\hline $\mathrm{W}^{*}$ Elevation difference & _ & -0.003 & -0.003 & -0.003 \\
\hline w "Elevation anterence & - & $(0.645)$ & $(0.765)$ & $(0.716)$ \\
\hline R-square & 0.37 & 0.44 & 0.44 & 0.44 \\
\hline & & vations $=$ & & \\
\hline
\end{tabular}

\section{$\mathrm{P}$-values in parenthesis}




\section{Appendix II.}

Table 7. Estimation results for minimum water charge SEM, SDM, SLX, and SDEM models

\begin{tabular}{|c|c|c|c|}
\hline Variable & SDM & SLX & SDEM \\
\hline Predicted water charge & $\begin{array}{c}0.36 \\
(0.000)\end{array}$ & $\begin{array}{c}0.37 \\
(0.000)\end{array}$ & $\begin{array}{c}0.36 \\
(0.000)\end{array}$ \\
\hline $\begin{array}{l}\text { Household with one or more } \\
\text { older than } 65\end{array}$ & $\begin{array}{c}0.04 \\
(0.619)\end{array}$ & $\begin{array}{c}0.04 \\
(0.682)\end{array}$ & $\begin{array}{c}0.05 \\
(0.563)\end{array}$ \\
\hline Per capita income & $\begin{array}{l}-0.008 \\
(0.932)\end{array}$ & $\begin{array}{c}0.008 \\
(0.921)\end{array}$ & $\begin{array}{c}0.027 \\
(0.759)\end{array}$ \\
\hline Home ownership rate & $\begin{array}{c}0.06 \\
(0.955)\end{array}$ & $\begin{array}{c}0.06 \\
(0.340)\end{array}$ & $\begin{array}{c}0.05 \\
(0.377)\end{array}$ \\
\hline Class II & $\begin{array}{c}-1.02 \\
(0.135)\end{array}$ & $\begin{array}{c}-1.06 \\
(0.658)\end{array}$ & $\begin{array}{c}-1.20 \\
(0.609)\end{array}$ \\
\hline SM & $\begin{array}{c}-4.56 \\
(0.368)\end{array}$ & $\begin{array}{c}-5.01 \\
(0.073)\end{array}$ & $\begin{array}{c}-4.75 \\
(0.072)\end{array}$ \\
\hline Water loss & $\begin{array}{c}0.007 \\
(0.825)\end{array}$ & $\begin{array}{l}-0.006 \\
(0.855)\end{array}$ & $\begin{array}{l}-0.007 \\
(0.823)\end{array}$ \\
\hline Constant & $\begin{array}{c}8.51 \\
(0.620)\end{array}$ & $\begin{array}{c}9.38 \\
(0.609)\end{array}$ & $\begin{array}{c}8.60 \\
(0.643)\end{array}$ \\
\hline Rho & $\begin{array}{c}0.24 \\
(0.097)\end{array}$ & - & - \\
\hline Lambda & - & - & $\begin{array}{c}0.12 \\
(0.198) \\
\end{array}$ \\
\hline $\mathrm{W}^{*}$ Predicted water charge & $\begin{array}{c}-0.04 \\
(0.718)\end{array}$ & $\begin{array}{c}0.06 \\
(0.952)\end{array}$ & $\begin{array}{c}0.07 \\
(0.897)\end{array}$ \\
\hline $\begin{array}{l}\mathrm{W}^{*} \text { Household with one or } \\
\text { more older than } 65\end{array}$ & $\begin{array}{c}-0.04 \\
(0.760)\end{array}$ & $\begin{array}{c}-0.23 \\
(0.860)\end{array}$ & $\begin{array}{c}-0.01 \\
(0.888)\end{array}$ \\
\hline $\mathrm{W}^{*}$ Per capita income & $\begin{array}{c}-0.03 \\
(0.750)\end{array}$ & $\begin{array}{c}-0.04 \\
(0.725)\end{array}$ & $\begin{array}{c}-0.04 \\
(0.720)\end{array}$ \\
\hline $\mathrm{W}^{*}$ Home ownership rate & $\begin{array}{c}-0.01 \\
(0.627)\end{array}$ & $\begin{array}{c}-0.01 \\
(0.603)\end{array}$ & $\begin{array}{c}-0.01 \\
(0.615)\end{array}$ \\
\hline $\mathrm{W}^{*}$ Class II & $\begin{array}{l}-10.29 \\
(0.112)\end{array}$ & $\begin{array}{l}-11.40 \\
(0.095)\end{array}$ & $\begin{array}{l}-11.16 \\
(0.112)\end{array}$ \\
\hline $\mathrm{W}^{*} \mathrm{SM}$ & $\begin{array}{c}-2.27 \\
(0.639)\end{array}$ & $\begin{array}{c}-4.77 \\
(0.454)\end{array}$ & $\begin{array}{c}-6.52 \\
(0.374)\end{array}$ \\
\hline $\mathrm{W}^{*}$ water loss & $\begin{array}{c}0.064 \\
(0.408)\end{array}$ & $\begin{array}{c}0.07 \\
(0.365)\end{array}$ & $\begin{array}{c}0.06 \\
(0.435)\end{array}$ \\
\hline R-square & 0.28 & 0.28 & 0.29 \\
\hline
\end{tabular}

\section{P-values in parenthesis}




\section{Appendix III.}

Table 8. Estimation results for water charge spatial model with the coal production variable

\begin{tabular}{|c|c|c|c|}
\hline & \multicolumn{3}{|c|}{ SAR } \\
\hline & Direct effect & Indirect effect & Total effect \\
\hline Network length pc & $\begin{array}{c}5.22 \\
(0.061)\end{array}$ & $\begin{array}{c}1.73 \\
(0.412)\end{array}$ & $\begin{array}{c}6.95 \\
(0.094)\end{array}$ \\
\hline Sold water (000) & $\begin{array}{c}-9.73 \\
(0.220)\end{array}$ & $\begin{array}{c}-3.09 \\
(0.522)\end{array}$ & $\begin{array}{c}-12.83 \\
(0.261)\end{array}$ \\
\hline Sold water ${ }^{2}(000)$ & $\begin{array}{c}0.001 \\
(0.738)\end{array}$ & $\begin{array}{l}0.0003 \\
(0.866)\end{array}$ & $\begin{array}{c}0.001 \\
(0.766)\end{array}$ \\
\hline Sold water pc & $\begin{array}{r}-130.31 \\
(0.003)\end{array}$ & $\begin{array}{l}-43.45 \\
(0.361)\end{array}$ & $\begin{array}{r}-173.77 \\
(0.020)\end{array}$ \\
\hline Sold water $\mathrm{pc}^{2}$ & $\begin{array}{c}153.742 \\
(0.003)\end{array}$ & $\begin{array}{c}51.27 \\
(0.362)\end{array}$ & $\begin{array}{l}205.02 \\
(0.020)\end{array}$ \\
\hline Debt pc & $\begin{array}{c}1.79 \\
(0.001)\end{array}$ & $\begin{array}{c}0.59 \\
(0.333)\end{array}$ & $\begin{array}{c}2.39 \\
(0.012)\end{array}$ \\
\hline Water loss & $\begin{array}{c}0.06 \\
(0.190)\end{array}$ & $\begin{array}{c}0.02 \\
(0.484)\end{array}$ & $\begin{array}{c}0.08 \\
(0.229)\end{array}$ \\
\hline Ground water & $\begin{array}{c}-5.12 \\
(0.006)\end{array}$ & $\begin{array}{c}-1.60 \\
(0.317)\end{array}$ & $\begin{array}{c}-6.72 \\
(0.014)\end{array}$ \\
\hline Population density (000) & $\begin{array}{c}-9.57 \\
(0.000)\end{array}$ & $\begin{array}{c}-3.18 \\
(0.327)\end{array}$ & $\begin{array}{c}-12.76 \\
(0.008)\end{array}$ \\
\hline Population density $^{2}(000)$ & $\begin{array}{c}0.001 \\
(0.002)\end{array}$ & $\begin{array}{l}0.0005 \\
(0.330)\end{array}$ & $\begin{array}{c}0.002 \\
(0.013)\end{array}$ \\
\hline Violation & $\begin{array}{c}0.13 \\
(0.398)\end{array}$ & $\begin{array}{c}0.04 \\
(0.624)\end{array}$ & $\begin{array}{c}0.17 \\
(0.424)\end{array}$ \\
\hline Elevation difference & $\begin{array}{l}-0.003 \\
(0.373)\end{array}$ & $\begin{array}{c}-0.001 \\
(0.557)\end{array}$ & $\begin{array}{c}-0.005 \\
(0.391)\end{array}$ \\
\hline Coal production & $\begin{array}{l}-0.000 \\
(0.352)\end{array}$ & $\begin{array}{l}-0.000 \\
(0.632)\end{array}$ & $\begin{array}{l}-0.000 \\
(0.390)\end{array}$ \\
\hline Constant & & $\begin{array}{l}45.807 \\
(0.000)\end{array}$ & \\
\hline Adjusted R- square & & 0.336 & \\
\hline Rho & & $\begin{array}{c}0.22 \\
(0.000)\end{array}$ & \\
\hline
\end{tabular}

P-values in parenthesis

Note: In this model, we control for the cumulative coal production to see if there is any impact for the municipalities that are located in counties with surface and underground coal production. As the Appendix III shows coal production is not an influential factor to determine the water charge in municipalities. 


\section{Appendix IV.}

Table 9. Estimation results for water charge spatial model with the distance from the river variable

\begin{tabular}{|c|c|c|c|}
\hline & \multicolumn{3}{|c|}{ SAR } \\
\hline & Direct effect & Indirect effect & Total effect \\
\hline Network length pc & $\begin{array}{c}5.43 \\
(0.063)\end{array}$ & $\begin{array}{c}1.96 \\
(0.278)\end{array}$ & $\begin{array}{c}7.40 \\
(0.081)\end{array}$ \\
\hline Sold water (000) & $\begin{array}{c}-8.65 \\
(0.252)\end{array}$ & $\begin{array}{c}-3.00 \\
(0.423)\end{array}$ & $\begin{array}{l}-11.65 \\
(0.271)\end{array}$ \\
\hline Sold water ${ }^{2}(000)$ & $\begin{array}{l}0.0005 \\
(0.884)\end{array}$ & $\begin{array}{l}0.0001 \\
(0.928)\end{array}$ & $\begin{array}{c}0.0006 \\
(0.894)\end{array}$ \\
\hline Sold water pc & $\begin{array}{r}-127.09 \\
(0.002)\end{array}$ & $\begin{array}{c}-45.24 \\
(0.184)\end{array}$ & $\begin{array}{c}-172.33 \\
(0.007)\end{array}$ \\
\hline Sold water $\mathrm{pc}^{2}$ & $\begin{array}{c}149.008 \\
(0.002)\end{array}$ & $\begin{array}{c}52.95 \\
(0.182)\end{array}$ & $\begin{array}{l}201.96 \\
(0.007)\end{array}$ \\
\hline Debt pc & $\begin{array}{c}1.79 \\
(0.002)\end{array}$ & $\begin{array}{c}0.63 \\
(0.189)\end{array}$ & $\begin{array}{c}2.43 \\
(0.007)\end{array}$ \\
\hline Water loss & $\begin{array}{c}0.05 \\
(0.310)\end{array}$ & $\begin{array}{c}0.01 \\
(0.468)\end{array}$ & $\begin{array}{c}0.06 \\
(0.328)\end{array}$ \\
\hline Ground water & $\begin{array}{c}-4.66 \\
(0.014)\end{array}$ & $\begin{array}{c}-1.61 \\
(0.186)\end{array}$ & $\begin{array}{c}-6.28 \\
(0.019)\end{array}$ \\
\hline Population density (000) & $\begin{array}{c}-9.72 \\
(0.000)\end{array}$ & $\begin{array}{c}-3.47 \\
(0.174)\end{array}$ & $\begin{array}{l}-13.20 \\
(0.003)\end{array}$ \\
\hline Population density $^{2}(000)$ & $\begin{array}{c}0.001 \\
(0.003)\end{array}$ & $\begin{array}{l}0.0006 \\
(0.190)\end{array}$ & $\begin{array}{c}0.002 \\
(0.009)\end{array}$ \\
\hline Violation & $\begin{array}{c}0.16 \\
(0.305)\end{array}$ & $\begin{array}{c}0.05 \\
(0.443)\end{array}$ & $\begin{array}{c}0.22 \\
(0.316)\end{array}$ \\
\hline Elevation difference & $\begin{array}{c}-0.006 \\
(0.097)\end{array}$ & $\begin{array}{c}-0.002 \\
(0.301)\end{array}$ & $\begin{array}{l}-0.008 \\
(0.115)\end{array}$ \\
\hline Distance from the river & $\begin{array}{c}-0.000 \\
(0.586)\end{array}$ & $\begin{array}{c}-0.000 \\
(0.656)\end{array}$ & $\begin{array}{c}-0.0001 \\
(0.591)\end{array}$ \\
\hline Constant & & $\begin{array}{l}45.600 \\
(0.000)\end{array}$ & \\
\hline Adjusted R-square & & 0.334 & \\
\hline Rho & & $\begin{array}{c}0.24 \\
(0.056)\end{array}$ & \\
\hline
\end{tabular}

P-values in parenthesis

Note: Distance to a river may influence the water charge. We expect to see municipalities that are closer to a river provide the water with a lower charge. To test for this hypothesis, we introduce a new variable that measure the distance from main rivers in West Virginia: North Branch Potomac River, Greenbrier River, Ohio River, Tug Fork, Hughes River, Monongahela River, Shavers Fork, Cheat River, Shenandoah River, Kanawha River, South Branch Potomac River, Tygart Valley River, New River, Cacapon River, Little Kanawha River, West Fork River, Guyandotte River, Twelvepole Creek, Back Creek, Elk River, Bluestone River, and Bukhannon River. The distance from a nearest river for the water utility is not an influential factor to determine the water charge. 


\section{Appendix V.}

Table 10. Estimation results for water charge spatial model with the possibility to have a private water well variable

\begin{tabular}{|c|c|c|c|}
\hline & \multicolumn{3}{|c|}{ SAR } \\
\hline & Direct effect & Indirect effect & Total effect \\
\hline \multirow{2}{*}{ Network length pc } & 5.21 & 1.85 & 7.06 \\
\hline & $(0.079)$ & $(0.349)$ & $(0.108)$ \\
\hline \multirow{2}{*}{ Sold water (000) } & -8.46 & -2.86 & -11.32 \\
\hline & $(0.279)$ & $(0.451)$ & $(0.294)$ \\
\hline \multirow{2}{*}{ Sold water ${ }^{2}(000)$} & 0.0007 & 0.0002 & 0.0009 \\
\hline & $(0.850)$ & $(0.895)$ & $(0.858)$ \\
\hline \multirow{2}{*}{ Sold water pc } & -126.81 & -44.72 & -171.53 \\
\hline & $(0.003)$ & $(0.270)$ & $(0.016)$ \\
\hline \multirow{2}{*}{ Sold water $\mathrm{pc}^{2}$} & 147.88 & 51.89 & 199.78 \\
\hline & $(0.003)$ & $(0.269)$ & $(0.016)$ \\
\hline \multirow{2}{*}{ Debt pc } & 1.87 & 0.65 & 2.52 \\
\hline & $(0.001)$ & $(0.238)$ & $(0.007)$ \\
\hline \multirow{2}{*}{ Water loss } & 0.05 & 0.01 & 0.07 \\
\hline & $(0.284)$ & $(0.465)$ & $(0.298)$ \\
\hline \multirow{2}{*}{ Ground water } & -4.78 & -1.61 & -6.40 \\
\hline & $(0.007)$ & $(0.240)$ & $(0.015)$ \\
\hline \multirow{2}{*}{ Population density (000) } & -9.97 & -3.48 & -13.45 \\
\hline & $(0.000)$ & $(0.216)$ & $(0.003)$ \\
\hline \multirow{2}{*}{ Population density ${ }^{2}(000)$} & 0.001 & 0.0005 & 0.002 \\
\hline & $(0.001)$ & $(0.229)$ & $(0.007)$ \\
\hline \multirow{2}{*}{ Violation } & 0.14 & 0.04 & 0.19 \\
\hline & $(0.375)$ & $(0.524)$ & $(0.390)$ \\
\hline \multirow{2}{*}{ Elevation difference } & -0.006 & -0.002 & -0.008 \\
\hline & $(0.104)$ & $(0.323)$ & $(0.122)$ \\
\hline \multirow{2}{*}{ Well } & -0.88 & -0.36 & -1.24 \\
\hline & $(0.665)$ & $(0.700)$ & $(0.661)$ \\
\hline Constant & & $\begin{array}{l}45.429 \\
(0.000)\end{array}$ & \\
\hline Adjusted R- square & & 0.333 & \\
\hline Rho & & $\begin{array}{c}0.24 \\
(0.060)\end{array}$ & \\
\hline
\end{tabular}

P-values in parenthesis

Note: Some argue having the access to a private water well may increase the water charge for the municipality. Because utility need to provide the drinking water to different locations while by having access to the private well, the number of customers may decrease. We test the hypothesis to see if having access to a private well tend to impact water charge in municipalities. The results show although the effects in negative but it is insignificant. 


\section{Appendix VI.}

Table 11. Estimation results for water charge spatial model with the water utility age variable

\begin{tabular}{|c|c|c|c|}
\hline & \multicolumn{3}{|c|}{ SAR } \\
\hline & Direct effect & Indirect effect & Total effect \\
\hline Network length pc & $\begin{array}{c}5.07 \\
(0.084)\end{array}$ & $\begin{array}{c}1.92 \\
(0.294)\end{array}$ & $\begin{array}{c}7.00 \\
(0.104)\end{array}$ \\
\hline Sold water $(000)$ & $\begin{array}{c}-8.83 \\
(0.263)\end{array}$ & $\begin{array}{c}-3.30 \\
(0.429)\end{array}$ & $\begin{array}{c}-12.13 \\
(0.283)\end{array}$ \\
\hline Sold water ${ }^{2}(000)$ & $\begin{array}{l}0.0009 \\
(0.809)\end{array}$ & $\begin{array}{l}0.0003 \\
(0.857)\end{array}$ & $\begin{array}{c}0.001 \\
(0.818)\end{array}$ \\
\hline Sold water pc & $\begin{array}{c}-120.24 \\
(0.006)\end{array}$ & $\begin{array}{c}-46.03 \\
(0.212)\end{array}$ & $\begin{array}{r}-166.27 \\
(0.018)\end{array}$ \\
\hline Sold water $\mathrm{pc}^{2}$ & $\begin{array}{c}40.22 \\
(0.006)\end{array}$ & $\begin{array}{c}53.41 \\
(0.208) \\
\end{array}$ & $\begin{array}{r}193.64 \\
(0.017)\end{array}$ \\
\hline Debt pc & $\begin{array}{c}1.82 \\
(0.001)\end{array}$ & $\begin{array}{c}0.69 \\
(0.202)\end{array}$ & $\begin{array}{c}2.52 \\
(0.007)\end{array}$ \\
\hline Water loss & $\begin{array}{c}0.05 \\
(0.237)\end{array}$ & $\begin{array}{c}0.02 \\
(0.398)\end{array}$ & $\begin{array}{c}0.07 \\
(0.253)\end{array}$ \\
\hline Ground water & $\begin{array}{c}-4.56 \\
(0.011)\end{array}$ & $\begin{array}{c}-1.69 \\
(0.203)\end{array}$ & $\begin{array}{c}-6.25 \\
(0.020)\end{array}$ \\
\hline Population density (000) & $\begin{array}{l}-10.51 \\
(0.000)\end{array}$ & $\begin{array}{c}-3.98 \\
(0.168)\end{array}$ & $\begin{array}{l}-14.50 \\
(0.002)\end{array}$ \\
\hline Population density $^{2}(000)$ & $\begin{array}{c}0.001 \\
(0.001)\end{array}$ & $\begin{array}{l}0.0007 \\
(0.179)\end{array}$ & $\begin{array}{c}0.002 \\
(0.006)\end{array}$ \\
\hline Violation & $\begin{array}{c}0.14 \\
(0.378)\end{array}$ & $\begin{array}{c}0.05 \\
(0.525)\end{array}$ & $\begin{array}{c}0.19 \\
(0.396)\end{array}$ \\
\hline Elevation difference & $\begin{array}{c}-0.005 \\
(0.117)\end{array}$ & $\begin{array}{c}-0.002 \\
(0.298)\end{array}$ & $\begin{array}{c}-0.007 \\
(0.129)\end{array}$ \\
\hline Utility age & $\begin{array}{c}-0.081 \\
(0.287)\end{array}$ & $\begin{array}{c}-0.032 \\
(0.441)\end{array}$ & $\begin{array}{c}-0.11 \\
(0.307)\end{array}$ \\
\hline Constant & & $\begin{array}{c}40.90 \\
(0.000)\end{array}$ & \\
\hline Adjusted R-square & & 0.334 & \\
\hline Rho & & $\begin{array}{c}0.25 \\
(0.048)\end{array}$ & \\
\hline
\end{tabular}

P-values in parenthesis

Note: Age of the facilities in a water utility system may effect water charges. Most of the municipality water utilities start performing in 1960 but there are some that start working earlier or later. We control for the age of the utility and the results are not significant. 
Figure 1. Map of West Virginia municipal utilities and their 2014 water charges

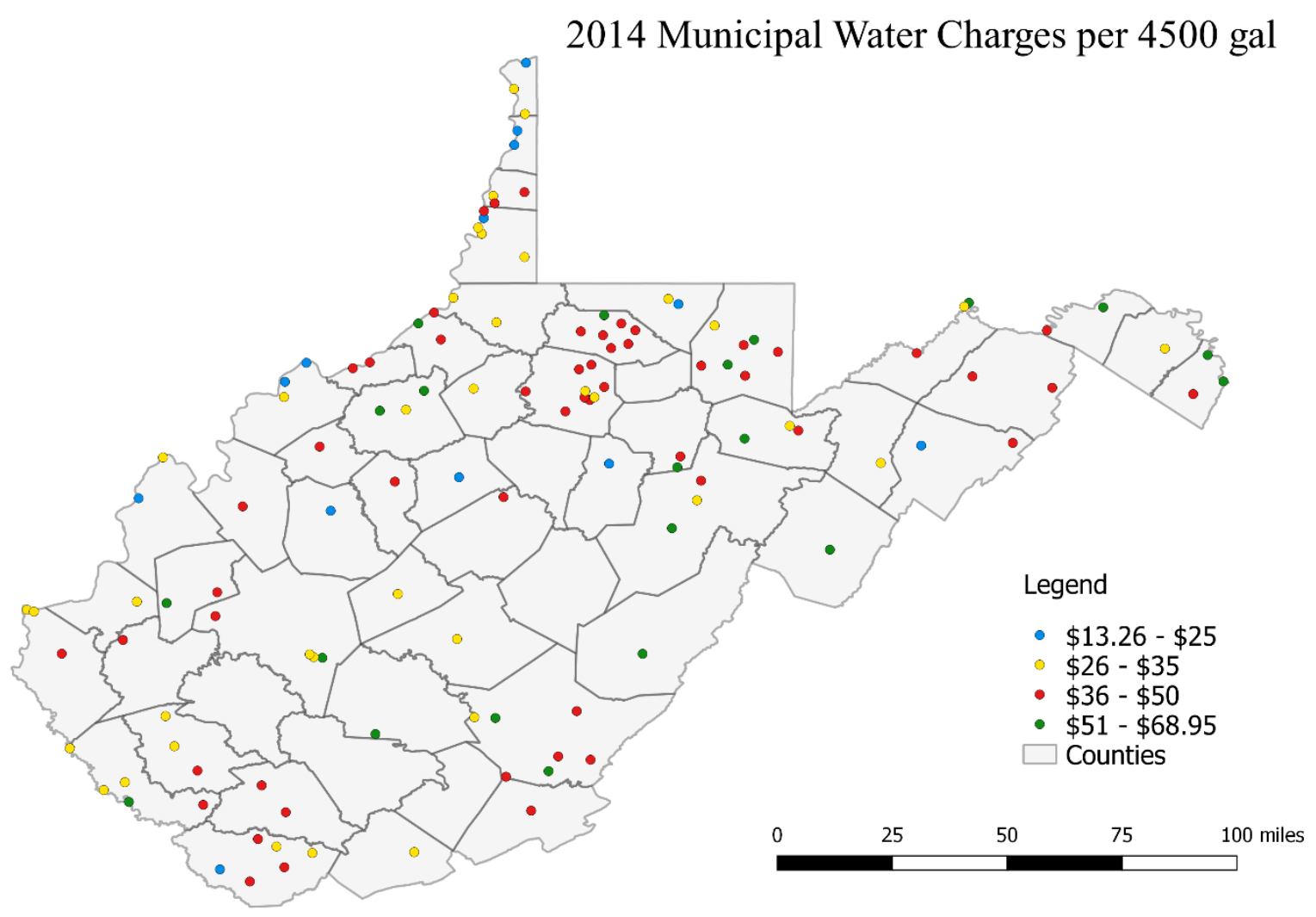




\section{CHAPTER 3}




\section{CHAPTER 3: THE IMPACTS OF NALOXONE ACCESS LAWS ON OPIOID OVERDOSE DEATHS IN THE U.S.}

\section{INTRODUCTION}

Opioid overdose is the leading cause of unintentional death in the U.S. (Visconti et al., 2015). From 2000 to 2014, half a million people in the U.S. died from opioid overdoses, with over 28,000 dying in 2014 alone. ${ }^{9}$ Overdose deaths have become such a problem in the U.S. that life expectancy has dropped two years in a row (Stobbe, 2017). When addressing the opioid crisis as a public health problem, state level responses can be categorized as either attempts to: (1) limit the supply of opioids through prescription drug monitoring programs, or (2) reduce the number of overdoses by authorizing the more widespread provision of overdose reversal drugs, such as Naloxone (Davis and Chang, 2013a; Davis et al., 2013b; Davis et al., 2014; Beheshti et al., 2015; Davis et al., 2017). Naloxone is a prescription drug that counteracts the effects of an overdose, making it an extremely powerful, though complicated, drug in that its provision may create a false sense of security among drug users.

In this research, we estimate the effect that state level Naloxone access laws have on overdose deaths using a spatial difference-in-differences framework. Given the vast array of literature focusing on opioid overdose death (Visconti et al., 2015; Stobbe, 2017; Scott et al., 2007; Rossen et al., 2013), there is a huge gap in coverage of possible spatial dependency in state and/or county level data. One can easily hypothesize that Naloxone access laws have spatial spillover effects on opioid overdose death rates across states due to factors such as cross-border movement

\footnotetext{
${ }^{9}$ For more information, please refer to Rudd et al. (2016)
} 
of Naloxone, prescription and illegal drugs, and physician shopping (see e.g. Buchmueller and Carey 2018). Thus, not accounting for spatial dependency in state level data allows for misspecification of the actual impact of these laws on the outcome variable.

To avoid this misspecification bias, the use of a spatial difference-in-difference analysis provides us with estimates of both within state and spillover effects among contiguous states from enactment of a Naloxone access law. The extent to which the law expands access to Naloxone varies state by state. The spillover analysis allows us to document biases present in the standard, non-spatial model. We find that Naloxone access laws (either as a binary variable, the days after the law, or when broken down into various provisions ${ }^{10}$ ) have positive and significant impacts on opioid overdose death rates and mostly these impacts occur within neighboring states. The impacts of a Naloxone access law within the state itself are not significant except for provisions which provide immunity for criminal and civil liability for a lay person. Thus, important state level spillover effects exist for Naloxone access laws on opioid overdose death rates.

Our main contribution to the literature is development of a SDID (Spatial Difference-inDifference) framework to investigate the spillover effects of state level Naloxone access laws on overdose death rates in surrounding states. In addition, we examine the different impacts of specific provisions of access law as explained in section 2. Enactment of Naloxone access laws demonstrates suggestive evidence of spatial dependence in that neighboring states begin to adopt these laws, especially after 2013. ${ }^{11}$ To the best of our knowledge, no previous study has controlled for the spatial interaction between Naloxone access laws and opioid overdose death rates so that the regional aspects of these laws has not been investigated.

\footnotetext{
${ }^{10}$ Provisions are identified later

${ }^{11}$ Available at: http://lawatlas.org/
} 
The rest of the manuscript proceeds as follows. Section 2 provides background information on trends in opioid overdose and Naloxone access laws. Section 3 provides an empirical model and section 4 describes the data. In section 5, we explain the methods and spatial econometric framework utilized, while section 6 reports the results. We conclude in section 7 with a discussion and policy implications.

Opioid overdose is the leading cause of unintentional death in the U.S. (Visconti et al., 2015). From 2000 to 2014, half a million people in the U.S. died from opioid overdoses, with over 28,000 dying in 2014 alone. ${ }^{12}$ Overdose deaths have become such a problem in the U.S. that life expectancy has dropped two years in a row (Stobbe, 2017). State responses to the opioid crisis can be categorized by attempts to limit the supply of opioids through prescription drug monitoring programs and attempts to reduce the number of overdoses by authorizing the provision of drugs such as Naloxone (Davis and Chang, 2013a; Davis and Burris, 2013b; Davis et al., 2014; Beheshti et al., 2015). Naloxone is a prescription drug that counteracts the effects of an overdose, making it an extremely powerful, though complicated, drug in that its provision may create a false sense of security among addicts.

In this research, we estimate the effect of state level Naloxone access laws on overdose deaths using a spatial difference-in-differences framework. Given the vast array of literature focusing on opioid overdose death (Visconti et al., 2015; Stobbe, 2017; Scott et al., 2007; Rosen et al., 2013), there is a huge gap in coverage of possible spatial dependency in state and/or county level data. One can easily hypothesize that Naloxone access laws have spatial spillover effects on opioid overdose death rates across states due to factors such as cross-border movement of both

\footnotetext{
${ }^{12}$ For more information, please refer to Rudd et al. (2016)
} 
Naloxone and opioid drugs. Thus, not accounting for spatial dependency in state level data allows for misspecification of the actual impact of the law on the outcome variable.

To avoid this misspecification bias, the use of a spatial difference-in-difference analysis provides us with estimates of both within state and spillover effects among contiguous states from enacting a Naloxone access law. In terms of the extent to which the law expands the access to Naloxone varies state by state. The spillover analysis allows us to document biases of the standard model. We find Naloxone access law (in general as a binary variable, the days after the law and breaking down Naloxone access laws into various provisions), has a mixture of positive and significant impacts on opioid overdose death rates occurs, particularly within neighboring states. Our results mean that state level adaptation of a Naloxone access law is statistically associated with higher opioid overdose deaths in neighboring states, although the impacts within the state itself are not significant. Thus, important spillover effects exist from the various provisions of Naloxone access laws on opioid overdose death rates.

Our main contribution to the literature is developing a SDID (Spatial Difference in Difference) framework to investigate the spillover effects of state level Naloxone access laws on overdose death rates in surrounding states. In addition, we examine the different impacts of specific provisions of access law as explained in section 2. Enactment of Naloxone access laws demonstrates suggestive evidence of spatial dependence in that neighboring states begin to adopt these laws, especially after $2013 .{ }^{13}$ To the best of our knowledge, no previous study has controlled for the spatial interaction between Naloxone access laws and opioid overdose death rates so that the regional aspects of these laws has not been investigated.

\footnotetext{
${ }^{13}$ Available at: http://lawatlas.org/
} 
The rest of the manuscript proceeds as follows. Section 2 provides background information on trends in opioid overdose and Naloxone access laws. Section 3 provides an empirical model and section four describes the data. In section five, we explain the methods and spatial econometric framework utilized, while section six reports the results and robustness checks. We conclude in section seven with a discussion and policy implications.

\section{BACKGROUND}

\section{Opioid trends}

Mortality from opioid overdose has more than quadrupled since $1999 .{ }^{14}$ Figure 2 compares opioid overdose death rates among states in 1999 and 2016. Opioid overdose death rates increased during this time period in every state. In 2016, West Virginia had the highest rate of overdose death, while Nebraska had the lowest rate. Between 1999 and 2016, increases in opioid overdose death rates per 100,000 ranged from 0.69 in Arkansas to 38.17 in West Virginia.

Overdoses occur when a person takes a lethal or toxic amount of opiates - such as an illicit drug (e.g. heroin) or prescription medications (e.g. oxycodone). ${ }^{15}$ Opiate overdoses can lead to depressed or slowed breathing, confusion, and the lack of oxygen to the brain. Overdoses potentially can occur with legitimate uses of opiates, such as pain relief from a work-related injury. $^{16}$

\footnotetext{
14 Available at: https://www.cdc.gov/drugoverdose/epidemic/index.html

${ }^{15}$ Importantly, many legally prescribed opioids are taken illegally by individuals who were not the original patient.

16 Available at: https://www.cdc.gov/niosh/topics/prescription/default.html
} 
Figure 2. Opioid overdose death per 100,000 population

by state, 1999 and 2016

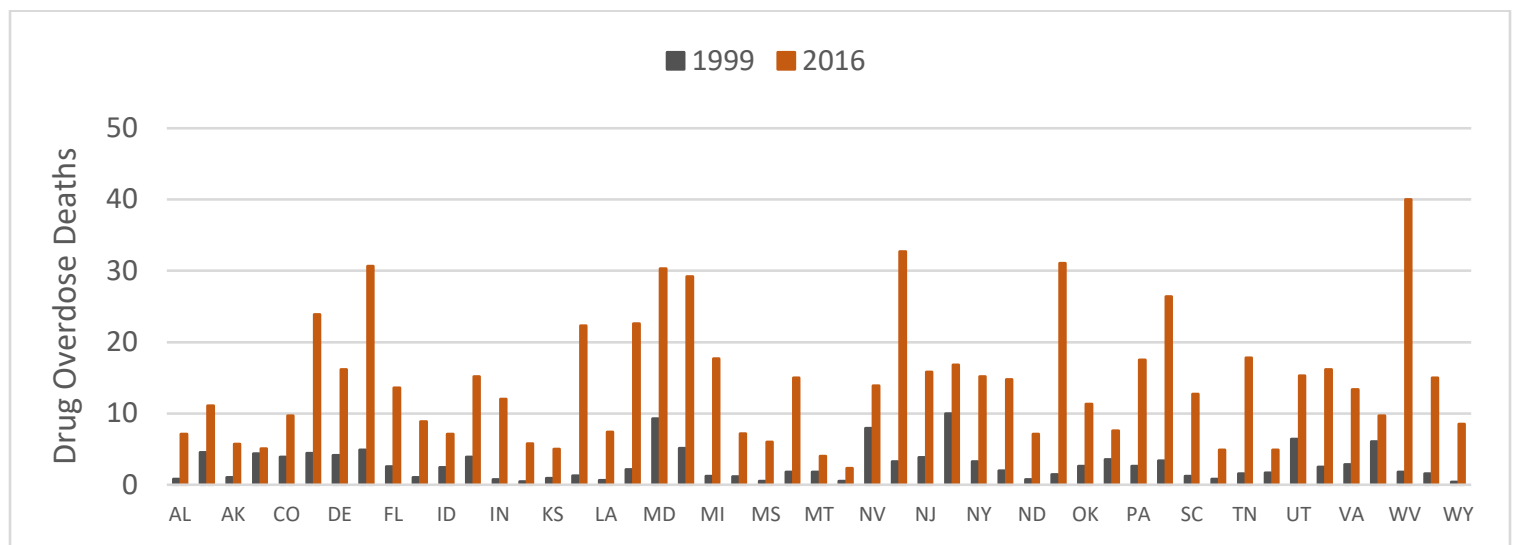

Source: CDC-WONDER

In 2015, 2.8 million private industry workers and 752,000 public sector workers suffered from nonfatal workplace injuries, many of which led to receiving opioid drug prescriptions and thereby leading to potential abuse, addiction, and/or overdose (Salsberg, 2017). Former Food and Drug Administration head David Kessler called the opioid epidemic one of the "great mistakes of modern medicine". ${ }^{17}$ Workplace injuries served as a driver for prescribing opioids that have the potential to transform into addiction and ultimately overdose and even death.

Reducing opioid abuse and controlling overdose deaths is an important policy goal for both state and federal governments. With a deadlier supply of drugs, controlling the opioid crisis became harder and harder over time. ${ }^{18}$ For many years, opioid overdose prevention programs have provided protection services. Since 1996, an increasing number of community-based programs have provided Naloxone (an opioid antagonist) to laypersons to reverse the effects of opioid overdose. Narcan TM (Naloxone) is a prescription medicine, but not a controlled

\footnotetext{
${ }^{17}$ Available at: https://www.cbsnews.com/news/former-fda-head-doctor-david-kessler-opioid-epidemic-one-of-great-mistakes-ofmodern-medicine/

${ }^{18}$ For more information, please refer to: https://www.washingtonpost.com/graphics/2017/health/opioidsscale/?utm_term $=.8748581 \mathrm{~d} 9268$
} 
substance that can block the effects of opioids with no life threatening effects on the opiate users. ${ }^{19},{ }^{20}$ Naloxone acts on a person's brain by attaching to the same part of the brain that receives the opioid (Open society foundation, 2017). Once administered, Naloxone takes two to three minutes for its effect to be felt. If an overdose victim does not wake up, a second dose should be administered.

News report examples of Naloxone being used to save lives abound. For instance, Chad Ward, an Emergency Medical Services Supervisor in Huntington, WV, noted that in 2015 there were 944 drug overdoses in Cabell County, but having access to Naloxone allowed him to save many patients at the scene of the overdose..$^{21}$ In another more famous example, the musician Prince suffered an oxycodone overdose on April 15, 2016. After being given two doses of Narcan, he recovered. However, six days later, he overdosed for the last time on Fentanyl -a synthetic opioid 50 times more powerful than heroin. ${ }^{22}$

The examples above demonstrate the conflicting viewpoints on Naloxone. Whether Naloxone saves lives or simply delays an eventual overdose death is the paradox at the center of whether it is a solution to the overdose epidemic. ${ }^{23},{ }^{24},{ }^{25},{ }^{26}$.

With the recent growth in overdose deaths, interest in assessing the effects of Naloxone access laws and overdose prevention programs on overdose deaths has increased (e.g. Walley et

\footnotetext{
${ }^{19}$ A controlled substance is generally an opioid or chemical whose manufacture, possession, or use is regulated by a government, such as illicitly used opioids or prescription medications.

${ }^{20}$ Available at: http://stopoverdoseil.org/narcan.html

${ }^{21}$ Available at: http://www.wsaz.com/content/news/WSAZ-Investigates-A-Dose-of-Reality-368538771.html

${ }^{22}$ Available at: https://www.cbsnews.com/news/official-pills-found-at-princes-estate-contained-fentanyl/

${ }^{23}$ Available at: https://www.nytimes.com/2017/05/09/us/opioids-narcan-drug-overdose-heroin-fentanyl.html?emc=eta1

${ }^{24}$ Available at: http://www.wsaz.com/content/news/WSAZ-Investigates-A-Dose-of-Reality-368538771.html

${ }^{25}$ Available at: https://www.cbsnews.com/news/official-pills-found-at-princes-estate-contained-fentanyl/

${ }^{26}$ Available at: https://www.ncbi.nlm.nih.gov/pmc/articles/PMC4675355/pdf/nihms742274.pdf
} 
al., 2013; Visconti et al., 2015). Adoption of Naloxone access laws has been found to be associated with a 9 to 11 percent reduction in opioid-related deaths (Rees et al., 2017). In a recent working paper, Doleac and Mukherjee (2018) argue that the positive association between Naloxone access laws and opioid-related emergency room visits along with opioid-related theft demonstrate a classic moral hazard problem among opioid abusers. For example, providing access to Naloxone may have increased the likelihood individuals took more potent drugs (Doleac and Mukherjee 2018). One reason for an increase in hospitalizations without a change in deaths for drug overdoses is that Naloxone allows individuals who otherwise would have died to make it to the hospital. There is a body of literature that show behavioral responses to different policies (Chan et al., 2015; Lakdawalla et al., 2006; Cohen and Einav, 2003). In another study, Siegler (2015) found a 16\% decrease in overdose deaths in New York City after the implementation of an overdose prevention program, but his results were not statistically significant for heroin-related overdose mortalities. Similarly, Rees et al. (2017) find statistically insignificant effects of Naloxone access laws on heroin-related deaths in the U.S.

None of these previous research efforts have accounted for the spatial spillovers of access laws between states. Without accounting for spatial spillovers, the results may be biased due to model misspecification. In other words, by ignoring spatial aspects, only within state effects of access laws are examined under the assumptions that both the access law and overdose death rate in one state are totally independent of access laws and death rates in neighboring states. The direction of this bias is ambiguous.

\section{Naloxone Access Laws}

Naloxone has been available by prescription since 1996, although the legal environment for prescribing and dispensing Naloxone varies by state. State legislators have enacted a variety 
of provisions to expand and to ease prescribing and distributing of Naloxone to prevent overdoses. For example, a number of states have enacted laws that involve less civil and criminal liability, whether for prescribers, dispensers or users (Lim et al., 2016). Davis and Carr (2015) argue that "at risk" individuals do not have regular contact with professional care givers so that laws and regulations need to ease access to Naloxone beyond traditional prescriptions.

In a traditional Naloxone prescription setting, prescribers prescribe Naloxone to high risk individuals, such as those who take high doses of opioids. In addition, under this setting, only pharmacists or physicians can distribute Naloxone. Because of the spike in opioid-related deaths, lawmakers and researchers have pushed to make Naloxone available for those most likely to respond to an overdose. The first responders include family, friends, harm reduction program staff, law enforcement officers, emergency medical technicians, and others (Davis and Carr, 2015).

State laws vary in terms of the extent to which they expand the access to Naloxone and/or remove the legal liabilities associated with prescribing, dispensing, or distributing Naloxone (Davis and Carr, 2017). In some states, prescriptions of Naloxone can be provided to third parties, or individuals likely to witness an overdose while not being personally at risk of overdose. In some states, prescribers, dispensers, and users are immune from criminal and/or civil liability when administering Naloxone. Additional versions of access laws remove criminal liability for possession of Naloxone. Certain states allow prescribing by a standing order, where prescribers give the authority to pharmacists and other healthcare providers to dispense Naloxone to the person in need (Davis and Carr, 2017; Green et al, 2015). Within states without an access law, Naloxone requires a written prescription by a physician. In these states, physicians who 
prescribe and individuals who use Naloxone are not immune from criminal and civil liability and professional sanctions.

The list below provided by the Prescription Drug Abuse Policy System (PDAPS) offers a breakdown of Naloxone access law (NAL) provisions into eleven types. ${ }^{27}$

Provision 1: Having immunity from criminal prosecution for prescribing, dispensing or distributing Naloxone to a layperson for prescribers.

Provision 2: Having immunity from civil liability for prescribing, dispensing or distributing Naloxone to a layperson for prescribers.

Provision 3: Having immunity from professional sanctions for prescribing, dispensing or distributing Naloxone to a layperson for prescribers.

Provision 4: Having immunity from criminal prosecution for prescribing, dispensing or distributing Naloxone to a layperson for dispensers.

Provision 5: Having immunity from civil liability for prescribing, dispensing or distributing Naloxone to a layperson for dispensers.

Provision 6: Having immunity from professional sanctions for prescribing, dispensing or distributing Naloxone to a layperson for dispensers.

Provision 7: Prescribers are allowed to provide Naloxone to third parties.

Provision 8: Pharmacists are allowed to dispense or distribute without a patient-specific prescription from another medical professional.

Provision 9: Immunity from criminal liability when administering Naloxone for a Layperson.

Provision 10: Immunity from civil liability when administering Naloxone for a layperson.

\footnotetext{
${ }^{27}$ For more information, please refer to: http://pdaps.org/datasets/laws-regulating-administration-of-naloxone-1501695139
} 
Provision 11: Removing criminal liability for possession of Naloxone ${ }^{28}$

New Mexico was the first state to amend its laws (in 2001) to make it easier for medical professionals to prescribe Naloxone and for lay administrators to use it without fear of legal repercussions. Table 12 shows the effective date of enacted Naloxone laws starting from 2001. At the end of 2016 a total of 48 states had adopted Naloxone access laws. Thirty-nine of these states allowed "standing orders" (also called "non-patient-specific prescriptions")

As it is shown in Table 13, states tend to implement Naloxone laws by grouping provisions together. For instance, immunity from civil liability for prescribers and dispensers is almost always implemented in the same state during the same year. The exceptions are North Carolina and Ohio. With the exception of Ohio, immunity from criminal liability for prescribers and dispensers is implemented in all the states simultaneously. Immunity from civil and criminal liability for the laypersons follows the same trend. These trends mean that when states implement a specific provision for a category of professional healthcare providers, they usually implement the same provision for other healthcare providers as well. As a result of this pattern, collinearity issues arise in regression models when including all 11 provisions in an empirical model. Because of this potential collinearity, we group these 11 provisions into five categories for our analysis, which we describe in more detail in the next section.

Numerous studies have analyzed the relationships between Naloxone access laws and overdose deaths (Coffin et al., 2003; Seal et al., 2005; Walley et al., 2013; Davis, 2015; Davis and Carr, 2015; Rowe et al., 2016; Coffin and Sullivan, 2013; Enteen, et al., 2010; Green, et al., 2008; Inocencio, et al., 2013; Lim et al., 2016; Wheeler et al., 2015). These studies generally

\footnotetext{
${ }^{28}$ Removing criminal liability for possession of Naloxone should increase access and encourage its use in emergency situations (Davis et al., 2013b).
} 
investigate the effectiveness of Naloxone access on overdose deaths in observational settings.

For instance, according to Wheeler et al. (2015) between 1996 and 2014, community organizations provided Naloxone rescue kits to 152,283 laypersons and received reports of 26,463 overdose reversals. Evidence of Naloxone access laws as a public health response to the opioid crisis being an overdose prevention tool on both nationwide and regional scales is still

mixed. In this study, we employ state level analyses using the dates of enactment for Naloxone access laws to investigate the spillover effects on opioid overdose death rates.

\section{EMPIRICAL MODEL}

Empirical studies have shown that a number of factors influence opioid overdose deaths in the U.S. Table 14 shows the important variables, study region, their impact on overdose deaths, and references. However, the opioid epidemic literature is lacking investigations that include the effects of high-risk injury occupations such as mining, manufacturing and constructions, availability of drug prescriptions and heroin related crime (as an indicator for availability of heroin) on opioid overdose deaths. 
Table 12. Effective Dates of Naloxone Access Laws, 1999-2016

\begin{tabular}{|c|c|}
\hline State & Naloxone Access Law Effective Date \\
\hline Alabama & June 10,2015 \\
\hline Alaska & March 15, 2016 \\
\hline Arizona & August 6, 2016 \\
\hline Arkansas & July 15,2015 \\
\hline California & January 1,2008 \\
\hline Colorado & May 10, 2013 \\
\hline Connecticut & October 1, 2003 \\
\hline Washington, D.C. & March 19, 2013 \\
\hline Delaware & August 4, 2014 \\
\hline Florida & June 10,2015 \\
\hline Georgia & April 24, 2014 \\
\hline Hawaii & June 6, 2016 \\
\hline Idaho & July 1, 2015 \\
\hline Illinois & January 1, 2010 \\
\hline Indiana & April 17, 2015 \\
\hline Iowa & May 27, 2016 \\
\hline Kentucky & June 25, 2013 \\
\hline Louisiana & August 15, 2015 \\
\hline Maine & April 29, 2014 \\
\hline Maryland & October 1, 2013 \\
\hline Massachusetts & August 2, 2012 \\
\hline Michigan & October 14,2014 \\
\hline Minnesota & May 10, 2014 \\
\hline Mississippi & July 1, 2015 \\
\hline Missouri & August 28, 2015 \\
\hline Nebraska & May 28, 2015 \\
\hline Nevada & October 1,2015 \\
\hline New Hampshire & June 2, 2015 \\
\hline New Jersey & July 1, 2013 \\
\hline New Mexico & April 3, 2001 \\
\hline New York & April 1, 2006 \\
\hline North Carolina & April 9, 2013 \\
\hline North Dakota & August 1, 2015 \\
\hline Ohio & March 11, 2014 \\
\hline Oklahoma & November 1, 2013 \\
\hline Oregon & June 6, 2013 \\
\hline Pennsylvania & December 1, 2014 \\
\hline Rhode Island & June 18, 2012 \\
\hline South Carolina & June 3, 2015 \\
\hline South Dakota & July 1, 2016 \\
\hline Tennessee & July 1, 2014 \\
\hline Texas & September 1, 2015 \\
\hline Utah & May 13, 2014 \\
\hline Vermont & July 1, 2013 \\
\hline Virginia & July 1, 2013 \\
\hline Washington & June 10, 2010 \\
\hline West Virginia & May 27, 2015 \\
\hline Wisconsin & April 9, 2014 \\
\hline
\end{tabular}

Source: Prescription Drug Abuse Policy System (PDAPS) 
Table 13. Effective Dates of Naloxone Access Law Provisions, 1999-2016 ${ }^{29}$

\begin{tabular}{|c|c|c|c|c|c|c|c|c|c|c|c|}
\hline Year & PR 1 & PR 2 & PR 3 & PR 4 & PR 5 & PR 6 & PR 7 & PR 8 & PR 9 & PR 10 & PR 11 \\
\hline 2001 & NM & NM & & NM & NM & & NM & & $\mathrm{NM}$ & NM & \\
\hline \multicolumn{12}{|l|}{2002} \\
\hline 2003 & CT & CT & & CT & CT & & & & & & \\
\hline \multicolumn{12}{|l|}{2004} \\
\hline \multicolumn{12}{|l|}{2005} \\
\hline \multicolumn{12}{|l|}{2006} \\
\hline 2007 & & & & & & & NY & & & & \\
\hline 2008 & CA & $\mathrm{CA}$ & & $\mathrm{CA}$ & $\mathrm{CA}$ & & & & & & \\
\hline \multicolumn{12}{|l|}{2009} \\
\hline 2010 & & & $\begin{array}{c}\text { IL } \\
\text { WA }\end{array}$ & & & $\begin{array}{c}\text { IL } \\
\text { WA }\end{array}$ & $\begin{array}{c}\text { IL } \\
\text { WA }\end{array}$ & IL & $\begin{array}{c}\text { IL } \\
\text { WA }\end{array}$ & & \\
\hline 2011 & & & & & & & & & $\mathrm{CA}$ & & \\
\hline 2012 & MA & & & & & & MA & & RI & RI & MA \\
\hline 2013 & $\begin{array}{l}\mathrm{CO} \\
\mathrm{NJ} \\
\mathrm{NC} \\
\mathrm{VT}\end{array}$ & $\begin{array}{l}\mathrm{CO} \\
\mathrm{NJ} \\
\mathrm{NC} \\
\mathrm{VT}\end{array}$ & $\begin{array}{c}\mathrm{CO} \\
\mathrm{KY} \\
\mathrm{MD} \\
\mathrm{NJ}\end{array}$ & $\begin{array}{l}\mathrm{CO} \\
\mathrm{NJ} \\
\mathrm{VT}\end{array}$ & $\begin{array}{l}\text { CO } \\
\mathrm{NJ} \\
\mathrm{VT}\end{array}$ & $\begin{array}{c}\mathrm{CO} \\
\mathrm{KY} \\
\mathrm{MD} \\
\mathrm{NJ}\end{array}$ & $\begin{array}{c}\text { KY } \\
\text { MD } \\
\text { NJ } \\
\text { NC } \\
\text { OK } \\
\text { OR } \\
\text { VT } \\
\text { VA }\end{array}$ & $\begin{array}{l}\text { KY } \\
\text { NJ } \\
\text { NC } \\
\text { OR } \\
\text { VT }\end{array}$ & $\begin{array}{c}\text { CO } \\
\text { DC } \\
\text { KY } \\
\text { NJ } \\
\text { NC } \\
\text { VT }\end{array}$ & $\begin{array}{l}\text { CO } \\
\text { DC } \\
\text { KY } \\
\text { NJ } \\
\text { NC } \\
\text { OR } \\
\text { VT } \\
\text { VA }\end{array}$ & $\begin{array}{l}\text { DC } \\
\text { VT }\end{array}$ \\
\hline 2014 & $\begin{array}{l}\text { DE } \\
\text { GA } \\
\text { MN } \\
\text { OH } \\
\text { PA } \\
\text { UT } \\
\text { WI }\end{array}$ & $\begin{array}{c}\text { DE } \\
\text { GA } \\
\text { MI } \\
\text { MN } \\
\text { OH } \\
\text { PA } \\
\text { TN } \\
\text { UT } \\
\text { WI }\end{array}$ & $\begin{array}{l}\text { CA } \\
\text { DE } \\
\text { GA } \\
\text { OH } \\
\text { PA } \\
\text { RI } \\
\text { TN } \\
\text { UT } \\
\text { WI }\end{array}$ & $\begin{array}{l}\text { DE } \\
\text { GA } \\
\text { PA } \\
\text { UT } \\
\text { WI }\end{array}$ & $\begin{array}{c}\text { DE } \\
\text { GA } \\
\text { MI } \\
\text { MN } \\
\text { PA } \\
\text { TN } \\
\text { UT } \\
\text { WI }\end{array}$ & $\begin{array}{l}\text { CA } \\
\text { DE } \\
\text { GA } \\
\text { PA } \\
\text { RI } \\
\text { TN } \\
\text { UT } \\
\text { WI }\end{array}$ & $\begin{array}{c}\text { CA } \\
\text { GA } \\
\text { ME } \\
\text { MI } \\
\text { OH } \\
\text { PA } \\
\text { RI } \\
\text { TN } \\
\text { UT } \\
\text { WI }\end{array}$ & $\begin{array}{l}\text { CA } \\
\text { DE } \\
\text { GA } \\
\text { MA } \\
\text { MN } \\
\text { NM } \\
\text { NY } \\
\text { OK } \\
\text { PA } \\
\text { RI } \\
\text { TN } \\
\text { WI }\end{array}$ & $\begin{array}{c}\text { CT } \\
\text { GA } \\
\text { MA } \\
\text { MI } \\
\text { MN } \\
\text { NY } \\
\text { OH } \\
\text { PA } \\
\text { WI }\end{array}$ & $\begin{array}{c}\text { CT } \\
\text { GA } \\
\text { MI } \\
\text { MN } \\
\text { NY } \\
\text { PA } \\
\text { TN } \\
\text { UT } \\
\text { WI }\end{array}$ & $\begin{array}{l}\text { MI } \\
\text { RI } \\
\text { WI }\end{array}$ \\
\hline 2015 & $\begin{array}{c}\text { AL } \\
\text { AK } \\
\text { FL } \\
\text { ID } \\
\text { IL } \\
\text { LA } \\
\text { MS } \\
\text { NE } \\
\text { NV } \\
\text { NH } \\
\text { ND } \\
\text { SC } \\
\text { TX } \\
\text { WV }\end{array}$ & $\begin{array}{c}\text { AL } \\
\text { AK } \\
\text { FL } \\
\text { ID } \\
\text { IN } \\
\text { LA } \\
\text { MD } \\
\text { MS } \\
\text { MO } \\
\text { NE } \\
\text { NH } \\
\text { ND } \\
\text { SC } \\
\text { TX } \\
\text { VA } \\
\text { WV }\end{array}$ & $\begin{array}{l}\text { AK } \\
\text { FL } \\
\text { ID } \\
\text { LA } \\
\text { MS } \\
\text { NE } \\
\text { NV } \\
\text { NH } \\
\text { ND } \\
\text { SC } \\
\text { TX }\end{array}$ & $\begin{array}{c}\text { AL } \\
\text { AK } \\
\text { FL } \\
\text { IL } \\
\text { LA } \\
\text { MS } \\
\text { NE } \\
\text { NE } \\
\text { NH } \\
\text { NC } \\
\text { ND } \\
\text { SC } \\
\text { TX } \\
\text { WA } \\
\text { WV }\end{array}$ & $\begin{array}{c}\text { AL } \\
\text { AK } \\
\text { FL } \\
\text { IL } \\
\text { IN } \\
\text { LA } \\
\text { MD } \\
\text { MS } \\
\text { NE } \\
\text { NH } \\
\text { NC } \\
\text { ND } \\
\text { OH } \\
\text { SC } \\
\text { TX } \\
\text { VA } \\
\text { WA } \\
\text { WV }\end{array}$ & $\begin{array}{l}\text { AK } \\
\text { CT } \\
\text { FL } \\
\text { LA } \\
\text { MS } \\
\text { NE } \\
\text { NV } \\
\text { NH } \\
\text { ND } \\
\text { OH } \\
\text { SC } \\
\text { TX }\end{array}$ & $\begin{array}{l}\text { AL } \\
\text { AK } \\
\text { CO } \\
\text { CT } \\
\text { FL } \\
\text { ID } \\
\text { IN } \\
\text { LA } \\
\text { MS } \\
\text { NE } \\
\text { NV } \\
\text { NH } \\
\text { ND } \\
\text { SC } \\
\text { TX } \\
\text { VA } \\
\text { WV }\end{array}$ & $\begin{array}{l}\text { AL } \\
\text { AK } \\
\text { CO } \\
\text { CT } \\
\text { ID } \\
\text { IN } \\
\text { LA } \\
\text { ME } \\
\text { MD } \\
\text { MS } \\
\text { NV } \\
\text { NH } \\
\text { ND } \\
\text { OH } \\
\text { SC } \\
\text { TX } \\
\text { VA } \\
\text { WA } \\
\text { WV }\end{array}$ & $\begin{array}{c}\text { AL } \\
\text { AK } \\
\text { ID } \\
\text { LA } \\
\text { MS } \\
\text { NE } \\
\text { NV } \\
\text { NH } \\
\text { ND } \\
\text { SC } \\
\text { TX }\end{array}$ & $\begin{array}{c}\text { AL } \\
\text { AK } \\
\text { FL } \\
\text { ID } \\
\text { IL } \\
\text { IN } \\
\text { LA } \\
\text { MD } \\
\text { MS } \\
\text { NE } \\
\text { NH } \\
\text { ND } \\
\text { SC } \\
\text { TX } \\
\text { WA } \\
\text { WV }\end{array}$ & $\begin{array}{c}\text { NV } \\
\text { ND } \\
\text { TX } \\
\text { WV }\end{array}$ \\
\hline 2016 & $\begin{array}{c}\text { AZ } \\
\text { ME } \\
\text { MO } \\
\text { SD } \\
\text { WA }\end{array}$ & $\begin{array}{c}\text { IA } \\
\text { ME } \\
\text { SD } \\
\text { WA }\end{array}$ & $\begin{array}{l}\mathrm{AZ} \\
\mathrm{ME} \\
\mathrm{MO} \\
\mathrm{SD}\end{array}$ & $\begin{array}{c}\mathrm{AZ} \\
\mathrm{CT} \\
\mathrm{ME} \\
\mathrm{MO} \\
\mathrm{SD}\end{array}$ & $\begin{array}{c}\mathrm{ME} \\
\mathrm{MO} \\
\mathrm{SD}\end{array}$ & $\begin{array}{l}\mathrm{AZ} \\
\mathrm{ME} \\
\mathrm{MO} \\
\mathrm{NM} \\
\mathrm{SD}\end{array}$ & $\begin{array}{l}\text { AZ } \\
\text { IA } \\
\text { SD }\end{array}$ & $\begin{array}{c}\text { AZ } \\
\text { FL } \\
\text { IA } \\
\text { MO } \\
\text { SD }\end{array}$ & $\begin{array}{c}\text { ME } \\
\text { MO } \\
\text { UT } \\
\text { WV }\end{array}$ & $\begin{array}{l}\text { AZ } \\
\text { IA } \\
\text { ME } \\
\text { MA } \\
\text { MO }\end{array}$ & $\begin{array}{l}\text { IA } \\
\text { LA } \\
\text { MO } \\
\text { NM }\end{array}$ \\
\hline
\end{tabular}

Source: Prescription Drug Abuse Policy System (PDAPS)

${ }^{29}$ Available at: http://pdaps.org/datasets/laws-regulating-administration-of-naloxone-1501695139 
The difference-in-difference (DID) technique is an econometric tool first applied in the $19^{\text {th }}$ century to control for before-and-after implementation of a treatment or policy ${ }^{30}$ (National Research Council, 2004). A standard DID model to evaluate the effects of a Naloxone access law by differentiating between treatment and control (untreated) states is represented by:

$$
\text { TODDrate }_{i t}=\alpha_{0}+\alpha_{1} X_{i t}+\alpha_{2} N A L_{i t} T_{i t}+v_{i}+w_{t}+\varepsilon_{i t}
$$

where TODDrate ${ }_{i t}$ is the opioid overdose death rate in state $\mathrm{i}$ in year t. $X_{i t}$ is a vector of timevarying covariates that control for factors influencing death rates such as those listed in Table 14. $N A L_{i t} T_{i t}$ is the DID variable which takes a value of 1 if the state had a Naloxone access law in that particular year and zero otherwise. ${ }^{31} v_{i}$ is an unobservable, time-invariant state effect, which subsumes the main effect of the Naloxone law, while $w_{t}$ is a vector of year fixed effects which subsumes the main effect of the variable $\mathrm{T}$ (time). $\varepsilon_{i t}$ is an error term.

The standard DID model presented in equation (1) raises a possible issue with endogeneity for the NAL variable, i.e. does the level of a state's opioid overdose death rate influence enactment of a Naloxone access law in that state? We tested for this by examining state overdose death rates in the year prior to enactment of an access law compared to rates in states without an access law. To account for different years of means, we subtracted the state means from the national mean in that year (for non-access law states, 2014 overdose death rates are used). A t-test showed no statistical difference between access law and no access law states $(\mathrm{t}=-0.611, \mathrm{p}=0.544)$. Based upon this evidence, endogeneity in equation (1) is not seen as an issue.

\footnotetext{
${ }^{30}$ More information is available at: https://www.mailman.columbia.edu/research/population-health-methods/difference-differenceestimation

${ }^{31}$ In Rees et al. (2017), those states that the law was in effect for less than a full year had NAL as a fraction.
} 
Under a non-spatial econometric estimation, observations do not depend on location (LeSage and Pace, 2009; Elhorst, 2014). They are independent points and therefore there is no correlation between them and their neighbors. However, LeSage and Pace (2009) explain the case of spatial dependency: "In contrast to point observations, for a region we rely on the coordinates of an interior point representing the center (the centroid). An important point is that in spatial regression models each observation corresponds to a location or region". In nonspatial models, each observation has a mean of $x_{i} \beta$ and a random component $\varepsilon_{i}$ where the observation $i$ represents a region or point in space at one location and is considered to be independent of observations in other locations. In other words, independent or statistically independent observations imply that $E\left(\varepsilon_{i} \varepsilon_{j}\right)=E\left(\varepsilon_{i}\right) E\left(\varepsilon_{j}\right)=0$. This assumption of independence greatly simplifies models.

In many cases, this assumption is not applicable and observations located at different points or regions are dependent (LeSage and Pace, 2009). Suppose we have two regions (neighbors) $i$ and $j$. If these two regions are spatially correlated and normality for error terms is assumed, then:

$$
y_{i} \leftrightarrow y_{j}
$$

where the dependent variable (y) in region $j$ influences the dependent variable in its neighbor region $i$, and vice versa.

All spatial models have a weight matrix (W), which quantifies the spillover between regions. Elhorst (2014) expresses the weight matrix as a tool to describe the spatial arrangement of the geographical units in the sample. There are variety of units of measurement for spatial 
dependency such as neighbors, distance, and links (Getis, 2007). ${ }^{32}$ In this study, we conducted and applied different weight matrices and chose the appropriate contiguity weight matrix based on the nature of the research. As Debarsy et al. (2012) point out given the cross-border shopping of goods a weight matrix for neighbors with border touching seems intuitively appealing.

The use of spatial difference-in-difference (SDID) models has gained attraction in urban economics in recent years (Dubé et al., 2014; Sunak and Madlener, 2014; Heckert, 2015). However, to the best of our knowledge, few studies perform SDID model in public health and public policy research (Chagas et al. (2016) and Andrade (2016) are noted exceptions). We argue that opioid overdose death rates and Naloxone access laws need to be evaluated within a regional framework. For example, adoption of an access law in one state could well be followed by surrounding states. Marijuana legalization status in U.S. states is a good example of mimicking law enactment in neighboring states. In such cases, not only would opioid overdose death rates be affected by its own state level variables, but it also may be affected by neighboring state control variables.

\footnotetext{
${ }^{32}$ For more details on the differences between the spatial weight matrices, please refer to Elhorst (2014) and Getis (2007).
} 
Table 14. List of the Variables Utilized in Overdose Death Research

\begin{tabular}{|c|c|c|c|}
\hline Variable & Study Region & $\begin{array}{l}\text { Coefficient } \\
\text { Sign }\end{array}$ & Reference \\
\hline Poverty & New York City districts & + & Marzuk et al., 1997 \\
\hline Income distribution & $\begin{array}{l}\text { New York City } \\
\text { neighborhoods }\end{array}$ & - & $\begin{array}{l}\text { Galea et al., } 2003 \\
\text { Nandi et al., } 2006\end{array}$ \\
\hline External characteristics of neighborhood & $\begin{array}{l}\text { New York City } \\
\text { neighborhoods }\end{array}$ & - & Hembree et al., 2005 \\
\hline Internal characteristics of neighborhood & $\begin{array}{l}\text { New York City } \\
\text { neighborhoods }\end{array}$ & - & Hembree et al., 2005 \\
\hline Police activity & $\begin{array}{c}\text { New York City } \\
\text { neighborhoods, New } \\
\text { York City police } \\
\text { precinct }\end{array}$ & + & $\begin{array}{l}\text { Nandi et al., } 2006 \\
\text { Bohnert et al., } 2011\end{array}$ \\
\hline Unemployment & Italy provinces & - & Gatti et al., 2007 \\
\hline Per capita GDP & Italy provinces & + & Gatti et al., 2007 \\
\hline Urbanization & Italy provinces & + & Gatti et al., 2007 \\
\hline Couples' separation & Italy provinces & & Gatti et al., 2007 \\
\hline Demographic factors (African-American men) & $\begin{array}{c}\text { Chicago } \\
\text { neighborhoods }\end{array}$ & + & Scott et al., 2007 \\
\hline Location relative to the U.S.-Mexico border & New Mexico counties & - & Shah et al., 2012 \\
\hline Heroin source/type, price and purity & 27 U.S. MSAs & $+/-$ & Unick et al., 2014 \\
\hline Educational attainment & U.S states & - & Richardson et al., 2015 \\
\hline State medical cannabis laws & U.S states & - & Bachhuber et al., 2014 \\
\hline Uninsured adults and health care cost & New Mexico counties & - & Shah et al., 2012 \\
\hline Substance Abuse Insurance Mandates & U.S states & - & Selby, 2017 \\
\hline
\end{tabular}

Since medications like Naloxone can be rather easily transferred across state borders, users can buy Naloxone in a neighboring state with an access law and use it in their home state without an access law. This type of transmission of Naloxone across state borders could affect the opioid overdose death rates in neighboring states. In addition, the opioid epidemic in the U.S. is observed to be clustered in specific regions such as Appalachia and the Southwest ${ }^{33,34}$

\footnotetext{
${ }^{33}$ For more details, please refer to: http://www.realclearhealth.com/articles/2017/06/14/analysis_peering_into_the_nations_opioid_crisis_through_a_regional_lens_1 10633.html

${ }^{34}$ For more details, please refer to: http://www.acutisdiagnostics.com/sites/default/files/Peeling_Back_the_Curtain_on_Regional_Variation_in_the_Opioid_Crisis_FI NAL_June_2017\%20\%281\%29.pdf
} 
(see Rudd et al., 2016). Therefore, analyzing the effectiveness of the Naloxone access law on opioid overdose deaths is more appropriate to investigate within a regional framework rather than a standard state level analysis.

When a spatial component (whether it is the spatial component of the dependent variable, control variables or the error term) is statistically significant, the coefficients estimated by nonspatial models (in our case a general DID) would be biased or not efficient. For example, if the spatial component is just in the error term, estimated coefficients in the non-spatial model are still unbiased and consistent, but not efficient (Case, 1991). In addition, variances may be nonefficient in non-spatial models (Griffith, 2005; LeSage and Pace, 2009). Accordingly, statistical tests such as t- and F-tests may be invalid, leading researchers to interpret their results improperly.

We conduct the estimation process by adding a spatial component to the non-spatial econometric analysis in a panel data framework. The SDID model developed for opioid overdose death rate can be written as

$$
\begin{gathered}
\text { TODDrate }_{i t}=\beta_{0}+\beta_{1} N A L_{i t} T_{i t}+\sum_{j=2}^{n} \beta_{j} X_{i j t}+\rho W \text { TODDrate }_{j t}+ \\
\vartheta W N A L_{j t} T_{j t}+\theta W X_{j t}+v_{i}+w_{t}+\varepsilon_{i t}
\end{gathered}
$$

where TODDrate stands for the opioid overdose deaths per 100,000 populations in state $i$ and time $t, N A L$ represents a dummy variable whether the state has a Naloxone access law in a given year. $X$ is a vector of demographic variables described above, while $v_{i}$ and $w_{t}$ are state and year fixed effects, respectively. The terms WTODDrate, WNAL T, and WX denote the spatial components of opioid overdose death rate, Naloxone access law, and other control variables, respectively. $\rho, \vartheta$, and $\theta$ represent the spillover effects of the dependent variable and 
independent variables, respectively. These variables explain the effects of dependent variable and independent variables of neighboring states $(j)$ on the dependent variable in specific state $(i)$.

We examine the impact of Naloxone access laws with three different models. First, following Rees et al. (2017), we impose a dummy variable for passage of a Naloxone access law at the state level in Model 1. For Model 2, we assess the impact of access laws by the number of days since the effective date of the law. ${ }^{35}$ To examine the impacts of access laws over time, a quadratic form of this variable was included in this model. Finally, Model 3 provides for a breakdown of access laws by their specific provisions. Since Naloxone access laws are not homogenous, to evaluate the effects of access laws on opioid overdose death rates, one needs to differentiate between the provisions included in each law. Keeping NAL 1 for the binary variable in Model 1, we control for access law provisions by imposing five binary variables in Model 3 with grouping provisions to avoid collinearity:

NAL 1: Having a Naloxone access law.

NAL 2: Immunity from criminal liability, civil liability and professional sanctions for prescribing, dispensing or distributing Naloxone to a layperson for prescribers and dispensers

NAL 3: Third parties' authorization to prescribe Naloxone

NAL 4: Pharmacists are allowed to dispense or distribute naloxone without a patientspecific prescription from another medical professional

NAL 5: Immunity from criminal and civil liability administering Naloxone to a layperson NAL 6: Removing criminal liability for possession of Naloxone

\footnotetext{
35 The days after law is measured by counting the days from the effective date to the last day of the year.
} 
A priori we would expect these Naloxone access laws to be associated unequivocally with greater access to Naloxone. However, whether these laws should lead to improvements in drug overdose rates remains an open question. Due to the overdose-reversing properties of Naloxone, we expect improved access to reduce overdose deaths. However, if as others have found, Naloxone leads to individuals behaving in riskier ways by taking more potent drugs or larger amounts of drugs, we may expect access to increase drug deaths. While understanding how each different provision will affect individuals is a goal of this research, ultimately, the sign and magnitudes of these effects are empirical questions.

For the $X$ vector of control variables, there is some evidence in the literature that poverty, unemployment, uninsured rate, and income inequality are each positively correlated with opioid overdose deaths (Galea et al., 2003; Nandi et al., 2006; Gatti et al., 2007; Shah et al., 2012). Conversely, income and education have negative relationships with opioid overdose deaths (Richardson et al., 2015). We expect to see positive effects from the availability of legal and illegal opioids on opioid overdose death rates. Medical marijuana laws are expected to have a negative effect on opioid overdose death rates because we expect opioids and marijuana to be substitutes so that medical marijuana laws will likely reduce the cost of receiving marijuana and therefore decrease the quantity of opioids demanded.

\section{DATA}

Data for constructing the three models come from a number of different sources. We use data from the Centers for Disease Control and Prevention (CDC) Wonder for 1999-2016 ${ }^{36}$ which contain the universe of opioid overdose deaths and opioid overdose death rates by state in the

\footnotetext{
${ }^{36}$ National Vital Statistics System (NVSS)
} 
U.S. We focus on the 48 continuous states of the U.S. and Washington, D.C. over this time period. These data were compiled using underlying cause of death compressed mortality files. The number of opioid overdose deaths by state were classified using the International Classification of Diseases, Tenth Revision (ICD-10). We included overdose deaths coded as unintentional (X40-44), homicide (X85), undetermined intent (Y10-Y14), and suicide cases (X60-64). ${ }^{37}$ Among deaths with opioid overdose as the underlying cause, the type of opioid involved is indicated by the following ICD-10 multiple cause-of-death codes: opioids (T40.0, T40.1, T40.2, T40.3, T40.4, or T40.6); heroin (T40.1); natural and semisynthetic opioids (T40.2); methadone (T40.3); and synthetic opioids other than methadone (T40.4). The dependent variable unit is the number of opioid overdose deaths per 100,000 populations. Population data are collected from the Centers for Disease Control and Prevention (CDC) Wonder.

For our variable of interest, we create measures of whether each state had a Naloxone law, the various provisions of each law, and effective dates from the Prescription Drug Abuse Policy System (PDAPS ${ }^{38}$ ). For control variables in the $X$ vector, Unick et al. (2014) recommend including illicit drug price. Without having access to such data for our time frame, we instead control for drug arrests and quantity of prescription drug sales. Sale and possession related arrests of opium or cocaine and their derivatives (Morphine, Heroin, and Codeine) were provided by the Federal Bureau of Investigation to control for illicit opioids supply. The availability of prescription opioids comes from controlled substances transactions of prescriptions available through Automated Reports and Consolidated Ordering System (ARCOS). ${ }^{39}$

\footnotetext{
${ }^{37}$ As a robustness check we test the total number of opioid overdose deaths as the dependent variable (not restricted to ICD-10 codes recommended by Ruhm (2016)).

${ }^{38}$ Available at: http://pdaps.org/

${ }^{39}$ Available at: https://www.deadiversion.usdoj.gov/arcos/retail_opioid_summary/
} 
State level economic variables of per pupil spending on education, poverty rate, unemployment rate as well as population density and uninsured rate were obtained from the U.S. Census Bureau. Income inequality, high school attainment, and the college attainment data were obtained from U.S. state-level income inequality data and annual state-level measures of human capital attainment at Mark W. Frank home page. ${ }^{40}$ Per capita personal income was based on the information provided by Federal Reserve Bank of St. Louis (FRED). ${ }^{41}$ Employment in mining, construction, and manufacturing and labor force were collected from Bureau of Labor Statistics (BLS). ${ }^{42}$ To compute the employment ratio for high-risk injury occupations, we added the number of employment in mining, manufacturing and construction and divided it by the total labor force. Medical marijuana law data were collected from the leading source for pros and cons of controversial issues ${ }^{43}$ Finally, the spatial weight matrix (a shape file of U.S. states consisting of the latitudinal and longitudinal coordinates of all the 48 states and D.C.) was adapted from the U.S. Census Bureau (Tiger) report.

To control for spillover effects of Naloxone access laws, the 48 continuous U.S. states plus District of Colombia were included in our analysis. In spatial analysis, contiguity and neighborhoods play vital roles (Tobler, 1970). We focused on contiguous states based on the first law of geography: everything is related to everything else, closer things even more so (Tobler, 1970). Descriptive statistics for each variable are reported in Table 15 along with the expected signs of Naloxone access law and control variables. Following previous studies (Rees

\footnotetext{
${ }^{40}$ Available at: http://www.shsu.edu/eco_mwf/inequality.html

${ }^{41}$ Available at: https://fred.stlouisfed.org/release?rid=151

${ }^{42}$ Available at: https://www.bls.gov/sae/data.htm

${ }^{43}$ Available at: http://medicalmarijuana.procon.org/view.resource.php?resourceID=000881
} 
et al., 2017) which found a negative effect of Naloxone access laws on opioid overdose deaths, we expect to have a negative effects of the law on opioid overdose death rates.

\section{METHODS}

\section{Exploring spatial dependency in opioid overdose death rates across states}

As we mentioned in the previous section, the economic distance concept is a motivation for spatial spillover effects. Before analyzing spatial dependency by corresponding econometric models, an intuitive way to identify clusters is by looking at a map of overdose death rates. As shown in Figure 2, opioid overdose death rates have increased over time. In 1999, only two states had an overdose death rate between 8 and 10 deaths per 100,000 population. By 2016, 34 states had overdose death rates between 8 and 40 deaths per 100,000 population. Also, some spatial clusters are obvious especially in 2016. New Mexico had the highest opioid overdose death rate in 1999. In 2016, its surrounding states also had high rates of overdose deaths. Substantial clustering also exists within states on the east coast.

Given the fact that opioid overdose death rates show visual evidence of clustering among states, the next step is to detect spatial autocorrelation. Spatial autocorrelation measures the interrelationship of opioid overdose death rate across neighboring states. A common index used to discover spatial autocorrelation is the Global Moran's I index. ${ }^{44}$ As pointed out by Chen and Haynes (2015), Moran's I is a test on a yearly basis. A significant and positive z-value for Moran's I index implies a positive spatial autocorrelation. Table 16 shows the results for Moran's I index for two points of time and its z-statistics and p-value. These tests reveal that there has been and still is (as of 2016) significant spatial autocorrelation among state level opioid

\footnotetext{
${ }^{44}$ More information is available at: http://ceadserv1.nku.edu/longa//geomed/ppa/doc/globals/Globals.htm
} 
overdose death rate in the U.S. This means state level opioid overdose death rates tend to be clustered together.

Moran's I index assesses the overall presence of spatial autocorrelation. This index could offset the effects of spatial autocorrelation if some observations have a positive spatial autocorrelation while the others show a negative spatial autocorrelation. For further examination, we also report the results of local Moran's I test (LISA). Scatter plots of LISA shows observations in four different quadrants: High value observation surrounded by high value observations (i.e. QI: HH) and three other clusterings for LH (QII), HL (QIV), and LL (QIII) quadrants. Figure 4 provides Moran scatter plots of the US opioid overdose death rates in 1999 and 2016. This figure illustrates that in both years, most of the states with high overdose rate are adjacent to states with high overdose rates. This also is true for the states with low overdose death rates. Thus, we apply a first-order contiguity weight matrix in our spatial analysis.

The existence of statistically significant spatial autocorrelation among states implies that the ordinary least square estimations (non-spatial models) may lead toward biased estimates of the regression results. Therefore, it is appropriate to apply spatial models in the analysis of Naloxone access laws and opioid overdose death rate. As Delgado and Florax (2015) point out, identification of causal effects is no longer valid if the Stable Unit Treatment Value Assumption (SUTVA $)^{45}$ is violated. A SUTVA violation means that in determining the treatment effect, considering one's own treatment status is not sufficient. Treatment status of neighboring regions (in our case states) has to be taken into account as well (Delgado and Florax (2015).

\footnotetext{
${ }^{45}$ Stable Unit Treatment Value Assumption: potential outcomes for person $i$ are unrelated to the treatment status of other individuals
} 
Table 15. Descriptive Statistics

\begin{tabular}{lccccc}
\hline \multicolumn{1}{c}{ Variables } & Mean & St. Dev. & Min & Max & $\begin{array}{c}\text { Expected } \\
\text { Sign }\end{array}$ \\
\hline Opioid overdose death rates (per 100K pop) & 7.05 & 5.12 & 0.26 & 40 & \\
Total opioid overdose death rates (per 100K pop) & 7.38 & 5.32 & 0.19 & 41.8 & - \\
NAL 1 & 0.173 & 0.363 & 0 & 1 & - \\
NAL 2 & 0.136 & 0.328 & 0 & 1 & - \\
NAL 3 & 0.135 & 0.327 & 0 & 1 & - \\
NAL 4 & 0.096 & 0.276 & 0 & 1 & - \\
NAL 5 & 0.133 & 0.323 & 0 & 1 & - \\
NAL 6 & 0.032 & 0.168 & 0 & 1 & - \\
Days after Naloxone access law (days/1000) & 0.234 & 0.712 & 0 & 5.745 & - \\
Square of the days after Naloxone access law & 349 & 1,978 & 0 & 25,150 & + \\
(days ${ }^{2}$ 1000) & & & & & \\
Presence of Medical marijuana law & 0.25 & 0.43 & 0 & 1 & - \\
Heroin arrest rate (arrests/100k pop) & 138.05 & 103.15 & 0.61 & 761.43 & + \\
Opioid prescription (kg/100k pop) & 56.527 & 41.023 & 6.911 & 496.506 & + \\
Employment ratio (\%) & 0.14 & 0.04 & 0.002 & 0.26 & + \\
Population density (pop./mi2) & 342.31 & $1,242.48$ & 5.028 & 10,013 & $-/+$ \\
Income inequality (Income share for the top \%10) (\%) & 44.72 & 4.98 & 33.27 & 62.17 & + \\
College attainment (the total number of college & 0.19 & 0.04 & 0.10 & 0.46 & - \\
graduates/ the total state population) (\%) & & & & & \\
Spending on education (\$1000) & 9.226 & 2.838 & 4.169 & 20.609 & - \\
Poverty rate (\%) & 13.38 & 3.34 & 5.60 & 23.90 & + \\
Unemployment rate (\%) & 5.71 & 2.06 & 2.30 & 13.70 & + \\
Uninsured rate (\%) & 12.69 & 4.14 & 3.00 & 26.10 & + \\
Median HH income (thousand dollars) & 47.15 & 8.36 & 29.29 & 76.16 & - \\
Per capita income (thousand dollars) & 38.03 & 9.09 & 20.56 & 75.75 & - \\
Number of observations & & & & \\
\hline & & & & & \\
\hline
\end{tabular}

Table 16. Moran's I index for State Level Opioid Overdose Death Rates

\begin{tabular}{lll}
\hline & 1999 & 2016 \\
\hline Moran's i & 0.407 & 0.581 \\
\hline z-statistics & 5.413 & 5.842 \\
\hline p-value & 0.010 & 0.000
\end{tabular}


Figure 3. Opioid overdose death rates in the U.S. 1999 and 2016


Opioid overdose death rate 2016

$\square 2.300000-6.000000$
$6.000001-9.700000$
$9.700001-13.900000$
$13.900001-17.800000$
$17.800001-26.400000$
$26.400001-40.000000$


Figure 4. Moran's scatter plot of state Level Opioid

Overdose Death Rates (1999 and 2016)
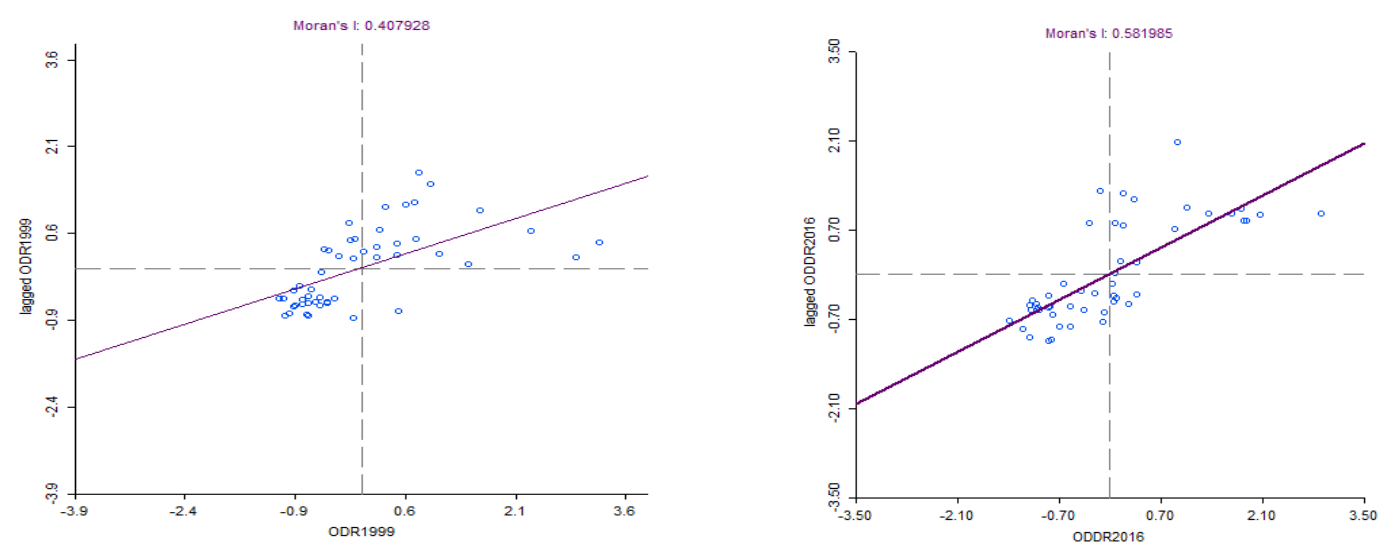

\section{Spatial econometric analysis}

There are five different spatial models. The first one is the spatial autoregressive lag model (SAR) where the dependent variable in neighbor $j$ influences the dependent variable in neighbor $i$ and vice versa. Second, a Spatial Error Model (SEM) assumes dependency in the error term. SLX model or spatial lag of control variables assumes that only control variables play a direct role in determining dependent variables. Lastly, there are Spatial Durbin Model (SDM) and Spatial Error Durbin Model (SDEM) that include spatial lags of the control variables as well as the dependent variable and a spatial lag of the control variables (WX), as well as spatially dependent disturbances.

As discussed above and based upon the results of the spatial analysis, we have strong reasons to suspect that spatial spillovers are important both theoretically and empirically when examining the effect of access policy for both state and temporal variation. To evaluate the effects of Naloxone access laws on opioid overdose death rates, we first test a general non-spatial specification against SAR and SEM models by conducting a Lagrange Multiplier (LM) test. In both cases, the spatial models were the appropriate specification (LM for non-spatial against 
$\mathrm{SAR}=45.51$ and $\mathrm{p}$-value $=0.00, \mathrm{LM}$ for non-spatial against $\mathrm{SEM}=10.01$ and $\mathrm{p}$-value $=0.00$ ).

The next step is testing SAR against SEM. By applying the robust LM test we failed to reject that the SAR model is the most appropriate specification ${ }^{46}(\mathrm{LM}$ spatial lag $=148.37>\mathrm{LM}$ spatial error $=112.86$ ). Knowing that the SAR, SEM, and SLX models are nested within SDM and SDEM and for applied works LeSage recommends applying either a SDM or $\mathrm{SDEM}^{47}$, we continue our estimations by focusing on SDM model which is a global spatial econometric model encompassing both SAR and SLX models. ${ }^{48}$

In addition to applying Lagrange multiplier, LM spatial lag, and LM spatial error tests, we also applied Bayesian posterior model probabilities to compare SDM and SDEM specifications. Consistent with the results from the LM tests, this analysis provides further support of the SDM specification in our context.

\section{SPATIAL RESULTS}

As discussed in the previous sections, considering cross border issues of Naloxone and opioid drugs, it is important to consider the spillover effects between states in regards to overdose death rates and Naloxone access laws. We argue that a first-order contiguity weight matrix is the right choice for several reasons. First, we need the weight matrix to be exogenous to our estimation, and a first-order contiguity matrix fits this requirement. Secondly, geographical proximity has been shown to be important for spillovers (e.g., Jaffe, 1989; Jaffe el al., 1993; Attila, 2000, Chagas et al., 2016).

\footnotetext{
${ }^{46}$ For more information, please refer to Florax et al. (2003)

${ }^{47}$ For more information, please refer to LeSage (2014)

${ }^{48}$ As noted by LeSage (2014), cross-border shopping has a local spillover rather than a global. We argue that in the case of legal prescriptions and illicit drugs, drug transfers occur through more than just neighboring states. In addition, state legislatures may adopt Naloxone access laws based upon neighboring states' overdose death rates and the adoption of an access law.
} 
Table 17 presents the spatial regressions results for Models 1 and 2 presented in section 3. Within these two models, there are no statistically significant, direct effects of Naloxone access laws on overdose death rates. That our direct effect results are small and statistically insignificant suggest that Naloxone laws do not affect overdose rates in the state they are enacted. Indirect effects are positive and statistically significant. When direct and indirect effects are combined, both models show positive impacts, meaning that opioid overdose death rates increase following the implementation of Naloxone access laws, with the majority of this effect coming through spatial spillovers.

This may seem a counterintuitive result, i.e., that a more lax legislative environment for Naloxone in a state leads to more deaths in surrounding states. However, it is important to note that Doleac and Mukherjee (2018) find evidence of higher hospitalization rates in states following Naloxone laws and some evidence of regional increases in deaths. They also note evidence of increased fentanyl use, a much more potent opiate than even heroin.

Model 3 differentiates between laws by breaking them down into five provision groupings. Table 18 shows the estimation results for access laws by provision. Given the statistically significant spatial autocorrelation coefficient $(\rho)$, the parameter estimates in the twoway fixed effects spatial autoregressive model cannot be interpreted as non-spatial models. We estimate the direct and indirect effects to yield an interpretation of the spatial spillover effects. These results show similar outcomes to Models 1 and 2 when we break down these laws by their provisions. With the exception of provisions of immunity from criminal and civil liability for administering Naloxone, the direct effects on overdose death rates are small and statistically insignificant, showing no evidence of reducing these rates. This direct effect suggests that some aspect of removing criminal liability of Naloxone distribution makes individuals more likely to 
fatally overdose. We can only speculate that perhaps this provision removes a stigma from taking drugs and further serves as an implicit approval to take more potent drugs (Doleac and Mukherjee 2018) or that Naloxone laws are correlated with fentanyl distribution.

Out of five provision groupings, immunity from criminal liability, civil liability and professional sanctions for prescribing, dispensing or distributing Naloxone to a layperson for prescribers and dispensers (NAL 2), the ability of prescribers to provide Naloxone to third parties (NAL 3), immunity from criminal and civil liability administering Naloxone to a layperson (NAL 5), and removing criminal liability for possession of Naloxone (NAL 6) have statistically significant indirect effects. NAL 2, NAL 5, and NAL 6 increase overdose death rates in the neighboring states where they are enacted, while the ability of prescribers to provide Naloxone to third parties decreases overdose death rates in the neighboring states. In each case, indirect effects are much larger than direct effects, from about 5 to 15 times greater than the corresponding direct effects. For total effects, NAL 5 and NAL 6 are statistically significant and positive; while NAL 3 is significantly negative (Table 17). Thus, while both negative and positive impacts on overdose death rates are found to exist for Naloxone access law provisions; positive impacts via spillover effects dominate the outcome of these laws.

While these spillover effects are large, we caution restraint when interpreting these coefficients. Previous research has differed on the effect of Naloxone laws on overdose deaths. Our direct effect results are small and statistically insignificant suggesting that Naloxone laws do not affect overdose rates in the state they are enacted. Several reasons may explain the size and direction of these spillover effects. First, these laws may be enacted in neighboring states because of perceived drug risk or even drug deaths occurring in nearby states. Additionally, the positive and statistically significant indirect effects of access laws may be explained by their 
potential impacts on the increased availability of high potency drugs (like heroin) in neighboring states. Our logic is that increased access to Naloxone keeps opioid drug abusers alive longer and leaves them seeking higher potency drugs, thus leading to more of these drugs flowing through illegal drug supply channels across multiple states.

Other influences on opioid overdose death rates include heroin related arrests and opioid prescription with positive and significant direct, indirect (only opioid prescription) and total effects (Table 17). Heroin related crime and prescriptions of opioids both increase opioid overdose death rates. Opioid prescription increases the overdose death rates within the state as well as surrounding states, while heroin related crime increases the overdose death rate only within the state. Employment of those who work at mining, construction and manufacture industries also increases opioid overdose death rates within the state while decreasing rates in neighboring states. 
Table 17. Estimation Results for Model 1 (dummy of access law NAL 1) and Model 2 (days after effective date of access law)

\begin{tabular}{|c|c|c|c|c|}
\hline \multirow[t]{2}{*}{ Variables } & \multicolumn{2}{|c|}{ Model 1} & \multicolumn{2}{|c|}{ Model 2} \\
\hline & Direct & Indirect & Direct & Indirect \\
\hline Naloxone access law 1 & $\begin{array}{c}0.238 \\
(0.554)\end{array}$ & $\begin{array}{c}5.767 * * * \\
(0.000)\end{array}$ & - & - \\
\hline Days after NAL & - & - & $\begin{array}{c}0.251 \\
(0.583)\end{array}$ & $\begin{array}{c}7.656 * * * \\
(0.000)\end{array}$ \\
\hline Days after $\mathrm{NAL}^{\wedge} 2$ & - & - & $\begin{array}{c}-0.00001 \\
(0.812)\end{array}$ & $\begin{array}{c}-0.001 * * * \\
(0.000)\end{array}$ \\
\hline Medical marijuana law & $\begin{array}{c}1.318^{* * *} * \\
(0.001)\end{array}$ & $\begin{array}{l}2.687 * \\
(0.058)\end{array}$ & $\begin{array}{c}1.109 * * \\
(0.010)\end{array}$ & $\begin{array}{c}1.772 \\
(0.217)\end{array}$ \\
\hline Heroin related arrest & $\begin{array}{c}0.008 * * * \\
(0.000)\end{array}$ & $\begin{array}{c}0.007 \\
(0.225)\end{array}$ & $\begin{array}{c}0.008 * * * \\
(0.000)\end{array}$ & $\begin{array}{l}0.009 * \\
(0.086)\end{array}$ \\
\hline Opioid prescription & $\begin{array}{c}0.010^{* * * *} \\
(0.003)\end{array}$ & $\begin{array}{l}0.021^{*} \\
(0.098)\end{array}$ & $\begin{array}{c}0.010 * * * \\
(0.002)\end{array}$ & $\begin{array}{c}0.024 * * \\
(0.048)\end{array}$ \\
\hline Employment ratio & $\begin{array}{c}34.104 * * * \\
(0.002)\end{array}$ & $\begin{array}{c}-68.280 * * \\
(0.039)\end{array}$ & $\begin{array}{c}36.500 * * * * \\
(0.001)\end{array}$ & $\begin{array}{l}-59.90^{*} \\
(0.061)\end{array}$ \\
\hline Population density & $\begin{array}{c}0.002 * * \\
(0.032)\end{array}$ & $\begin{array}{l}-0.006 \\
(0.327)\end{array}$ & $\begin{array}{c}0.003 \\
(0.014)\end{array}$ & $\begin{array}{c}0.009 \\
(0.142)\end{array}$ \\
\hline Income inequality index & $\begin{array}{c}-0.011 \\
(0.825)\end{array}$ & $\begin{array}{l}-0.035 \\
(0.817)\end{array}$ & $\begin{array}{l}-0.015 \\
(0.757)\end{array}$ & $\begin{array}{c}-0.052 \\
(0.736)\end{array}$ \\
\hline College graduate & $\begin{array}{l}-0.060 \\
(0.434)\end{array}$ & $\begin{array}{c}0.118 \\
(0.633)\end{array}$ & $\begin{array}{l}-0.034 \\
(0.653)\end{array}$ & $\begin{array}{c}0.151 \\
(0.536)\end{array}$ \\
\hline Education spending per student & $\begin{array}{c}0.116 \\
(0.431)\end{array}$ & $\begin{array}{c}0.045 \\
(0.921)\end{array}$ & $\begin{array}{c}0.124 \\
(0.425)\end{array}$ & $\begin{array}{c}-0.019 \\
(0.966)\end{array}$ \\
\hline Poverty & $\begin{array}{c}0.169 \\
(0.307)\end{array}$ & $\begin{array}{c}1.570 * * * \\
(0.004)\end{array}$ & $\begin{array}{l}-0.043 \\
(0.791)\end{array}$ & $\begin{array}{c}1.210 \\
(0.822)\end{array}$ \\
\hline Unemployment & $\begin{array}{l}-0.161 \\
(0.205)\end{array}$ & $\begin{array}{l}-0.529 \\
(0.186)\end{array}$ & $\begin{array}{l}-0.163 \\
(0.198)\end{array}$ & $\begin{array}{c}-0.359 \\
(0.353)\end{array}$ \\
\hline Uninsured & $\begin{array}{c}0.052 \\
(0.321)\end{array}$ & $\begin{array}{l}0.333^{*} \\
(0.052)\end{array}$ & $\begin{array}{c}0.071 \\
(0.195)\end{array}$ & $\begin{array}{c}0.420^{* *} \\
(0.025)\end{array}$ \\
\hline Per capita income & $\begin{array}{c}-2.130 * * * \\
(0.002)\end{array}$ & $\begin{array}{l}4.246^{*} \\
(0.096)\end{array}$ & $\begin{array}{c}-2.571 * * * \\
(0.000)\end{array}$ & $\begin{array}{c}1.84 \\
(0.474)\end{array}$ \\
\hline$\rho$ & & & & \\
\hline $\mathbf{R}^{2}$ & & & & \\
\hline Observations & & & & \\
\hline
\end{tabular}


Table 18. Direct, Indirect, and Total Effects of SDM Model (Based on Model 3)

\begin{tabular}{|c|c|c|c|}
\hline Variables & Direct Effect & Indirect Effect & Total Effect \\
\hline \multirow[t]{2}{*}{ Naloxone access law 2} & -0.199 & $2.970 * *$ & 2.771 \\
\hline & $(0.710)$ & $(0.016)$ & $(0.178)$ \\
\hline \multirow[t]{2}{*}{ Naloxone access law 3} & -0.555 & $-5.948 * * *$ & $-6.503 * *$ \\
\hline & $(0.382)$ & $(0.006)$ & $(0.013)$ \\
\hline \multirow[t]{2}{*}{ Naloxone access law 4} & -0.237 & 4.165 & 3.928 \\
\hline & $(0.708)$ & $(0.102)$ & $(0.179)$ \\
\hline \multirow[t]{2}{*}{ Naloxone access law 5} & $1.994 * * *$ & $9.659 * * *$ & $11.653^{* * *}$ \\
\hline & $(0.009)$ & $(0.001)$ & $(0.001)$ \\
\hline \multirow[t]{2}{*}{ Naloxone access law 6} & 0.373 & $5.710 * *$ & $6.084 * *$ \\
\hline & $(0.539)$ & $(0.012)$ & $(0.017)$ \\
\hline \multirow[t]{2}{*}{ Medical marijuana law } & $0.815^{*}$ & 0.308 & 1.124 \\
\hline & $(0.059)$ & $(0.825)$ & $(0.504)$ \\
\hline \multirow[t]{2}{*}{ Heroin related arrest } & $0.008 * * *$ & 0.005 & $0.014 * *$ \\
\hline & $(0.000)$ & $(0.271)$ & $(0.017)$ \\
\hline \multirow[t]{2}{*}{ Opioid prescription } & $0.012 * * *$ & $0.030 * *$ & $0.042 * * *$ \\
\hline & $(0.000)$ & $(0.016)$ & $(0.003)$ \\
\hline \multirow[t]{2}{*}{ Employment ratio } & $31.699 * * *$ & -49.547 & -17.847 \\
\hline & $(0.003)$ & $(0.116)$ & $(0.609)$ \\
\hline \multirow[t]{2}{*}{ Population density } & 0.001 & -0.002 & -0.0003 \\
\hline & $(0.214)$ & $(0.744)$ & $(0.957)$ \\
\hline \multirow[t]{2}{*}{ Income inequality index } & -0.008 & -0.026 & -0.034 \\
\hline & $(0.868)$ & $(0.859)$ & $(0.835)$ \\
\hline \multirow[t]{2}{*}{ College graduate rate } & -0.048 & 0.163 & 0.114 \\
\hline & $(0.508)$ & $(0.491)$ & $(0.678)$ \\
\hline \multirow[t]{2}{*}{ Education spending per student } & 0.155 & 0.432 & 0.587 \\
\hline & $(0.289)$ & $(0.322)$ & $(0.240)$ \\
\hline \multirow[t]{2}{*}{ Poverty rate } & 0.011 & 0.636 & 0.647 \\
\hline & $(0.941)$ & $(0.218)$ & $(0.257)$ \\
\hline \multirow[t]{2}{*}{ Unemployment rate } & 0.035 & 0.274 & 0.310 \\
\hline & $(0.787)$ & $(0.518)$ & $(0.500)$ \\
\hline \multirow[t]{2}{*}{ Uninsured rate } & -0.0007 & 0.030 & 0.030 \\
\hline & $(0.987)$ & $(0.855)$ & $(0.877)$ \\
\hline \multirow[t]{2}{*}{ Per capita income } & $-2.179 * * *$ & 3.584 & 1.404 \\
\hline & $(0.002)$ & $(0.149)$ & $(0.614)$ \\
\hline \multirow[t]{2}{*}{$\rho$} & & 0.47 & \\
\hline & & $(0.000)$ & \\
\hline $\mathbf{R}^{2}$ & & 0.86 & \\
\hline Observations & & 882 & \\
\hline
\end{tabular}

Note: Numbers in the parentheses represent p-values.

$*, * *$, and $* * *$ refer to $10 \%, 5 \%$, and $1 \%$ significance levels, respectively.

Per capita income has a significant and negative direct effect on opioid overdose death rates. The implication is that states with higher per capita incomes have lower opioid overdose death rates, while states with lower per capita incomes suffer from higher opioid overdose death rate. Contrary to our expectations, states which passed a medical marijuana law have slightly higher overdose death rates. Other variables (income inequality, education spending per student, 
poverty rate, and uninsured rate) do not have statistically significant effects on overdose death rates.

In terms of control variables, our results are consistent with those found by Keyes et al. (2014) but contradict Gatti et al. (2007). The Gatti et al. study focuses on Italy, a very different context from ours.

Finally, as a robustness check, a new dependent variable of total opioid overdose death rates introduced in section 4 is examined. As pointed out by Rees et al. (2017), opioid overdose deaths published by CDC is based on the underlying cause of death (accidental, intentional, and undetermined intent), for example see Ruhm (2016). For this check, the new dependent variable represents a comprehensive and unrestricted measure of opioid overdoses using Model 3. The relative magnitude and sign for all statistically significant effects from Naloxone access law provision groupings and all other variables are unchanged from Table $18 .{ }^{49}$

\section{CONCLUSIONS}

Opioid overdose deaths are the leading cause of unintentional death in the U.S. These drugs are associated with more deaths than car accidents and guns. To address this nationwide public health emergency, state governments have implemented Naloxone access laws to ease access to this overdose reversal drug. In this research, we examine the impact of these Naloxone access laws on opioid overdose deaths and their spillover effects to surrounding states. No endogeneity between overdose death rates and access laws is found to exist.

We applied spatial econometrics models to avoid potential bias in coefficient estimation and our regression results from all three models indicate no matter how we control for Naloxone

\footnotetext{
${ }^{49}$ These estimated results are available from the corresponding author upon request.
} 
access laws, we find no statistical evidence to show that Naloxone access laws help to reduce drug overdose death rates. When measuring Naloxone access laws in three different ways, positive spillover effects of these laws are statistically significant and dominate direct effects in terms of magnitude. Thus, Naloxone access laws have more regional than state level effects. We are the first study to explore the spatial spillovers of these Naloxone access laws across states.

It is useful to compare the magnitude of the aggregate effects from groupings of Naloxone access law provisions with the effects for heroin related arrests and drug prescriptions. To do that, we use state level means to compare relative magnitudes. For example, if an overdose prevention policy could reduce opioid prescriptions by $50 \%$, the impact of this policy would reduce opioid overdose death rates by slightly over one per 100,000 population. Conversely, the total effect of enactment of a Naloxone access law containing the three significant provisions (NAL 3, 5, and 6) results in an increase in overdose death rates by 11 per 100,000 population. This simple calculation indicates that compared to a supply side policy, the overall effect of a Naloxone access law on opioid overdose death rates is much higher, however, in the opposite of the intended direction.

Spatial econometrics has an important role to play in research on drug epidemics (see e.g., Partridge et al. (2012) for a general discussion of the importance of spatial econometrics). ${ }^{50}$ Due to movement of opioid drugs and Naloxone across state borders, in this paper, we demonstrate that the use of conventional, non-spatial analyses may be biased in this environment. Overall, due to a statistically significant spatial autoregressive component, the opioid overdose death rate in one state is associated with opioid overdose death rates in its

\footnotetext{
${ }^{50}$ For more information, please refer to Gibbons and Overman (2012), McMillen (2012), and Corrado and Fingleton (2012).
} 
neighboring states. This result means that there are spillover effects in opioid overdose death rates among neighboring regions (states). An increasing trend in opioid overdose death rates in one particular state may be followed by neighboring states as well.

Naloxone as a harm reduction strategy works well by reversing overdoses and saving lives. To combat opioid overdose deaths, however, Naloxone access laws do not appear to be a suitable strategy. The fight against opioid overdose rates requires policy makers to focus on dealing with opioid addiction and find ways to treat addiction. State level enactment of a Naloxone access law can be viewed as a starting point to a strategy of implementing and expanding access to save lives, but not as a sufficient response to the opioid crisis and overdose problems. In addition to enactment of access laws, both federal and state governments should consider the next steps such as policy recommendations presented by Clark (2017) (e.g. teambased care model, more collaboration with pharmacists, expanding harm reduction treatment model). Both federal and state governments need to be involved in preventive policies more focused on regional rather than state-specific solutions.

The combination of Naloxone access law and increasing availability of high potency drugs could be partially responsible for not finding a significant result within the states that pass such a law (Doleac and Mukherjee 2018). We are not able to control for an accurate measurement of opioid potency, but studies suggest opioid users shift toward consuming stronger, more illicit drugs like heroin and synthetic opioids like fentanyl when policies are enacted limiting opioid misuse (Alpert et al. Forthcoming; Evans et al. 2018; Jones et al. 2018; Gladden et al. 2016). ${ }^{51}$ There are two channels to explaining this shift: less availability of

\footnotetext{
${ }^{51}$ For more information, please refer to: https://www.vox.com/science-and-health/2017/5/8/15454832/fentanyl-carfentanil-opioidepidemic
} 
prescription painkillers and drug users seeking out a stronger high. ${ }^{52}$ In addition, cross border movement of Naloxone may influence our results for the direct effects of access laws.

Our results are broadly consistent with Doleac and Mukherjee (2018), who point that while broadening Naloxone access increases opioid-related emergency room visits and opioidrelated theft, it does not reduce overdose deaths. Conversely, while Rees et al. (2017) show that the heroin related overdose deaths are not associated with the Naloxone access law, they provide support for a protective effect of Naloxone access laws on overall drug-related deaths. We contribute to this literature by showing that Naloxone access has regional effects. Failing to control for spillover effects across state borders likely biases results.

We recognize several limitations in our research. First, many states have only recently enacted Naloxone access laws. Our data cover years 1999 to 2016, for those 19 states with newly enacted laws in 2015 and 2016, we do not have post implementation data. Empirical results may change with more post implementation data for these 19 states. Second, county level analysis would be preferable to assess the spillover effects across states, but these data were not consistently and publicly available for overdose death rates. ${ }^{53}$

One future avenue of research is to employ a mechanism that differentiates the relationship between neighbors by whether or not they have an access law. Our analysis does not differentiate between these types of neighboring states and this distinction may be important in determining the magnitude of the spillover effect. Further research also should consider applying a hierarchical analysis and provide spillover estimates at both levels of the hierarchy (including both county and state level data in county level model). Finally, research should

\footnotetext{
52 For more information, please refer to: https://www.vox.com/science-and-health/2017/8/3/16079772/opioid-epidemic-drugoverdoses

${ }^{53}$ For example, the CDC does not publish county level observations with less than nine overdose deaths.
} 
examine enactment of Naloxone access laws in conjunction with other policy responses, such as increased intervention and treatment programs for addiction to assess the impact of multiple policies on overdose death rates as well to limit the unintended consequences of Naloxone access on risky drug behaviors.

\section{REFERENCES}

Alpert, A., Powell, D., \& Pacula, R. L. (2017). Supply-side drug policy in the presence of substitutes: Evidence from the introduction of abuse-deterrent opioids (No. w23031). National Bureau of Economic Research.

Andrade, L. C. D. (2016). Spillover effects of blacklisting policy in the Brazilian Amazon (Doctoral dissertation, Universidade de São Paulo).

Attila, V. (2000). Local academic knowledge spillovers and the concentration of economic activity.

Bachhuber, M. A., Saloner, B., Cunningham, C. O., \& Barry, C. L. (2014). Medical cannabis laws and opioid analgesic overdose mortality in the United States, 1999-2010. JAMA internal medicine, 174(10), 1668-1673.

Beheshti, A., Lucas, L., Dunz, T., Haydash, M., Chiodi, H., Edmiston, B. \& Sobota, B. (2015). An evaluation of naloxone use for opioid overdoses in West Virginia: a literature review. American medical journal, 6(1), 9.

Bohnert, A. S., Nandi, A., Tracy, M., Cerdá, M., Tardiff, K. J., Vlahov, D., \& Galea, S. (2011). Policing and risk of overdose mortality in urban neighborhoods. Opioid and alcohol dependence, 113(1), 62-68.

Buchmueller, T. C., \& Carey, C. (2018). The effect of prescription drug monitoring programs on opioid utilization in medicare. American Economic Journal: Economic Policy, 10(1), 77 112.

Case, A. C. (1991). Spatial patterns in household demand. Econometrica: Journal of the Econometric Society, 953-965.

Chagas, A. L., Azzoni, C. R., \& Almeida, A. N. (2016). A spatial difference-in-differences analysis of the impact of sugarcane production on respiratory diseases. Regional Science and Urban Economics, 59, 24-36. 
Chan, T. Y., Hamilton, B. H., \& Papageorge, N. W. (2015). Health, risky behaviour and the value of medical innovation for infectious disease. The Review of Economic Studies, 83(4), 1465-1510.

Chen, Z., \& Haynes, K. E. (2015). Public surface transportation and regional output: A spatial panel approach. Papers in Regional Science, 94(4), 727-751.

Clark, M. N. (2017). Qualitative study of opioid overdose education and naloxone access strategies in community health center primary care settings: opportunities for expanding access and saving lives (Doctoral dissertation, Boston University).

Coffin, P. O., Fuller, C., Vadnai, L., Blaney, S., Galea, S., \& Vlahov, D. (2003). Preliminary evidence of health care provider support for naloxone prescription as overdose fatality prevention strategy in New York City. Journal of Urban Health, 80(2), 288-290.

Coffin, P. O., \& Sullivan, S. D. (2013). Cost-effectiveness of distributing naloxone to heroin users for lay overdose reversal. Annals of Internal Medicine, 158(1), 1-9.

Cohen, A., \& Einav, L. (2003). The effects of mandatory seat belt laws on driving behavior and traffic fatalities. Review of Economics and Statistics, 85(4), 828-843.

Corrado, L., \& Fingleton, B. (2012). Where is the economics in spatial econometrics?. Journal of Regional Science, 52(2), 210-239.

Davis, C., \& Chang, S. (2013a). Legal interventions to reduce overdose mortality: Naloxone access and overdose Good Samaritan laws. The Network for Public Health Law. 32(19), 2.

Davis, C., Webb, D., \& Burris, S. (2013b). Changing law from barrier to facilitator of opioid overdose prevention. The Journal of Law, Medicine \& Ethics, 41(s1), 33-36.

Davis, C. S., Ruiz, S., Glynn, P., Picariello, G., \& Walley, A. Y. (2014). Expanded access to naloxone among firefighters, police officers, and emergency medical technicians in Massachusetts. American journal of public health, 104(8), e7-e9.

Davis, C. (2015). Naloxone for community opioid overdose reversal. Public Health Law Research. Retrieved June, 25, 2015.

Davis, C. S., \& Carr, D. (2015). Legal changes to increase access to naloxone for opioid overdose reversal in the United States. Opioid and alcohol dependence, 157, 112-120.

Davis, C., Chang, S., \& Carr, D. (2017). Legal interventions to reduce overdose mortality: naloxone access and overdose Good Samaritan laws. Network for Public Health Law.

Davis, C., \& Carr, D. (2017). State legal innovations to encourage naloxone dispensing. Journal of the American Pharmacists Association, 57, S180-S184. 
Debarsy, N., Ertur, C., \& LeSage, J. P. (2012). Interpreting dynamic space-time panel data models. Statistical Methodology, 9(1), 158-171.

Delgado, M., \& Florax R. (2015). Difference-in-Differences Techniques for Spatial Data: Local Autocorrelation and Spatial Interaction Tinbergen Institute Discussion Paper 15091/VIII. Available at SSRN: https://ssrn.com/abstract=2637764 or http://dx.doi.org/10.2139/ssrn.2637764.

Doleac, J. L., \& Mukherjee, A. (2018). The moral hazard of lifesaving innovations: naloxone access, opioid abuse, and crime.

Dubé, J., Legros, D., Thériault, M., \& Des Rosiers, F. (2014). A spatial Difference-inDifferences estimator to evaluate the effect of change in public mass transit systems on house prices. Transportation Research Part B: Methodological, 64, 24-40.

Elhorst, J. P. (2014). Spatial econometrics: from cross-sectional data to spatial panels (pp. 2025). Heidelberg: Springer.

Enteen, L., Bauer, J., McLean, R., Wheeler, E., Huriaux, E., Kral, A. H., \& Bamberger, J. D. (2010). Overdose prevention and naloxone prescription for opioid users in San Francisco. Journal of Urban Health, 87(6), 931-941.

Evans, W. N., Lieber, E., \& Power, P. (2018). How the reformulation of OxyContin ignited the heroin epidemic (No. w24475). National Bureau of Economic Research.

Florax, R. J., Folmer, H., \& Rey, S. J. (2003). Specification searches in spatial econometrics: the relevance of Hendry's methodology. Regional Science and Urban Economics, 33(5), 557-579.

Frank, M. W. (2015). US State-Level Income Inequality Data. Huntsville, TX. Available at: http://www. shsu. edu/eco_mwf/inequality. html.

Galea, S., Ahern, J., Vlahov, D., Coffin, P. O., Fuller, C., Leon, A. C., \& Tardiff, K. (2003). Income distribution and risk of fatal opioid overdose in New York City neighborhoods. Opioid and alcohol dependence, 70(2), 139-148.

Gatti, U., Tremblay, R. E., \& Schadee, H. M. (2007). Community characteristics and death by homicide, suicide and opioid overdose in Italy: The role of civic engagement. European Journal on Criminal Policy and Research, 13(3-4), 255-275.

Getis, A. (2007). Reflections on spatial autocorrelation. Regional Science and Urban Economics, 37(4), 491-496.

Gibbons, S., \& Overman, H. G. (2012). Mostly pointless spatial econometrics?. Journal of Regional Science, 52(2), 172-191. 
Gladden, R. M. (2016). Fentanyl law enforcement submissions and increases in synthetic opioidinvolved overdose deaths - 27 states, 2013-2014. MMWR. Morbidity and mortality weekly report, 65 .

Green, T. C., Heimer, R., \& Grau, L. E. (2008). Distinguishing signs of opioid overdose and indication for naloxone: an evaluation of six overdose training and naloxone distribution programs in the United States. Addiction, 103(6), 979-989.

Green, T. C., Dauria, E. F., Bratberg, J., Davis, C. S., \& Walley, A. Y. (2015). Orienting patients to greater opioid safety: models of community pharmacy-based naloxone. Harm reduction journal, 12(1), 25.

Griffith, D. A. (2005). Effective geographic sample size in the presence of spatial autocorrelation. Annals of the Association of American Geographers, 95(4), 740-760.

Heckert, M. (2015). A Spatial Difference-in-Differences Approach to Studying the Effect of Greening Vacant Land on Property Values. Cityscape, 17(1), 51.

Hembree, C., Galea, S., Ahern, J., Tracy, M., Piper, T. M., Miller, J. \& Tardiff, K. J. (2005). The urban built environment and overdose mortality in New York City neighborhoods. Health \& place, 11(2), 147-156.

Inocencio, T. J., Carroll, N. V., Read, E. J., \& Holdford, D. A. (2013). The Economic Burden of Opioid-Related Poisoning in the United States. Pain medicine, 14(10), 1534-1547.

Jaffe, Adam B. (1989). Real effects of academic research. American Economic Review 79(5): 957-970.

Jaffe, Adam B., Manuel Trajtenberg, and Rebecca Henderson. (1993) Geographic localization of knowledge spillovers as evidenced by patent citations. The Quarterly journal of Economics 108(3): 577-598.

Jones, C. M., Einstein, E. B., \& Compton, W. M. (2018). Changes in Synthetic Opioid Involvement in Drug Overdose Deaths in the United States, 2010-2016. Jama, 319(17), 1819-1821.

Keyes, K. M., Cerdá, M., Brady, J. E., Havens, J. R., \& Galea, S. (2014). Understanding the rural-urban differences in nonmedical prescription opioid use and abuse in the United States. American journal of public health, 104(2), e52-e59.

Lakdawalla, D., Sood, N., \& Goldman, D. (2006). HIV breakthroughs and risky sexual behavior. The Quarterly Journal of Economics, 121(3), 1063-1102.

LeSage, J. P. (2014). What regional scientists need to know about spatial econometrics. The review of Regional Studies, 44: 13-32. 
LeSage, J., \& Pace, K., (2009). Introduction to Spatial Econometrics. Taylor \& Francis Group, LLC.

Lim, J. K., Bratberg, J. P., Davis, C. S., Green, T. C., \& Walley, A. Y. (2016). Prescribe to Prevent: Overdose Prevention and Naloxone Rescue Kits for Prescribers and Pharmacists. Journal of addiction medicine. 10(5), 300.

Marzuk, P. M., Tardiff, K., Leon, A. C., Hirsch, C. S., Stajic, M., Portera, L., \& Hartwell, N. (1997). Poverty and fatal accidental opioid overdoses of cocaine and opiates in New York City: an ecological study. The American journal of opioid and alcohol abuse, 23(2), 221228.

McMillen, D. P. (2010). Issues in spatial data analysis. Journal of Regional Science, 50(1), 119141.

Open society foundation. (2017) "Naloxone: Frequently Asked Questions," Last accessed December 2017 at: http://naloxoneinfo.org/sites/default/files/Frequently\%20Asked\%20QuestionsNaloxone_EN.pdf

Nandi, A., Galea, S., Ahern, J., Bucciarelli, A., Vlahov, D., \& Tardiff, K. (2006). What explains the association between neighborhood-level income inequality and the risk of fatal overdose in New York City?. Social science \& medicine, 63(3), 662-674.

National Research Council. (2004). Indicators for waterborne pathogens. National Academies Press.

Partridge, M. D., Boarnet, M., Brakman, S., \& Ottaviano, G. (2012). Introduction: whither spatial econometrics?. Journal of Regional Science, 52(2), 167-171.

Rees, D. I., Sabia, J. J., Argys, L. M., Latshaw, J., \& Dave, D. (2017). With a Little Help from My Friends: The Effects of Naloxone Access and Good Samaritan Laws on OpioidRelated Deaths (No. w23171). National Bureau of Economic Research.

Richardson, R., Charters, T., King, N., \& Harper, S. (2015). Trends in Educational Inequalities in Opioid Poisoning Mortality: United States, 1994-2010. American journal of public health, 105(9), 1859-1865.

Rossen, L. M., Khan, D., \& Warner, M. (2013). Trends and geographic patterns in drugpoisoning death rates in the US, 1999-2009. American journal of preventive medicine, 45(6), e19-e25.

Rowe, C., Santos, G. M., Vittinghoff, E., Wheeler, E., Davidson, P., \& Coffin, P. O. (2016). Neighborhood-Level and Spatial Characteristics Associated with Lay Naloxone Reversal Events and Opioid Overdose Deaths. Journal of Urban Health, 93(1), 117-130. 
Rudd, R. A., Aleshire, N., Zibbell, J. E., \& Matthew Gladden, R. (2016). Increases in opioid and opioid overdose deaths_-United States, 2000-2014. American Journal of Transplantation, 16(4), 1323-1327.

Ruhm, C. J. (2016). Drug poisoning deaths in the United States, 1999-2012: a statistical adjustment analysis. Population health metrics, 14(1), 2.

Salsberg, B. (2017). "Workers comp programs fight addiction among injured workers." Associated Press News. Last accessed January 2018 at:

https://apnews.com/ccea326c84b747cdb1d7bff83efdb303/workers-comp-programs-fightaddiction-among-injured-workers

Scott, G., Thomas, S. D., Pollack, H. A., \& Ray, B. (2007). Observed patterns of illicit opiate overdose deaths in Chicago, 1999-2003. Journal of Urban Health, 84(2), 292-306.

Seal, K. H., Thawley, R., Gee, L., Bamberger, J., Kral, A. H., Ciccarone, D., ... \& Edlin, B. R. (2005). Naloxone distribution and cardiopulmonary resuscitation training for injection opioid users to prevent heroin overdose death: a pilot intervention study. Journal of Urban Health, 82(2), 303-311.

Selby, R. J. (2017). The Impact of Substance Abuse Insurance Mandates.

Shah, N. G., Lathrop, S. L., Flores, J. E., \& Landen, M. G. (2012). The influence of living along the US-Mexico border on unintentional opioid overdose death, New Mexico (USA), 2005-2009. Opioid and alcohol dependence, 125(1), 19-26.

Siegler, A. E. (2015). Effect of the New York City Overdose Prevention Program on Unintentional Heroin-related Overdose Death, 2000-2012. City University of New York.

Stobbe, M. (2017). “Soaring overdose death rates cut US life expectancy for $2^{\text {nd }}$ year." Associated Press story published in the Charleston Gazette-Mail, last accessed December 2017 at: http://abcnews.go.com/Health/wireStory/soaring-overdose-deaths-cut-us-life-expectancy2nd-51924911

Sunak, Y., \& Madlener, R. (2014). "Local impacts of wind farms on property values: a spatial difference-in-differences analysis." FCN Working Paper No. 1/2014. Last Accessed March $2017 \quad$ at: https://www.fcn.eonerc.rwthaachen.de/global/show_document.asp?id=aaaaaaaaaajuzwl

Tobler, W. R. (1970). A computer movie simulating urban growth in the Detroit region. Economic geography, 46(sup1), 234-240.

Unick, G., Rosenblum, D., Mars, S., \& Ciccarone, D. (2014). The relationship between US heroin market dynamics and heroin-related overdose, 1992-2008. Addiction, 109(11), 1889-1898. 
Visconti, A. J., Santos, G. M., Lemos, N. P., Burke, C., \& Coffin, P. O. (2015). Opioid overdose deaths in the city and county of San Francisco: prevalence, distribution, and disparities. Journal of Urban Health, 92(4), 758-772.

Walley, A. Y., Xuan, Z., Hackman, H. H., Quinn, E., Doe-Simkins, M., Sorensen-Alawad, A. \& Ozonoff, A. (2013). Opioid overdose rates and implementation of overdose education and nasal naloxone distribution in Massachusetts: interrupted time series analysis. BMJ, 346, f174.

Wheeler, E., Davidson, P. J., Jones, T. S., \& Irwin, K. S. (2012). Community-based opioid overdose prevention programs providing naloxone-United States, 2010. MMWR. Morbidity and mortality weekly report, 61(6), 101. 
CHAPTER 4 


\section{CHAPTER 4: AIR QUALITY AND ASTHMA HOSPITALIZATION: EVIDENCE OF PM2.5 CONCENTRATION IN PENNSYLVANIA COUNTIES}

\section{INTRODUCTION}

Ambient air pollution adversely impacts air quality and human health (Nel, 2005; Kampa and Castanas, 2008; Anderson et al., 2012). The National Ambient Air Quality Standards (NAAQS) set by the Environmental Protection Agency (EPA) include six principal pollutants (i.e., Carbone Monoxide $(\mathrm{CO})$, Lead $(\mathrm{Pb})$, Nitrogen Dioxide $\left(\mathrm{NO}_{2}\right)$, Ozone $\left(\mathrm{O}_{3}\right)$, Particulate Matters $(\mathrm{PM})$, and Sulfur Dioxide $\left.\left(\mathrm{SO}_{2}\right)\right)$ as "criteria air pollutants" (EPA, 2016). Over the last few decades, air pollution concerns have changed from concentrations of $\mathrm{SO}_{2}$ and coarse particles towards more traffic-related air pollutants (TAP) (i.e., nitrogen oxides (NOx), small particles and organic compounds) (Pénard-Morand et al., 2010). The national average trend of $\mathrm{SO}_{2}$ air quality shows an 87\% decrease between 1980-2016 (EPA, 2018a). With decreasing trends in $\mathrm{SO}_{2}$, ozone, and nitrogen dioxide, particulates have gained more attention (Brunekreef and Holgate, 2002).

The World Health Organization (WHO) named particulate matter (PM) as the pollutant that affects people more than any other pollutant (WHO, 2016). The severity and magnitude of PM health impacts is a function of its size. The smaller the size of PM, the more potential there is to cause severe damage to the human body (EPA, 2018b). The negative health impacts of PM are widely discussed in the literature (Pope et al., 2009; Raaschou-Nielsen, 2013; Wang et al., 2014; Zhu et al., 2017). More specifically, many researchers have investigated the effects of short-term and longterm exposure to PM and resulting asthma symptoms (Silverman and Ito, 2010; Samoli et al., 2011; Iskandar et al., 2012; Zang et al., 2015). 
The EPA has continuously updated its standards for criteria air pollutants since the passage of the Clean Air Act of 1990. For instance, the standards for PM have changed three times and ozone pollution standards have changed two times. One element of enforcement for these standards is designation of attainment or nonattainment by an area. Attainment/ nonattainment classification by EPA is based on the level of air pollutants. In the case of a geographic area where pollutant levels are below the NAAQS threshold, this area is categorized as an attainment area. Unlike an attainment area, a nonattainment area deals with persistent air quality problems and violates federal healthrelated standards for outdoor quality (Pennsylvania Department of Environmental Protection, 2016).

As a demonstration, Appendix I shows nonattainment designation for $\mathrm{PM}_{2.5}$ concentrations in Pennsylvania are located primarily at or adjacent to metropolitan areas in the southeast and southwestern portions of the state during the time-period 2001 to 2014. Pollution dischargers within nonattainment areas are required to comply with tighter environmental regulations than similar dischargers in attainment areas. For instance, in nonattainment areas, existing pollution sources are required to install "reasonably available control technology" (RACT) while new sources of pollution are required to achieve the "lowest available emission rate" in addition to the RACT requirement (Curtis, 2018).

The main objective in this research is to examine what factors, including PM 2.5 concentrations, explain asthma hospitalization rates in Pennsylvania. Applying a spatial regression model, this analysis provides us with estimates of both within county and spillover effects among contiguous counties from $\mathrm{PM}_{2.5}$ concentrations. The spillover analysis allows us to document the existence of biases that would be found when using standard, non-spatial models in estimating the impacts of $\mathrm{PM}_{2.5}$ concentrations. 
By imposing a prevailing wind pattern in deriving the weight matrix, positive and significant effects of $\mathrm{PM}_{2.5}$ concentrations are found to occur on asthma hospitalization rate both within county and in neighboring counties. These results reveal that county $\mathrm{PM}_{2.5}$ concentrations are associated with higher asthma hospitalization rates in neighboring counties, and within the county itself. Thus, important spillover effects exist from the $\mathrm{PM}_{2.5}$ concentrations on asthma hospitalization rates.

The main contribution of this research to the literature is investigating the spillover effects of the sources of $\mathrm{PM}_{2.5}$ pollutions on asthma hospitalization rates. In addition, the study introduces a new approach to evaluating who is considered neighboring regions based upon prevailing wind direction when analyzing the health effects of air quality. After examining the literature, no previous study has controlled for the spatial interaction between $\mathrm{PM}_{2.5}$ concentrations and asthma hospitalization rates, so that the regional aspects of $\mathrm{PM}_{2.5}$ concentrations have not been investigated. Since $\mathrm{PM}_{2.5}$ and other air pollutant concentrations move through the atmosphere, neglecting their transportation underestimates the real impact of air quality.

The rest of the manuscript proceeds as follows. Section 2 provides background information on national and states' trends in asthma and its associated costs to society. Section 3 discusses ambient air pollution and, specifically, $\mathrm{PM}_{2.5}$ concentrations and asthma. Section 4 explains the study area. Section 5 provides details of the model developed for this research. Section 6 describes the data and spatial data considerations. Section 7 provides the results and section 8 concludes with a discussion and policy implications.

\section{ASTHMA: SYMPTOMS, TIME TREND, AND COST}

Asthma is a chronic respiratory and inflammatory lung disease characterized by episodes or attacks of impaired breathing. Even though scientists argue that there is not a specific, well-known cause for asthma, a combination of environmental factors and genetics are considered as the disease 
triggers (Centers for Disease Control and Prevention, 2013). Being exposed to multiple environmental factors exacerbate asthma symptoms. Akinbami et al. (2011) and Akinbami et al. (2012) list airway irritants such as tobacco smoke and air pollution, allergens, respiratory infections, stress and exercise among common asthma attach triggers that exacerbate symptoms. According to Bostantzoglou et al. (2015), asthma symptoms may include coughing, shortness of breath, wheezing, chest tightness and chest pain and be caused by inflammation and narrowing of small airways. Whether the disease severity is mild or persistent, a person's quality of life may be affected by asthma. People with a mild disease may suffer severe attacks as well as those with a more severe and persistent symptom.

\section{National and state asthma trend}

Since the early 1980s, asthma has shown an upward trend in all ages, genders, and racial groups in the U.S. (Asher et al., 2006; National Center for Health Statistics, 2017). About 25 million Americans currently suffer from asthma, about one in every 13 people. Asthma is leading chronic disease and the third leading cause of hospitalization among individuals under 18 years of age (Centers for Disease Control and Prevention, 2017).

Figure 5 shows the number of current prevalence (current prevalence is defined as those who answered "yes" to both "Have you ever been told by a doctor or other health professional that you had asthma?" and "Do you still have asthma?") of asthma in the U.S. between 2001 and 2015. Even though the overall trend of asthma's current prevalence is increasing on both the national and the state levels over a period of 15 years, individual states follow a different pattern. 
Figure 5. National current asthma prevalence, 2001-2015



The Behavioral Risk Factor Surveillance System (BRFSS) provides the current asthma prevalence on the state level. Florida, Alabama, Pennsylvania, and Utah are among the high increase states for adult asthma prevalence. Compared to the average percentage increase in the U.S. between 2001-2015 (43\%), Pennsylvania experienced a slightly higher increase rate at $47 \%$.

\section{The burdensome cost of asthma on society}

Asthma can affect people of different age and racial groups, but is more common among minorities. Asthma represents a significant burden on individuals and society in terms of reducing productivity and increasing healthcare system demands (Crighton et al., 2012). In estimating the total cost of disease, three classifications of cost are considered. Costs related to management, complementary investigation or treatment and other costs like domestic or professional preventive measures, assistance in home care, and transportation to medical visits are categorized as direct costs. Indirect costs include work-related losses whether it is related to temporary, early, or permanent disability and early mortality. Finally, costs related to reductions in quality of life, increases in pain 
or suffering, limitation of physical activities and job changes are classified as intangible costs (Nunes et al., 2017).

According to the EPA's asthma fact report, "asthma accounts for 14.2 million physician office visits, 439,000 discharges from hospital inpatient care, and 1.8 million emergency department visits each year" (EPA, 2016, p. 1). In 2008, 14.2 million reported asthma as the reason for missed days of work (CDC, 2014). Reports show asthma accounts for 13.8 million missed school days in 2013 (United States Environmental Protection Agency, 2017).

In a number of studies, researchers estimate the costs associated with asthma. Stanford et al. (1999) assess the treatment cost of asthma in which the patient goes to the emergency department (ED). They report that, on average, each American paid \$234.48 for an ED visit in 1996-1997. In a more recent assessment, Wang et al. (2014) report an estimate of $\$ 1,502$ for asthma care charges in the ED based on data for 2006-2008. Average asthma hospitalization cost is much higher than an ED visit. Most of the cost of hospitalization belongs to inpatient nursing care and an average hospital visit of 3.8 days costs $\$ 3,102.53$. Barret et al. (2014) differentiate between asthma hospitalization costs for adults versus children. While each hospital stays for a child in 2010 averaged a total of $\$ 3,600$, the total cost for an adult was $\$ 6,600$ for each hospital stay.

What the previous studies have in common is a steady increase in asthma cost. The most recent estimates for the annual economic cost of asthma in the U.S. shows an increase from $\$ 12$ billion in 1994 to $\$ 56$ billion in 2011 (NHAMCS, 2010; NHAMCS, 2011a; NHAMCS, 2011b). Direct costs account for $\$ 50.1$ billion, mostly for hospital stays. The rest of the costs include lost pay from sickness or death and lost work output from missed school or work days (\$3.8 billion) and premature death ( $\$ 2.1$ billion) (Barnett and Nurmagambetov, 2011; CDC, 2011). The cost involving asthma hospitalization in Pennsylvania follows the same increasing trend over years (Pennsylvania 
Department of Health, 2012). Although there is no cure for asthma, it could be controlled by limiting exposure to triggers. In the next section, the connection between ambient air pollution and $\mathrm{PM}_{2.5}$ will be discussed.

\section{Asthma and ambient air pollution}

Ambient air pollution impacts public health both on short and long-term bases. The most recent estimate reports that outdoor air pollution is responsible for more than $3 \%$ of the annual disability-adjusted life years lost in 2010 (Guarnieri and Blames, 2014). Traffic and fossil-fuel power generation contribute the largest shares to urban air pollution (Perera, 2017; Cohen et al., 2004). With the increasing rate of urbanization in the U.S., more individuals face the negative effects of exposure to pollution. In general, the association between exposure to ambient air pollution and human health outcomes has been addressed in both older and more recent studies. Specifically, the following health conditions have received attention: cardiovascular and respiratory diseases (Schwartz and Morris, 1995; Brook et al., 2004; Brook, 2008), lung cancer (Hamra et al., 2015; Cohen and Pope, 1995; Raaschou-Nielsen, 2013; Nafstad et al., 2003), low birth weight (Duagandzic et al., 2006; Pedersen et al., 2013; Yang and Chou, 2015; Yang et al., 2017), and morbidity and mortality (Currie and Neidell, 2005; Krewski et al., 2009; Woodruff et al., 2008).

The negative effects of $\mathrm{PM}_{2.5}$ on human health in general and particularly on asthma are at the core of this study. Many researchers address the effects of short-term and long-term exposure to PM2.5 (Tatum and Shapiro, 2005; Eder et al., 2006; Künzli et al., 2009; Andersen et al., 2012; Harris et al, 2017; Vermchuk et al., 2018). For example, a one-year exposure to $10 \mu \mathrm{g} / \mathrm{m}^{3}$ in $\mathrm{PM}_{2.5}$ has been estimated to increase mortality by $7.5 \%$ (Global Catholic Climate Movement, 2017). In another recent study, scientists show that an annual exposure increase of $10 \mu \mathrm{g} / \mathrm{m}^{3}$ for $\mathrm{PM}_{2.5}$ leads to an average loss of life expectancy between 9 and 11 years (Andersen, 2017). One of the issues with 
$\mathrm{PM}_{2.5}$ concentrations is that there is not an exact threshold for the concentration level. Recent studies show that the harmful effects are observed even in areas with concentration less than a third of the EPA current standard (Datz, 2015).

Inhalation of particulate matter has been estimated to be responsible for 500,000 excess deaths each year worldwide (WHO, 1994). In a study done by the Schneider et al. (2010), estimates for the health impacts of $\mathrm{PM}_{2.5}$ emitted from coal-fired power plants and automobiles in the U.S. show over 13,000 deaths, 9,700 hospitalizations, and 20,000 heart attacks in 2010 with a total monetized value of more than $\$ 100$ billion. Beelen et al. (2014), Schwartz et al. (2008), and Schneider et al. (2010) argue that long-term exposure to $\mathrm{PM}_{2.5}$ is associated with higher mortality risk, even when concentrations are below the standard limit. In other words, they believe there is no "safe threshold" for PM.

Glad et al. (2012), and U.S. EPA, (2011) show the impacts of $\mathrm{PM}_{2.5}$ on asthma emergency department visits and early deaths, respectively. Mann et al (2010), Meng et al (2010), Liu et al. (2009), Jacquemin et al. (2012), Malig et al. (2013), Samoli et al. (2011), and Silverman et al. (2010) describe the effects of $\mathrm{PM}_{2.5}$ on asthma symptoms. Riedl and Diaz (2005), Namdeo et al. (2011), Ristovski et al. (2012), and WHO (2016) discuss the effects of $\mathrm{PM}_{2.5}$ on respiratory and cardiovascular disease. Lipsett et al. (1997) show the relationship between emergency room visits and exposure to $\mathrm{PM}_{10}$. Nel (2005) relates the exacerbation of asthma and chronic bronchitis to exposure to $\mathrm{PM}_{10}$ and $\mathrm{PM}_{2.5}$. WHO (2016) also reveals an association between $\mathrm{PM}_{2.5}$ plus $\mathrm{PM}_{10}$ and lung cancer.

While numerous studies have analyzed the relationship between ambient air pollutants and asthma, evidence of this association on a regional scale is still mixed. The discussion presented by North Carolina Attorney General in 2006 arguing pollution from TVA's coal-fired power plants in 
Tennessee causing damages the health of North Carolina's residents is an example of the regional effects of ambient air pollution (Environmental Appeals Court, 2008). No previous research, however, has estimated the spatial spillover of $\mathrm{PM}_{2.5}$ pollution. Due to a misspecification issue when not accounting for spatial spillover, the results of any regression estimation may be biased. In other words, when using a non-spatial regression analysis, we assume health outcomes at a county basis, like asthma hospitalization, are independent of the pollution levels ( $\mathrm{PM}_{2.5}$ concentrations for example) in neighboring counties. This assumption ignores the effects of $\mathrm{PM}_{2.5}$ concentrations on adjacent counties. By ignoring spatial spillover effects, the total effect of $\mathrm{PM}_{2.5}$ concentrations on health outcomes may be underestimated.

\section{STUDY AREA}

Asthma related indicators are not available for all the states on a county level. Because of this data limitation, instead of a regional or national analysis, we focus on one state, Pennsylvania.

Asthma in Pennsylvania is a serious concern. In 2017, the current asthma prevalence rate in Pennsylvania for adults was reported at $10.9 \%$; that is far higher than the average rate among adults in the U.S. (7.6\%) (Henry J Kaiser Family Foundation, 2017). Delaware, Philadelphia, Montgomery, Bucks, and Washington are the counties with the highest asthma hospitalization rate, while Mifflin, Snyder, Juniata, Clinton, and Huntington counties have the lowest number of asthma hospitalizations. What the counties with a high asthma hospitalization rate and counties with a low asthma hospitalization rate have in common is their population density. Counties with a higher population density are struggling with more asthma triggers than counties with lower asthma hospitalization rate, which are usually more rural.

According to 2015 Pennsylvania asthma fact sheet in 2013, the average cost for inpatient hospitalization was $\$ 26,952$ which is significantly higher than the national average $(\$ 6,600)$ 
(Pennsylvania Department of Health, 2015). While the cost involving asthma hospitalization in Pennsylvania is much higher than the U.S. average, there are other states, such as California and Wisconsin where the average cost per asthma hospitalization is also much higher than the U.S. average. For example, the average cost per asthma hospitalization in California in 2010 was $\$ 33,749$. The total health care cost involving asthma and absenteeism for 2010 was estimated to be approximately $\$ 1.7$ billion in Pennsylvania. With an almost 50 percent increase projected by 2020 , asthma costs are estimated to be approximately $\$ 2.6$ billion, which is an increased burden on the state economy at $0.34 \%$ of the state GDP as of 2017.

\section{MODELS}

A spatial regression model is used to investigate the impacts of $\mathrm{PM}_{2.5}$ concentrations on asthma hospitalization rates. Spatial regression models differ from regression models by inclusion of a spatial interrelationship between observations of geographic areas such as cities, counties, states, or even countries (Elhorst, 2014). In a spatial model, each observation belongs to a location whereas observations in a non-spatial regression are independent (LeSage and Pace, 2009). This locational linkage is a fundamental point for the observation dependency assumption in spatial regression.

Among the three types of spatial interaction effects, this study focuses on exogenous interactions among the independent variable (X). The spatial lag of X model (SLX) assumes that the dependent variable for each observational unit depends on an independent variable from other units of observations.

Independent variable $x$ of unit $j \leftrightarrow$ Dependent variable $y$ of unit $i$

A SLX model can be expressed as

$Y=\alpha \mathrm{l}_{N}+X \beta+W X \theta+u$ 
where $Y$ is asthma hospitalization rate, $W X$ denotes the interaction among the independent variables. $\beta$ and $\theta$ represent a $\mathrm{K} \times 1$ vector of parameters to be estimated. $W$ is the spatial weight matrix which accounts for identification of neighbors. There are four types of spatial weight matrices commonly used in applied studies: (i) $p$-order binary contiguity matrices. Contiguity weight matrices assume only those units of observations that share a common border are neighbors $(p=1$ also called firstorder neighbors). When $p=2$, neighbors and neighbors of neighbors are considered and so on; (ii) inverse distance matrices are based on distance between observation $i$ and $j$; (iii) $q$-nearest neighbor matrices when $\mathrm{q}$ is a positive and an integer number defined based on the research question by the researcher; and (iv) block diagonal matrices when a group of units have intercorrelation with each other, but not with the rest of the observations (Elhorst, 2014).

As pointed out by Anselin and Rey (1991), the proper choice of a spatial weight matrix is an important issue in empirical research. Generally, all mentioned forms of neighbors in spatial models deal with symmetric weight matrices. However, sometimes the most accurate definition of neighbors does not follow a symmetric form. Commuting flows in the transportation literature and regional labor market performance are two well-known examples of asymmetric spatial weight matrices. More related to our study, Chen and Ye (2018) capture the effect of wind direction on the $\mathrm{PM}_{10}$ concentrations at the municipal level in China as an example of a dynamic and asymmetric spatial weight matrix dependent on weather patterns.

Yang et al. (2017) and Yang and Chou (2015) explore the effects maternal exposure to downwind sulfur dioxide levels on the occurrence of low birth weight (LBW). They used zip code level of observations and control for wind direction by implementing a four-step procedure. Since these two studies did not apply a spatial regression model, this research is motivated by Cheng et al. (2014) and Chen and Ye (2018) who introduce dynamic, asymmetric weight matrices into traffic 
modeling and $\mathrm{PM}_{10}$ concentrations, respectively. These authors argue that for some cases, such as network data and $\mathrm{PM}_{10}$ concentrations, a general homogeneous spatial weight matrix is inadequate and we need to apply a heterogeneous (and/or dynamic) spatial weight matrix.

Applying this same rationale, our study introduces an empirical model based on a weight matrix built upon prevailing wind direction. Based on this prevailing wind pattern, unit $i$ is considered a neighbor for unit $j$ if and only if it is located upwind of $j$. Since unit $j$ is downwind of unit $i$, unit $j$ is not considered a neighbor for unit $i$. Following this logic, a weight matrix is constructed based upon the annual average prevailing wind map for Pennsylvania counties (World Forecast Directory, 2019).

Figure 6. Annual prevailing wind direction

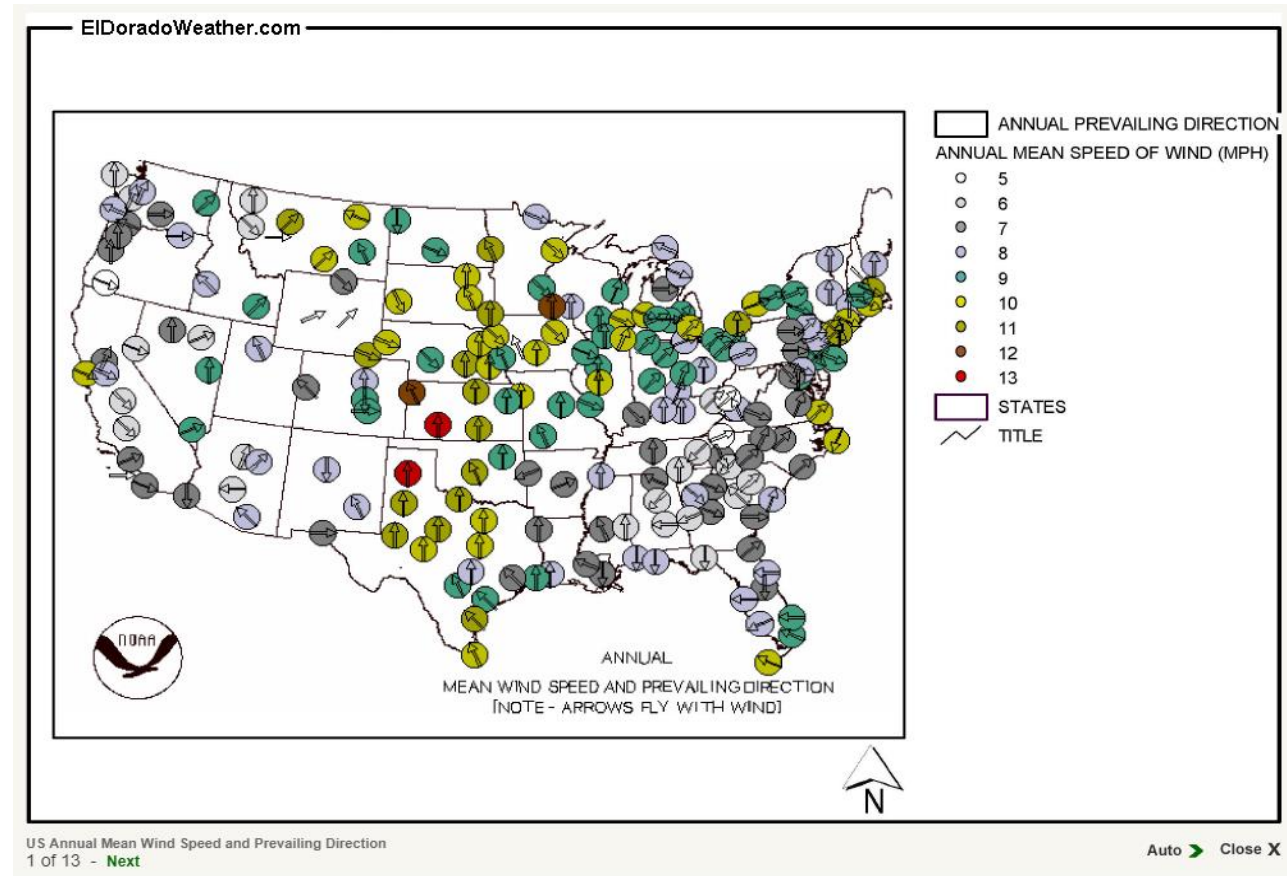

Figure 6 shows the annual prevailing wind directions in the U.S. Based upon this map, the prevailing wind direction in Pennsylvania is southwest to northeast. According to this prevailing wind direction, for instance, Washington County is considered to be a neighbor of Allegany and Westmoreland Counties, but Allegany County or Westmoreland County are not neighbors for 
Washington County. Since a weight matrix needs to be exogenous to the estimation procedure, a geographical weight matrix based upon prevailing wind direction fits this requirement. The notion of geographical proximity has been applied widely in previous literature (e.g., Jaffe, 1989; Jaffe el al., 1993; Varga, 2000; Chagas et al., 2016).

In addition to ambient $\mathrm{PM}_{2.5}$ concentrations, empirical studies have shown several other factors are associated with asthma incidents. Included among the independent variables are: smoking rate (Chen et al., 1999; Thomson et al., 2004; Gilliland et al., 2006), and population density (Leinberger, 2010; Solé et al., 2007) and per capita income. Each control variable is expected to be positively correlated with asthma incidence. Per capita income level has been shown to be negatively correlated with asthma incidence (Kozyrskyj et al., 2010), while weather variables of precipitation and humidity have had mixed effects in the literature (Jerrett et al., 2008; Ho et al., 2007).

The empirical model is defined as:

$$
\begin{gathered}
\text { AsthmaHospitalization }_{i t}=\beta_{0}+\beta_{1} \text { PM }_{2.5} \text { Concenterations }_{i t}+ \\
\beta_{2} \text { Precipitation }_{i t}+\beta_{3} \text { PerCapitaIncome }+\beta_{4} \text { SmokingRate }_{i t}+ \\
\beta_{5} \text { PopulationDensity }_{i t}+\theta \text { OWPM }_{2.5} \text { Concenterations }_{j t}+v_{i}+w_{t}+\varepsilon_{i t}
\end{gathered}
$$

where AsthmaHospitalization stands for the asthma hospitalization rate in county $i$ and time $t$, $P M_{2.5}$ Concenterations represents $\mathrm{PM}_{2.5}$ concentrations in county $i$ and time $t$, SmokingRate is the smoking rate in county $i$ and time $t$, PopulationDensity shows the population density in county $i$ and time $t$, Precipitation shows the precipitation in county $i$ and time $t$, while $v_{i}$ and $w_{t}$ are county and year fixed effects, respectively. With county fixed effects, there is not a need to control for the availability of hospitals in each county, as the number of hospitals in each county does not change very much over time the same as population break down, which is not changing disproportionately 
in different counties over time. The term $W P M_{2.5}$ Concenterations denotes the spatial components of $\mathrm{PM}_{2.5}$ concentrations. $\theta$ represents the spillover effects of $\mathrm{PM}_{2.5}$ concentrations. This coefficient explains the effects of $\mathrm{PM}_{2.5}$ concentrations of neighboring county $(j)$ on the asthma hospitalization rate in county $(i)$.

Elhorst (2014) notes that "for the specification of more complicated behavioral hypotheses, including effects" (time fixed effect, space fixed effect, and two-way fixed effect) (p. 2). Spatial units have unique characteristics which are not always possible to control for all of them. Panel estimation introduces a dummy variable for spatial units in the estimation to capture unobservable predictors for units $\left(v_{i}\right)$. Our model also controls for time fixed effects to capture unobservable predictors over time $\left(w_{t}\right)$.

\section{DATA}

Data for constructing the empirical models come from different sources. The rate of hospitalizations for asthma are derived from the National Environmental Public Health Tracking Program (NEPHTP) for 2001-2014 and classified using the International Classification of Diseases, ninth Revision (ICD-9). We work with both age-adjusted hospitalization rate and crude hospitalization rate. Rates are age-adjusted applying the direct method using 2000 U.S. standard population (Klein and Schoenborn, 2001). The data covers ICD-9-CM: 493.XX diagnosis codes. More asthma related indicators such as asthma prevalence among adults, asthma prevalence among children, and emergency department visits for asthma are reported, but only over a more limited number of years and states. By definition, hospitalization data does not include asthma among individuals who do not receive medical care or who have not been hospitalized, including those who die in emergency rooms, in nursing homes, or at home without being admitted to a hospital, and 
those treated in outpatient settings. NEPHTP provides asthma hospitalization information by counties for 28 selected states. Data are based on the date of admission rather than the date of discharge. Data represents the number of admissions rather than the number of individuals admitted to the hospital. In most cases, admissions of residents to out-of-state hospitals are excluded. Data are based on the county of individual residency.

For the independent variable of interest, we created a measurement of annual $\mathrm{PM}_{2.5}$ concentrations level based on data provided by CDC-NEPHTP. NEPHTP reports different air quality indicators, such as air toxics, mortality benefit associated with reducing $\mathrm{PM}_{2.5}$ concentrations level, and days above regulatory standard for Ozone and $\mathrm{PM}_{2.5}$. $\mathrm{PM}_{2.5}$ concentrations levels are based on seasonal averages and daily measurement for monitor and modeled data. A Downscaler (DS) model is applied to predict the measurements for county and day observations with missing values in monitoring data. The data generation process in DS is based on statistical fusion of the Air Quality System (AQS) and Community Multiscale Air Quality (CMAQ) model-predicted concentration values. AQS was used for observations with monitoring data.

Population data come from the Bureau of Economic Analysis (BEA). Precipitation data are collected through PRISM climate group is supported by the USDA Risk Management Agency, and the National Center for Biotechnology Information published cigarette smoking prevalence in U.S. counties. Finally, for the spatial weight matrix, a shape file of Pennsylvania counties consisting of the latitudinal and longitudinal coordinates of all the 67 counties is adapted from the U.S. Census Bureau (Tiger) report.

Contiguity and neighborhoods in spatial analysis play vital roles (Tobler, 1970). To control for spillover effects of $\mathrm{PM}_{2.5}$ concentrations, 67 contiguous counties were included in our analysis. Wind map of the United States and World Forecast Directory, El Dorado Weather, Inc. are used to 
make the weight matrix. Descriptive statistics for each variable are reported in Table 19 along with the expected signs of $\mathrm{PM}_{2.5}$ concentrations and the control variables.

Table 19. Descriptive statistics

\begin{tabular}{lccccc}
\hline \multicolumn{1}{c}{ Variables } & Mean & St. Dev. & Min & Max & $\begin{array}{c}\text { Expected } \\
\text { sign }\end{array}$ \\
\hline Asthma Hospitalization age-adjusted rate (per 10,000) & 12.51 & 4.78 & 4.6 & 32 & \\
\hline Asthma Hospitalization crude rate (per 10,000) & 13.00 & 4.88 & 4.6 & 31.4 & \\
\hline PM $_{2.5}$ Concentrations $\left(\boldsymbol{\mu g} / \mathbf{m}^{3}\right.$ ) & 12.23 & 2.42 & 7.8 & 23.3 & + \\
\hline Smoking Rate (\% of population age 18 and older) & 19.67 & 2.95 & 9.04 & 25.7 & + \\
\hline Precipitation (Inches) & 46.03 & 8.54 & 24.73 & 83.86 & + \\
\hline Per Capita Income (Thousand dollars) & 33.725 & 8.343 & 18.263 & 75.835 & - \\
\hline Population Density (Pop./mi ${ }^{2}$ ) & 446.87 & $1,330.46$ & 12.04 & $10,911.16$ & + \\
\hline Hispanic Population (Thousand people) & 9.472 & 24.034 & 0.019 & 213.487 & + \\
\hline Hispanic Population 19 and below (Thousand people) & 3.811 & 9.467 & 0.008 & 78.000 & + \\
\hline Number of observations & \multicolumn{5}{c}{938} \\
\hline
\end{tabular}

Our motivation to work with a spatial model in this analysis is based upon air pollution movement tied to geographical distance. One should expect to see the residence of downwind locations being affected by air pollution levels from upwind areas. Before we analyze the model in a spatial regression framework, we used an intuitive way to identify asthma hospitalization rate clusters. Figure 7 shows a map of asthma hospitalization rates for 2014, the last year of the dataset. Some spatial clusters are obvious in 2014. Philadelphia, Montgomery, Delaware and Bucks counties in the southeastern part of the state had asthma hospitalization rates in the highest category. In addition, there is another cluster of high category rates in the southwest part of the state. Each cluster is associated with large metropolitan areas. 
Figure 7. Asthma hospitalization rates in Pennsylvania counties, 2014 data

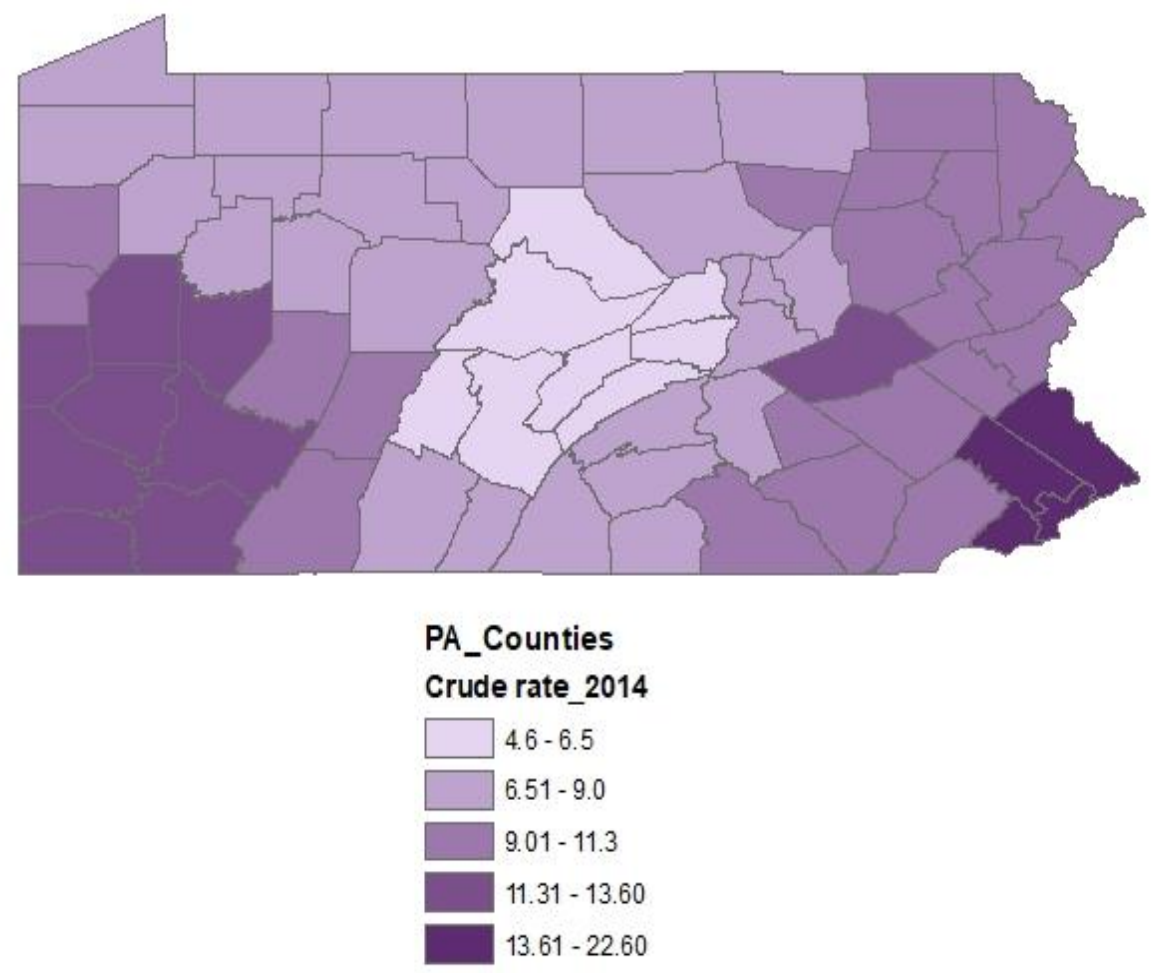

The next step after visualizing asthma hospitalization among counties is to detect spatial autocorrelation. To test for asthma hospitalization rate autocorrelation, we applied the 1st-order spatial autoregressive (FAR) estimates code written by James P. LeSage, available through the spatial econometrics Toolbox for Matlab. FAR output includes the rho coefficients that indicates the autocorrelation between a dependent variable and a dependent variable in surrounding neighbors. Table 20 shows the results for the 1st-order spatial autoregressive estimates for two points of time and its z-probability. These tests reveal that there are significant spatial autocorrelations among counties in Pennsylvania. This means that Pennsylvania asthma hospitalization rates tend to be clustered together. 
Table 20. Results of 1st-order spatial autoregressive rho calculations for county level asthma hospitalization rates in Pennsylvania (age adjusted rates)

\begin{tabular}{lll}
\hline & 2001 & 2014 \\
\hline Rho & 0.961 & 0.980 \\
\hline z-probability & 0.000 & 0.000 \\
\hline
\end{tabular}

\section{RESULTS}

The objective of this study is to investigate both the in-county and out-of-county effects of $\mathrm{PM}_{2.5}$ concentrations on asthma hospitalization. To be able to respond to this question by estimating a two-way fixed effect spatial panel model, we tested the null hypothesis that the spillover effects of $\mathrm{PM}_{2.5}$ concentrations is statistically different from zero. As discussed in the previous sections, finding an accurate algorithm to deal with the spillover between pollutants and asthma matters. The weight matrix which defines the neighbors based on wind direction was determined to be the most accurate algorithm to investigate spillover effects of the pollution. To do a placebo test and check the reliability of the model, we tried applying a different weight matrix by using the reverse prevailing wind direction and the results shows statistically insignificant indirect effects.

The estimated results for the model are reported in Table 21. We report the results following the crude rate asthma hospitalization. ${ }^{54}$ The $\mathrm{PM}_{2.5}$ concentrations variable has a positive and significant coefficient, meaning that there is a positive, within county correlation between $\mathrm{PM}_{2.5}$ concentration and asthma hospitalization rates. A one $\mu \mathrm{g} / \mathrm{m}^{3}$ increase in $\mathrm{PM}_{2.5}$ concentrations is associated with an estimated 0.71 per 10,000 population increase in the asthma hospitalization rate

\footnotetext{
54 We select the crude rate estimation as the most representative estimate of the existence of spillover effects from $\mathrm{PM}_{2.5}$ concentrations. This judgement is based on analyses using the number of county level asthma hospitalizations as a dependent variable, which consistently showed indirect effects were positive and statistically significant.
} 
within the county where this increased concentration occurs. The indirect effects of $\mathrm{PM}_{2.5}$ concentrations are shown by the coefficient of $\mathrm{PM}_{2.5}$ concentrations in neighboring counties' variable (Table 21). This coefficient is positive and statistically significant at the $10 \%$ level, meaning that asthma hospitalization rates increase with increasing $\mathrm{PM}_{2.5}$ concentrations in upwind counties. A one $\mu \mathrm{g} / \mathrm{m}^{3}$ increase in $\mathrm{PM}_{2.5}$ concentrations in county $i$ is associated with an estimated 0.12 per 10,000 higher rate of asthma hospitalizations in downwind counties.

Table 21. Asthma hospitalization estimation results for the SLX model

\begin{tabular}{lcc}
\hline Variable & SLX model (age-adjusted rate) & SLX model (crude rate) \\
\hline \multirow{2}{*}{$\mathrm{PM}_{2.5}$ Concentrations } & $0.697^{* * *}$ & $0.712^{* * *}$ \\
& $(0.000)$ & $(0.000)$ \\
\hline \multirow{2}{*}{ Precipitation } & $0.071^{* * *}$ & $0.073^{* * *}$ \\
& $(0.000)$ & $(0.000)$ \\
\hline \multirow{2}{*}{ Per Capita Income } & $0.300^{* * *}$ & $0.303^{* * *}$ \\
& $(0.000)$ & $(0.000)$ \\
\hline \multirow{2}{*}{ Smoking Rate } & $0.650^{* * *}$ & $0.654^{* * *}$ \\
& $(0.000)$ & $(0.000)$ \\
\hline \multirow{2}{*}{ Population Density } & $0.001^{* * *}$ & $0.001^{* * *}$ \\
& $(0.000)$ & $(0.000)$ \\
PM ${ }_{2.5}$ Concentrations in neighboring & 0.062 & $0.119^{*}$ \\
counties & 0.294 & $(0.057)$ \\
& $-23.633^{* * *}$ & $-24.234^{* * *}$ \\
Constant & $(0.000)$ & $(0.000)$ \\
\hline Year fixed effect & Yes & Yes \\
\hline County fixed effect & Yes & Yes \\
Adjusted R-squared & 0.53 & 0.49 \\
\hline Number of observations & 938 & 938 \\
\hline Ne: N
\end{tabular}

Note: Numbers in the parentheses represent P-values

$*, * *$, and $* * *$ refer to $10 \%, 5 \%$, and $1 \%$ significance levels, respectively.

Other positive and statistically significant influences on asthma hospitalization include the percentage of smokers in a county and the density of the county's population. A $1 \%$ increase in smoking rate is associated with an increase of 0.65 per 10,000 population in asthma hospitalizations rate within a county. The positive effects of higher population density, precipitation and per capita income are much smaller than smoking. 
In addition to $\mathrm{PM}_{2.5}$ concentrations, the percentage of smokers in a county is another variable in our model that is alterable by public policy. While neither the health effects of smoking nor $\mathrm{PM}_{2.5}$ concentrations are limited to asthma prevalence (heart disease, stroke, cardiovascular disease, chronic obstructive pulmonary disease (COPD), and lung cancer increase with smoking), it is worth considering the comparative public health benefits from policies focusing on smoking rate reduction versus lowering of $\mathrm{PM}_{2.5}$ concentrations. We calculate the impacts of reducing both the smoking rate and $\mathrm{PM}_{2.5}$ concentrations by 10 percent from their current mean value over all counties. The results show that the effects of reducing $\mathrm{PM}_{2.5}$ concentrations on asthma hospitalization rates has less of an impact than reducing smoking rate (for example, 134 vs. 198 less hospitalizations in Philadelphia County). Finally, since the constant term in a fixed effect panel estimate that includes both year and county fixed effects is essentially not interpretable, we provide no explanation for the constant in this model.

\section{CONCLUSIONS AND POLICY IMPLICATIONS}

The objective of this study is to understand the asthma related health impacts from $\mathrm{PM}_{2.5}$ concentrations. More specifically, the impact of $\mathrm{PM}_{2.5}$ concentrations on asthma hospitalization rates in Pennsylvania is investigated. A balanced panel of 67 counties in Pennsylvania over fourteen years (2001-2014) is applied to estimate the effects and capture the spillovers from $\mathrm{PM}_{2.5}$ concentrations on asthma hospitalization rates across counties. In this research, we identify an important aspect missing in the health impact analysis literature of ambient air pollution - the presence of statistically significant spatial autocorrelation among county level asthma hospitalization rates. This presence implies that the ordinary least square estimations (non-spatial models) may lead to a biased result and underestimate the overall impact of $\mathrm{PM}_{2.5}$ concentrations on asthma hospitalization rates. Spatial models incorporate the intercorrelation between county level $\mathrm{PM}_{2.5}$ concentrations and thereby 
capture the spillover effects of these concentrations. In addition, applying spatial analysis without correctly employing wind direction to identify each unit's neighbors also generates inaccurate estimations of $\mathrm{PM}_{2.5}$ concentrations impacts. Putting into practice the proper upwind and downwind relationships between counties within an ambient air pollution impact assessment is a key element to derive a precise impact estimations.

Our results suggest that county level $\mathrm{PM}_{2.5}$ concentration is important explanatory factor in asthma hospitalization rates. This finding is similar to the findings of numerous studies, including Glad et al. (2012), Mann et al (2010), Meng et al (2010), Liu et al. (2009), Jacquemin et al. (2012), Malig et al. (2013), Samoli et al. (2011), and Silverman et al. (2010). While there are several GISbased studies focused on the locational impacts of asthma (Yap et al., 2013; Crighton et al., 2012; Hanchette et al., 2011), asthma hospitalization impacts from $\mathrm{PM}_{2.5}$ concentrations occurring in upwind counties have not been discussed in the literature before.

From Table 21 results, a one $\boldsymbol{\mu g} / \mathbf{m}^{3}$ increase in $\mathrm{PM}_{2.5}$ concentrations is associated with a combined asthma hospitalization rate increase of 0.8 per 10,000 population within both the county itself where the increase occurs as well as in downwind counties. Considering the average charge for inpatient hospitalization in Pennsylvania $(\$ 26,952)$, the total annual cost from a one $\mu \mathrm{g} / \mathrm{m}^{3}$ increase in $\mathrm{PM}_{2.5}$ concentrations in Philadelphia county (the most urban county in Pennsylvania) is \$3.1 million. Conversely, the total annual cost such an increase in $\mathrm{PM}_{2.5}$ concentrations in the most rural county (Cameron) is $\$ 37,732$.

We estimate the impact of this same one $\mu \mathrm{g} / \mathrm{m}^{3}$ increase throughout all Pennsylvania counties on the number of asthma hospitalization using 2014 data. A total of 1,244 additional asthma hospitalizations would occur with $26.8 \%$ of these hospitalizations happening in downwind counties because of increased $\mathrm{PM}_{2.5}$ concentrations in upwind neighboring counties. Using the average cost 
of asthma hospitalization noted above, the additional cost is $\$ 33.51$ million with $\$ 8.9$ million being added due to spillover effects of $\mathrm{PM}_{2.5}$ concentrations. Thus, ambient air pollution represents a regional issue rather than one related specifically to attainment or non-attainment of air quality standards at the county level.

This study's findings have policy implications for both federal and local governments. In December 2012, EPA reduced PM pollution standards by tightening the annual $\mathrm{PM}_{2.5}$ standard from 15 to $12 \mu \mathrm{g} / \mathrm{m}^{3}$. Even small changes at lowering the standard could have significant impacts on public health. Giannadaki et al. (2016) note that governments continue to adopt stricter limits for annual mean $\mathrm{PM}_{2.5}$ level. As shown in this research, lower limits for $\mathrm{PM}_{2.5}$ concentrations lead to substantial reductions in at least one negative human health outcome - asthma hospitalizations.

Although ambient air pollution has gained more attention for many years and there has been implementation of many regulations and air quality standards to help control pollution levels, still more work needs to be done. As one example, if the existing method to calculate the $\mathrm{PM}_{2.5}{ }^{-}$ attributable health effects is not capturing the spillover effects, the findings from this study show that inclusion of the out of area health effects of $\mathrm{PM}_{2.5}$ concentrations are potentially important in the consideration of setting or revising primary PM standards. Because the regulation of pollutants is an economic burden for the power generation sector and society in general (Curtis 2018), the most accurate accounting of human health effects is needed when considering pollution standard reductions - i.e. those which incorporate spillovers effects. Since nonattainment designations along with their incumbent increased regulation on pollution dischargers happen at city and county levels, the spillover benefits from these additional regulations need to be considered as the human health impacts of air pollution knows no boundaries. 
Several limitations in the research are recognized. First, to account for wind patterns, future research should consider a more detailed algorithm that involves wind speed and wind rose when computing a weight matrix. Wind rose is a diagram that shows the relative frequency of wind direction in a particular place. In practice, wind direction and speed change over time, so to investigate the effects of ambient air pollution, one needs to continually adjust the neighbors according to the frequency of wind direction and speed. For this research, corresponding information about direction and speed were not available for each county and each year. Thus, the empirical results found here may change with more accurate data of wind patterns. The weak statistically significant indirect effect of $\mathrm{PM}_{2.5}$ concentrations could be an indicator showing that this analysis might benefit from generating a more precise wind direction weight matrix.

Second, asthma hospitalization is currently the only data available at the county level for Pennsylvania. Access to asthma prevalence and asthma emergency department visits data for conducting new estimations using these asthma related incidents would provide researchers with a better estimation of $\mathrm{PM}_{2.5}$ impacts.

Finally, expanding the study region by applying all U.S. counties will provide a better understanding of the health impacts of the pollution. Unfortunately, data for all the counties in the U.S. are not available in this point. Having access to these point data pollution levels may enable the researchers to achieve results that are more accurate. Unfortunately, the pollution data for points in county level in a time series is not readily available. One would expect point source data on pollution show greater effects on asthma hospitalization.

Further research should consider improving on the above limitations by imposing a more accurate wind pattern, expanding estimations to include emergency department visits and asthma prevalence, and a county level analysis on the national level are recommended for future works. The 
current outcome does contribute to the literature by examining the impact of ambient air pollution

on human health by specifically documenting and estimating the cost of asthma spillover effects across Pennsylvania counties from $\mathrm{PM}_{2.5}$ concentrations.

\section{REFERENCES}

Akinbami, O. J., Moorman, J. E., \& Liu, X. (2011). Asthma prevalence, health care use, and mortality: United States, 2005-2009 (pp. 1-14). Washington, DC: US Department of Health and Human Services, Centers for Disease Control and Prevention, National Center for Health Statistics.

Akinbami, O. J., Moorman, J. E., Bailey, C., Zahran, H. S., King, M., Johnson, C. A., \& Liu, X. (2012). Trends in asthma prevalence, health care use, and mortality in the United States, 2001-2010.CDC Stacks, NCHS Data Brief, 95, 1202-1209.

Anderson, J. O., Thundiyil, J. G., \& Stolbach, A. (2012). Clearing the air: a review of the effects of particulate matter air pollution on human health. Journal of Medical Toxicology, 8(2), 166-175.

Andersen, M. S. (2017). Co-benefits of climate mitigation: Counting statistical lives or lifeyears? Ecological Indicators, 79, 11-18.

Anselin, L., \& Rey, S. (1991). Properties of tests for spatial dependence in linear regression models. Geographical Analysis, 23(2), 112-131.

Asher, M. I., Montefort, S., Björkstén, B., Lai, C. K., Strachan, D. P., Weiland, S. K., ... \& ISAAC Phase Three Study Group. (2006). Worldwide time trends in the prevalence of symptoms of asthma, allergic rhinoconjunctivitis, and eczema in childhood: ISAAC Phases One and Three repeat multicountry cross-sectional surveys. The Lancet, 368(9537), 733-743.

Attila, V. (2000). Local academic knowledge spillovers and the concentration of economic activity. Journal of Regional Science, 40(2), 289-309. doi.org/10.1111/0022-4146.00175.

Barrett, M. L., Wier, L. M., \& Washington, R. (2014). Trends in pediatric and adult hospital stays for asthma, 2000-2010. HCUP Statistical Brief, 169. Agency for Healthcare Research and Quality, Rockville, MD. Available at: http://www.hcupus.ahrq.gov/reports/statbriefs/sb169-Asthma-Trends-Hospital-Stays.pdf.

Barnett, S. B. L., \& Nurmagambetov, T. A. (2011). Costs of asthma in the United States: 20022007. Journal of Allergy and Clinical Immunology, 127(1), 145-152. 
Beelen, R., Raaschou-Nielsen, O., Stafoggia, M., Andersen, Z. J., Weinmayr, G., Hoffmann, B., \& Vineis, P. (2014). Effects of long-term exposure to air pollution on natural-cause mortality: an analysis of 22 European cohorts within the multicentre ESCAPE project. The Lancet, 383(9919), 785-795.

Bostantzoglou, C., Delimpoura, V., Samitas, K., Zervas, E., Kanniess, F., \& Gaga, M. (2015). Clinical asthma phenotypes in the real world: opportunities and hallenges. Breathe, 11(3), 186-93. doi: 10.1183/20734735.008115.

Brook, R. D. (2008). Cardiovascular effects of air pollution. Clinical Science, 115(6), 175-187.

Brook, R. D., Franklin, B., Cascio, W., Hong, Y., Howard, G., Lipsett, M., Luepker, R., Mittleman, M., Samet, J., SmithJr, S., \& Tager, I. (2004). Air pollution and cardiovascular disease: a statement for healthcare professionals from the Expert Panel on Population and Prevention Science of the American Heart Association. Circulation, 109(21), 2655-2671.

Brunekreef, B., \& Holgate, S. T. (2002). Air pollution and health. The Lancet, 360(9341), 12331242.

Centers for Disease Control and Prevention. (2011). Vital signs: asthma prevalence, disease characteristics, and self-management education: United States, 2001--2009. MMWR. Morbidity and mortality weekly report, 60(17), 547-552. Date accessed May 20, 2017. Available at: https://www.cdc.gov/mmwr/preview/mmwrhtml/mm6017a4.htm.

Centers for Disease Control and Prevention. (2013). Asthma facts - CDC's national asthma control program grantees. Atlanta, GA: US Department of Health and Human Services, Centers for Disease Control and Prevention. Date accessed May 14, 2017. Available at: https://www.cdc.gov/asthma/pdfs/asthma_facts_program_grantees.pdf.

Centers for Disease Control and Prevention. (2014). Asthma's Impact on the Nation Data from the CDC National Asthma Control Program. Date accessed May 19, 2017. Available at: https://www.cdc.gov/asthma/impacts_nation/asthmafactsheet.pdf.

Chagas, A. L., Azzoni, C. R., \& Almeida, A. N. (2016). A spatial difference-in-differences analysis of the impact of sugarcane production on respiratory diseases. Regional Science and Urban Economics, 59, 24-36.

Chen, Y., Dales, R., Krewski, D., \& Breithaupt, K. (1999). Increased effects of smoking and obesity on asthma among female Canadians: the National Population Health Survey, 1994-1995. American Journal of Epidemiology, 150(3), 255-262.

Chen, X., \& Ye, J. (2018). When the wind blows: spatial spillover effects of urban air pollution. In 2018 Conference, July 28-August 2, 2018, Vancouver, British Columbia (No. 277146). International Association of Agricultural Economists. 
Cheng, T., Wang, J., Haworth, J., Heydecker, B., \& Chow, A. (2014). A dynamic spatial weight matrix and localized space-time autoregressive integrated moving average for network modeling. Geographical Analysis, 46(1), 75-97.

Cohen, A. J., \& Pope 3rd, C. A. (1995). Lung cancer and air pollution. Environmental Health Perspectives, 103(Suppl 8), 219. doi.org/10.1289/ehp.95103s8219.

Cohen, A. J., Anderson, H. R., Ostro, B., Pandey, K. D., Krzyzanowski, M., Künzli, N., Gutschmidt, K., Pope, C.A., Romieu, I., Samet, J.M., \& Smith, K. R. (2004). Urban air pollution. In Ezzati M., Lopez A.D., Rodgers A., Murray C.J.L. (Eds.). Comparative Quantification of Health Risks (pp. 1353-1433). Geneva, Switzerland. World Health Organization.

Crighton, E. J., Feng, J., Gershon, A., Guan, J., \& To, T. (2012). A spatial analysis of asthma prevalence in Ontario. Can J Public Health, 103(5), 384-389.

Datz, T. (2015). Air pollution below EPA standards linked with higher death rates. Harvard T.H. CHAN, school of Public Health. Date accessed June 1, 2017. Available at: https://www.hsph.harvard.edu/news/press-releases/air-pollution-below-epa-standardslinked-with-higher-death-rates/.

Currie, J., \& Neidell, M. (2005). Air pollution and infant health: what can we learn from California's recent experience? The Quarterly Journal of Economics, 120(3), 1003-1030.

Curtis, E.M. (2018). The employment and concentration effects of the nonattainment standards: Evidence from the 2004 expansion. Presentation at the AERE 2017 Summer Conference, IZA's Labor Market Effects of Environmental Policies Workshop, East Carolina University.

Dugandzic, R., Dodds, L., Stieb, D., \& Smith-Doiron, M. (2006). The association between low level exposures to ambient air pollution and term low birth weight: a retrospective cohort study. Environmental health, 5(1), 3. doi: 10.1186/1476-069X-5-3.

Eder, W., Ege, M. J., \& von Mutius, E. (2006). The asthma epidemic. New England Journal of Medicine, 355(21), 2226-2235.

EPAa, (2016). Criteria Air Pollutants, NAAQS Table. Date accessed December 12, 2018. Available at: https://www.epa.gov/criteria-air-pollutants/naaqs-table.

EPAb, (2016). Asthma Facts. Accessed January 2, 2019. Available at: https://www.epa.gov/sites/production/files/201605/documents/asthma_fact_sheet_english_05_2016.pdf.

EPAa, (2018). Air Trends, Sulfur Dioxide Trends. Date accessed December 20, 2018. Available at: https://www.epa.gov/air-trends/sulfur-dioxide-trends. 
EPAb, (2018). Particulate Matter (PM) Pollution, Health and Environmental Effects of Particulate Matter (PM). Date accessed November 25, 2018. Available at: https://www.epa.gov/pm-pollution/health-and-environmental-effects-particulate-matter$\mathrm{pm}$.

Elhorst, J. P. (2014). Spatial panel data models. In Spatial Econometrics (pp. 37-93). Springer, Berlin, Heidelberg.

Environmental Appeals Court. (2008). State of North Carolina v. Tennessee Valley Authority. Date accessed June 14, 2017. Available at: http://environmentalappealscourt.blogspot.com/2008/02/state-of-north-carolina-vtennessee.html.

Giannadaki, D., Lelieveld, J., \& Pozzer, A. (2016). Implementing the US air quality standard for PM 2.5 worldwide can prevent millions of premature deaths per year. Environmental Health, 15(1), 88. doi.org/10.1186/s12940-016-0170-8.

Gilliland, F. D., Islam, T., Berhane, K., Gauderman, W. J., McConnell, R., Avol, E., \& Peters, J. M. (2006). Regular smoking and asthma incidence in adolescents. American Journal of Respiratory and Critical Care Medicine, 174(10), 1094-1100.

Glad, J. A., Brink, L. L., Talbott, E. O., Lee, P. C., Xu, X., Saul, M., \& Rager, J. (2012). The relationship of ambient ozone and PM2. 5 levels and asthma emergency department visits: possible influence of gender and ethnicity. Archives of Environmental \& Occupational Health, 67(2), 103-108.

Global Catholic Climate Movement. (2017). Air Quality and Pro-life: Recent Research Findings on the Impacts of Air Pollution on Life \& Health. Date accessed June 25, 2017. Available at: https://catholicclimatemovement.global/air-quality-and-pro-life-recent-researchfindings-on-the-impacts-of-air-pollution-on-life-health/.

Guarnieri, M., \& Balmes, J. R. (2014). Outdoor air pollution and asthma. The Lancet, 383(9928), 1581-1592.

Hamra, G. B., Laden, F., Cohen, A. J., Raaschou-Nielsen, O., Brauer, M., \& Loomis, D. (2015). Lung cancer and exposure to nitrogen dioxide and traffic: a systematic review and metaanalysis. Environmental Health Perspectives, 123(11), 1107-1112.

Hanchette, C., Lee, J. H., \& Aldrich, T. E. (2011). Asthma, Air Quality and Environmental Justice in Louisville, Kentucky. In Maantay J., McLafferty S. (Eds.). Geospatial Analysis of Environmental Health (pp. 223-242). Springer Dordrecht.

Harris, D. A., Mainardi, A., Iyamu, O., Rosenthal, M. S., Bruce, R. D., Pisani, M. A., \& Redlich, C. A. (2018). Improving the asthma disparity gap with legal advocacy? A qualitative study of patient-identified challenges to improve social and environmental factors that contribute to poorly controlled asthma. Journal of Asthma, 55(8), 924-932. 
Henry J Kaiser Family Foundation. (2017). Adult Self-Reported Current Asthma Prevalence Rate by Race/Ethnicity. Date accessed December 1, 2017. Available at: https://www.kff.org/other/state-indicator/asthma-prevalence-byre/?currentTimeframe=0\&sortModel=\%7B $\% 22$ colId $\% 22: \% 22$ Location $\% 22, \% 22$ sort $\% 22$ :\%22asc\%22\%7D.

Ho, W. C., Hartley, W. R., Myers, L., Lin, M. H., Lin, Y. S., Lien, C. H., \& Lin, R. S. (2007). Air pollution, weather, and associated risk factors related to asthma prevalence and attack rate. Environmental Research, 104(3), 402-409.

Iskandar A, Andersen ZJ, Bønnelykke K, Ellermann, T., Andersen, K., Bisgaard, H. (2012). Coarse and fine particles but not ultrafine particles in urban air trigger hospital admission for asthma in children. Thorax, 67(3), 252-257.

Jacquemin, B., Kauffmann, F., Pin, I., Le Moual, N., Bousquet, J., Gormand, F., Just, J., Nadif, R., Pison, C., Velvloer, D., Siroux, V., \& Künzli, N. (2011). Air pollution and asthma control in the Epidemiological study on the Genetics and Environment of Asthma. Journal of Epidemiology \& Community Health, 66(9), 796-802.

Jaffe, A. B., Trajtenberg, M., \& Henderson, R. (1993). Geographic localization of knowledge spillovers as evidenced by patent citations. the Quarterly Journal of Economics, 108(3), 577-598.

Jaffe, A. B. (1989). Real effects of academic research. The American Economic Review, 79(5), 957-970.

Jerrett, M., Shankardass, K., Berhane, K., Gauderman, W. J., Künzli, N., Avol, E., ... \& Thomas, D. C. (2008). Traffic-related air pollution and asthma onset in children: a prospective cohort study with individual exposure measurement. Environmental Health Perspectives, 116(10), 1433-1438.

Kameel, M., \& Steve, S. (2014). The spatial epidemiology of asthma: a chronic noncommunicable disease and a neglected epidemic. Journal of Allergy and Asthma, 1(1), 2.

Kampa, M., \& Castanas, E. (2008). Human health effects of air pollution. Environmental Pollution, 151(2), 362-367.

Klein, R. J., \& Schoenborn, C. A. (2001). Age adjustment using the 2000 projected US population.Kozyrskyj, A. L., Kendall, G. E., Jacoby, P., Sly, P. D., \& Zubrick, S. R. (2010). Association between socioeconomic status and the development of asthma: analyses of income trajectories. American Journal of Public Health, 100(3), 540-546.

Krewski, D., Jerrett, M., Burnett, R. T., Ma, R., Hughes, E., Shi, Y., \& Thun, M. J. (2009). Extended follow-up and spatial analysis of the American Cancer Society study 
linking particulate air pollution and mortality (No. 140). Boston, MA: Health Effects Institute.

Künzli, N., Bridevaux, P. O., Liu, S., Garcia-Esteban, R., Schindler, C., Gerbase, M., \& Rochat, T. (2009). Traffic-related air pollution correlates with adult-onset asthma among neversmokers. Thorax.64(8), 664-670.

Leinberger, C. B. (2010). The option of urbanism: Investing in a new American dream. Island Press.

LeSage, J., \& Pace, K. (2009). Introduction to Spatial Econometrics. Taylor \& Francis Group, LLC.

LeSage, J. (2014). Spatial Econometrics: From Cross-Sectional Data to Spatial Panels. Berlin: Springer.

Lipsett, M., Hurley, S., \& Ostro, B. (1997). Air pollution and emergency room visits for asthma in Santa Clara County, California. Environmental Health Perspectives, 105(2), 216-222.

Liu L, Poon R, Chen L, et al. (2009). Acute effects of air pollution on pulmonary function, airway inflammation, and oxidative stress in asthmatic children. Environ Health Perspect, $117,668-74$.

Lwebuga-Mukasa, J., Oyana, T., Wydro, P. (2004). Risk factors for asthma prevalence and chronic respiratory illnesses among residents of different neighborhoods in Buffalo, New York. J Epidemiol Community Health 58, 951-957. doi: 10.1136/jech.2003.015750.

Mann, J. K., Balmes, J. R., Bruckner, T. A., Mortimer, K. M., Margolis, H. G., Pratt, B., ... \& Tager, I. B. (2010). Short-term effects of air pollution on wheeze in asthmatic children in Fresno, California. Environmental Health Perspectives, 118(10), 1497.

Malig BJ, Green S, Basu R, et al. (2013). Coarse particles and respiratory emergency department visits in California. Am. J. Epidemiol, 178, 58-69.

Mayrides, M., \& Levy, R. (2005). Ethnic disparities in the burden and treatment of asthma. Asthma and Allergy Foundation of America. Available at: https://www.aafa.org/media/1633/ethnic-disparities-burden-treatment-asthma-report.pdf

Meng YY, Rull RP, Wilhelm M, et al. (2010). Outdoor air pollution and uncontrolled asthma in the San Joaquin Valley, California. J Epidemiol Community Health, 64, 142-7.

Nafstad, P., Håheim, L. L., Oftedal, B., Gram, F., Holme, I., Hjermann, I., \& Leren, P. (2003). Lung cancer and air pollution: a 27 year follow up of 16209 Norwegian men. Thorax, 58(12), 1071-1076. 
Namdeo, A., Tiwary, A., Farrow, E., 2011. Estimation of age-related vulnerability to air pollution: assessment of respiratory health at local scale. Environ. Int. 37, 829-837.

National Hospital Ambulatory Medical Care Survey: (2011a). Outpatient Department Summary Tables. Date accessed January 2, 2017. Available at:

www.cdc.gov/nchs/data/ahcd/nhamcs_outpatient/2011_opd_web_tables.pdf 10.

National Hospital Ambulatory Medical Care Survey: (2011b). Emergency Department Summary Tables. Date accessed January 4, 2017. Available at: www.cdc.gov/nchs/data/ahcd/nhamcs_emergency/2011_ed_web_tables.pdf.

Nel, A. (2005). Air pollution-related illness: effects of particles. Science, 308(5723), 804-806.

Nunes, C., Pereira, A. M., \& Morais-Almeida, M. (2017). Asthma costs and social impact. Asthma research and practice, 3(1), 1. DOI 10.1186/s40733-016-0029-3

Pedersen, M., Giorgis-Allemand, L., Bernard, C., Aguilera, I., Andersen, A. M. N., Ballester, F., ... \& Dedele, A. (2013). Ambient air pollution and low birthweight: a European cohort study (ESCAPE). The Lancet Respiratory Medicine, 1(9), 695-704.

Pénard-Morand, C., Raherison, C., Charpin, D., Kopferschmitt, C., Lavaud, F., Caillaud, D., \& Annesi-Maesano, I. (2010). Long-term exposure to close-proximity air pollution and asthma and allergies in urban children. European Respiratory Journal, 36(1), 33-40.

Pennsylvania Department of Health. (2015). Asthma hospitalization in Pennsylvania. Date accessed May 1, 2017: Available at:

https://www.health.pa.gov/topics/Documents/Programs/2015\%20Asthma\%20Hospitaliza tion\%20in\%20Pennsylvania\%20fact\%20Sheet.pdf.

Pennsylvania Department of Health. (2012). Pennsylvania Asthma Burdon Report. Date accessed May 8, 2017: Available at:

http://www.paasthma.org/images/docs/2012_asthma_burden_report.pdf.

Pennsylvania Department of Environmental Protection. (2016). Attainment Status by Principal Pollutants. Date accessed May 21, 2017. Available at:

https://www.dep.pa.gov/business/air/baq/regulations/pages/attainment-status.aspx.

Perera, F. (2017). Pollution from Fossil-Fuel Combustion is the Leading Environmental Threat to Global Pediatric Health and Equity: Solutions Exist. International journal of environmental research and public health, 15(1), 16. DOI: 10.3390/ijerph15010016

Pope C, Burnett T, Krewski D, Jerrett M, Shi Y, Calle E, et al. (2009). Cardiovascular mortality and exposure to airborne fine particulate matter and cigarette smoke: shape of the exposure- response relationship. Am Heart Assoc., 120, 941-8. http://dx.doi.org/10. 1161/CIRCULATIONAHA.109.857888. 
Raaschou-Nielsen, O., Andersen, Z. J., Beelen, R., Samoli, E., Stafoggia, M., Weinmayr, G., ... \& Xun, W. W. (2013). Air pollution and lung cancer incidence in 17 European cohorts: prospective analyses from the European Study of Cohorts for Air Pollution Effects (ESCAPE). The Lancet Oncology, 14(9), 813-822.

Riedl, M., \& Diaz-Sanchez, D. (2005). Biology of diesel exhaust effects on respiratory function. Journal of Allergy and Clinical Immunology, 115(2), 221-228.

Ristovski ZD, Miljevic B, Surawski NC, Morawska L, Fong KM, Goh F, Yang IA. (2012). Respiratory health effects of diesel particulate matter. Respirology, 17(2), 201-212.

Samoli E, Nastos PT, Paliatsos AG, et al. (2011). Acute effects of air pollution on pediatric asthma exacerbation: evidence of association and effect modification. Environ Res, 111, 418-24.

Schneider, C. G., Banks, J. M., \& Tatsutani, M. (2010). The toll from coal: An updated assessment of death and disease from America's dirtiest energy source. Clean Air Task Force. Date accessed July 20, 2017. Available at: http://www.catf.us/wpcontent/uploads/2010/09/CATF_Pub_TheTollFromCoal.pdf.

Schwartz, J., \& Morris, R. (1995). Air pollution and hospital admissions for cardiovascular disease in Detroit, Michigan. American Journal of Epidemiology, 142(1), 23-35.

Schwartz J; Coull B; Laden F; Ryan L (2008). The effect of dose and timing of dose on the association between airborne particles and survival. Environ Health Perspectives, 116, 64-69.

Silverman RA, Ito K. (2010). Age-related association of fine particles and ozone with severe acute asthma in New York City. J Allergy Clin Immunol, 125, 367-73.

Solé, D., Cassol, V. E., Silva, A. R., Teche, S. P., Rizzato, T. M., Bandim, L. C., \& CameloNunes, I. C. (2007). Prevalence of symptoms of asthma, rhinitis, and atopic eczema among adolescents living in urban and rural areas in different regions of Brazil. Allergologia et immunopathologia, 35(6), 248-253.

Stanford, R., Mclaughlin, T., \& Okamoto, L. J. (1999). The cost of asthma in the emergency department and hospital. American Journal of Respiratory and Critical Care Medicine, 160(1), 211-215.

Tatum, A. J., \& Shapiro, G. G. (2005). The effects of outdoor air pollution and tobacco smoke on asthma. Immunology and Allergy Clinics of North America, 25(1), 15-30.

Thomson, N. C., Chaudhuri, R., \& Livingston, E. (2004). Asthma and cigarette smoking. European Respiratory Journal, 24(5), 822-833. 
Tobler, W. R. (1970). A computer movie simulating urban growth in the Detroit region. Economic Geography, 46(sup1), 234-240.

U.N. Environment Program and WHO Report. (1994). Air pollution in the world's megacities. A Report from the U.N. Environment Programme and WHO. Environment, 36, 5-37.

United States. Environmental Protection Agency. Office of Air and Radiation. (2011). The Benefits and Costs of the Clean Air Act from 1990 to 2020: Final Report, Rev. A. US Environmental Protection Agency, Office of Air and Radiation. Date accessed February 3, 2017. Available at: https://www.epa.gov/sites/production/files/201507/documents/fullreport_rev_a.pdf.

Riedl, M., \& Diaz-Sanchez, D. (2005). Biology of diesel exhaust effects on respiratory function. Journal of Allergy and Clinical Immunology, 115(2), 221-228.

United States Environmental Protection Agency. (2017). “Asthma Facts.” Date accessed November 18, 2017. Available at: https://www.epa.gov/sites/production/files/201708/documents/2017_asthma_fact_sheet.pdf

Veremchuk, L. V., Tsarouhas, K., Vitkina, T. I., Mineeva, E. E., Gvozdenko, T. A., Antonyuk, M. V., ... \& Golokhvast, K. S. (2018). Impact evaluation of environmental factors on respiratory function of asthma patients living in urban territory. Environmental Pollution, 235: 489-496.

Wang, T., Srebotnjak, T., Brownell, J., \& Hsia, R. Y. (2014). Emergency department charges for asthma-related outpatient visits by insurance status. Journal of Health Care for the Poor and Underserved, 25(1), 396-405.

World Forecast Directory. (2019). Mean Wind Speed and Prevailing Direction. Date accessed April 2, 2017. Available at: https://eldoradoweather.com/climate/US\%20Climate\%20Maps/Lower\%2048\%20States/ Wind/Mean\%20Wind\%20Speed\%20and\%20Prevailing\%20Direction/Gallery/meanwind-speed-and-prevailing-direction.html\#location1.

World Health Organization. (2016). Ambient (outdoor) air quality and health. Fact sheet, 313. Date accessed April 5, 2017. Available at: https://www.who.int/news-room/factsheets/detail/ambient-(outdoor)-air-quality-and-health.

Woodruff, T. J., Darrow, L. A., \& Parker, J. D. (2008). Air pollution and postneonatal infant mortality in the United States, 1999-2002. Environmental Health Perspectives, 116(1): 110-115.

Yang, M., Bhatta, R. A., Chou, S. Y., \& Hsieh, C. I. (2017). The Impact of Prenatal Exposure to Power Plant Emissions on Birth Weight: Evidence from a Pennsylvania Power Plant Located Upwind of New Jersey. Journal of Policy Analysis and Management, 36(3), 557583. 
Yang, M., \& Chou, S. Y. (2015). Impacts of Being Downwind of a Coal-Fired Power Plant on Infant Health at Birth: Evidence from the Precedent-Setting Portland Rule (No. w21723). National Bureau of Economic Research. Available at: https://www.nber.org/papers/w21723

Yap, P. S., Gilbreath, S., Garcia, C., Jareen, N., \& Goodrich, B. (2013). The influence of socioeconomic markers on the association between fine particulate matter and hospital admissions for respiratory conditions among children. American Journal of Public Health, 103(4), 695-702.

Zhang, Q., Qiu, Z., Chung, K. F., \& Huang, S. K. (2015). Link between environmental air pollution and allergic asthma: East meets West. Journal of Thoracic Disease, 7(1), 14-22.

Zhu, L., Ge, X., Chen, Y., Zeng, X., Pan, W., Zhang, X., Ben, S., Yuan, Q., Xin, J., Shao, W., Ge, Y., Wu, D., Han, Z., Zhang, Z., Chu, H., \& Wang, M. (2017). Short-term effects of ambient air pollution and childhood lower respiratory diseases. Scientific Reports, 7(1), 4414. DOI: $10.1038 / \mathrm{s} 41598-017-04310-7$ 


\section{Appendix VII.}

Figure 8. Attainment vs. nonattainment designation status in Pennsylvania counties based on PM2.5 concentrations criteria.
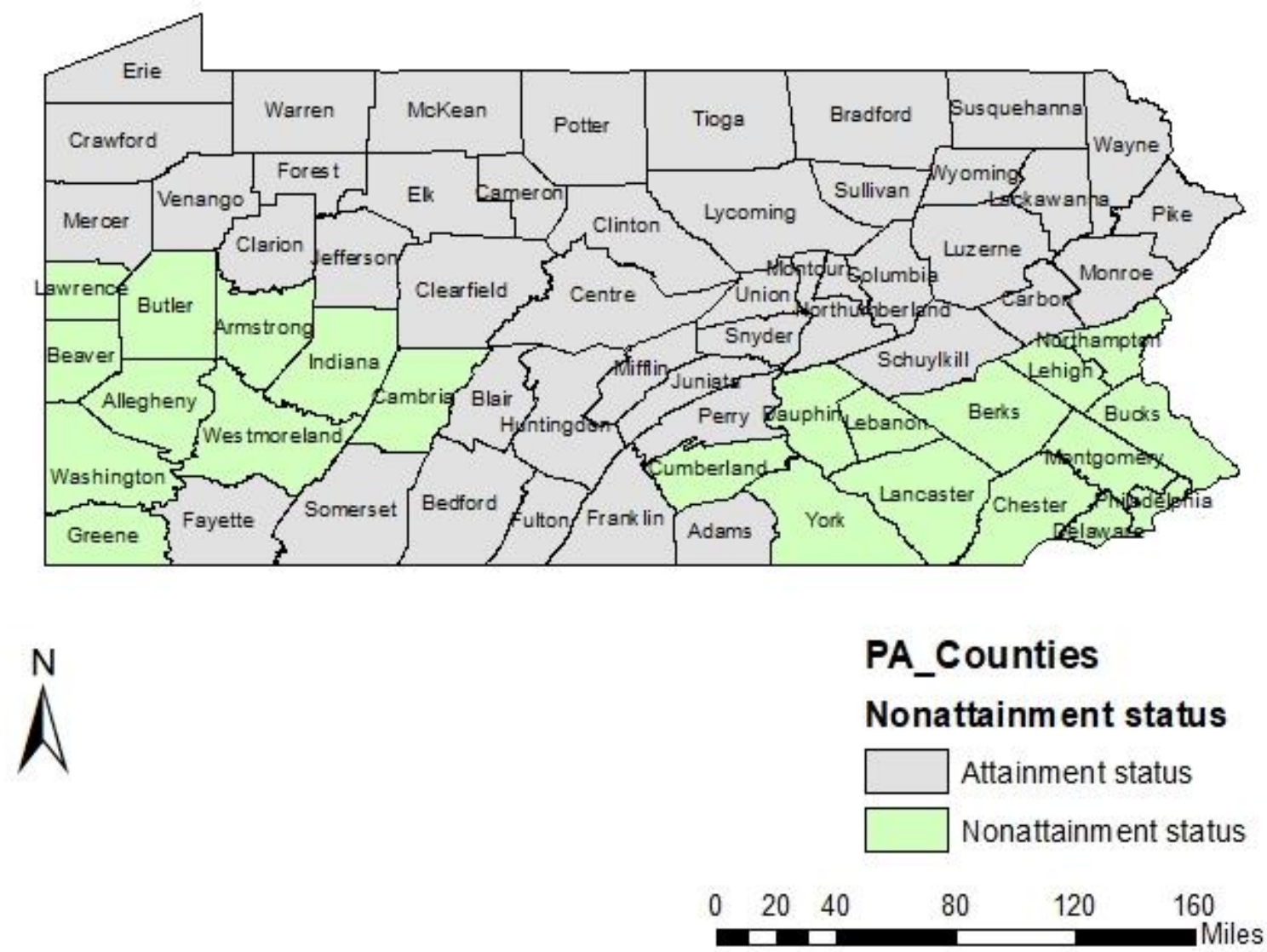

Note: Using the data from EPA Green Book, National Area and County-Level Multi-Pollutant Information, we define attainment vs. nonattainment counties based on the $\mathrm{PM}_{2.5}$ concentrations criteria. If the county falls in a nonattainment status in any years between 2001 and 2014, we consider it a nonattainment county, otherwise the county falls in an attainment status. 
CHAPTER 5 


\section{CHAPTER 5: SUMMARY AND CONCLUSIONS}

\section{Study Summary}

Spatial econometrics has an important role to play in research (see e.g., Partridge et al. (2012) for a general discussion of the importance of spatial econometrics). ${ }^{1}$ By applying spatial models in three different research areas, I demonstrate in this dissertation the use of conventional, non-spatial analyses are biased in this environment. Overall, due to a significant spatial autoregressive component found in all models (water charge and minimum monthly access from essay 1 , opioid overdose deaths and the Naloxone access law in essay 2, and $\mathrm{PM}_{2.5}$ concentration and asthma hospitalization in essay 3), I found spillover effects exist in all three topics. The existence of spillover effects can lead federal and local policymakers to a better understanding of the impacts of policies and strategies they make for their jurisdiction on the neighboring regions.

In the first essay, I found that water charges in municipality level are influenced by long-term debt and the water source. Also, water charge follows a spatial pattern so that municipalities and the PSC are adjusting water rates considering water charges from neighboring utilities. It could be the results of geographical and institutional characteristics or following the rates in neighboring municipalities. For the second model in essay 1 , the question considered is whether or not socioeconomic factors are considered to set the

\footnotetext{
${ }^{1}$ For more information, please refer to Gibbons and Overman (2012), McMillen (2012), and Corrado and Fingleton (2012).
} 
minimum water access. The results showed affordability is not a significant factor to predict and explain the minimum access charge.

Second essay investigated the impacts of a public health policy (Naloxone access law) on opioid overdose deaths in the U.S. Aside from findings that show heroin availability, opioid prescriptions, high-risk occupations, population density, and college graduate rate are the influential factors to determine the opioid overdose deaths, I found while Naloxone access law doesn't impact the opioid overdose death rate in the state which a law is implemented, there are positive spillover effects on death rates in surrounding states.

In the third essay I presented a new approach to evaluate the effects of ambient air pollution on health outcome. To be more specific I considered the spillover effects of $\mathrm{PM}_{2.5}$ concentrations on asthma hospitalization in Pennsylvania counties. The results showed that the $\mathrm{PM}_{2.5}$ concentrations in county $\mathrm{i}$ impacts on the asthma hospitalization in downwind counties.

In the next part based on the results I will explain the policy implication for each essay.

\section{Implications}

The findings of the study have some policy implications for both federal and local governments. Findings from first essay highlighted the role of financial constraint and source of water in water charge determination. According to the results protecting ground water quality with source water protection programs seems a reasonable strategy to control and keep the water charge low. Our water charge model results provide the basis for a rough estimate of the benefits from this ground water protection. Allowing for a $\$ 5$ saving for each 4,500 gallons of use, the over 240,000 households in West Virginia served by municipalities 
using ground water have an annual cost savings of $\$ 3.6$ million in their water charges compared to other water sources.

In terms of the long term debt, prior to the 1987 amendments to the Clean Water Act, municipal utility assistance was provided through grants with the federal government picking up 55\% of project cost. This amendment changed grants to low-interest rate loans. This change means that now local governments are responsible for $100 \%$ of projects' cost (Copeland, 1999). This societal change of replacing the federal government grants to municipal utilities with low-interest loans has increased long term utility debt, which has increased water charges to customers.

Also our results indicate that the average share of water costs across West Virginia households with municipal water utilities is about $1.5 \%$ of household income devoted to water charges with a maximum share being $4 \%$. With such reasonable costs of water for households, this could be a factor explaining why our models find no significant effects from socioeconomic factors on monthly minimum charges for access to water.

Findings from the second essay have profound implications for Naloxone access law policy. For the provisions with positive coefficients we find that in each case the effect of Naloxone access laws is to increase opioid death rates outside the states where these laws have been enacted. Looking across multiple provisions, these findings provide no statistical evidence that these laws reduce opioid death rates.

Our results show that when access laws are evaluated in isolation of any other state level policy response to opioids, increasing access to Naloxone does not reduce, but leads to increased overdose death rates. Thus, the moral hazard perspective of this policy is the more accurate assessment of the outcome when access laws are evaluated as the only policy. 131 
Immunity from civil and criminal liability for healthcare professionals and immunity from criminal liability for possession of Naloxone are provisions that show the change in behavior of the users and we see a positive effect of these laws on opioid overdose death rates. The end result is that while administering Naloxone prevents an overdose death, the expanded ability to administer Naloxone does not reduce overdose death rates. Enactment of a Naloxone access law is a starting point in implementing and expanding access to save lives seems a necessary strategy, but not a sufficient response to the overdose problem.

Findings from the third essay highlighted the role of external sources of $\mathrm{PM}_{2.5}$ concentrations in upwind counties on asthma hospitalization in downwind counties. Although ambient air pollution has gained more attention for many years and has led to the implementation of many regulations and air quality standards to help control the level of pollution, more work still needs to be done. If the existing method to calculate the $\mathrm{PM}_{2.5}$ attributable health effects is not capturing the spillovers, this study recommends the inclusion of the indirect health effects of $\mathrm{PM}_{2.5}$ concentrations to set or revise the primary PM standards. Because the regulation of pollutants is an economic burden for the power generation sector and society, the most real and accurate human health effects need to be measured.

An accurate measurement of pollutants should incorporate spillovers. The real cost involving asthma hospitalization is not limited to the discharge within the county; this is true in the state level as well. Even if a local government manages to decrease the ambient air pollution, public health may still be influenced by pollution levels in neighboring units. To control ambient air pollution, this study recommends regional cooperation rather than a state 
regulation. Both federal and local governments should be involved in policies more focused on regions rather than a specific state or county.

\section{Study Limitation}

I recognize several limitations in my research. First, the data available for the water plants locations in the first essay is limited. The best way to model geographical characteristics is having access to the water plants locations. Spatial interpolation methods such as Kriging may help us to predict the location point with a high degree of confidence.

In the second essay, many states have only recently enacted Naloxone access laws. Since our data cover years 1999 to 2016 , for those 10 states with newly enacted laws in 2014, we do not have post implementation data. Furthermore, 10 more states enacted laws in 2013, so that only one year of data is included in our dataset. Empirical results may change with more post implementation data for these 20 states. Second, county level analysis would be preferable to assess the spillover effects across states, but these data were not consistently available for public for overdose death rates. Religion and social attitude toward drugs may have influences on overdose death rates. Empirical results may change after controlling for these variables. Future works may consider dynamic spatial models. Empirical results may change with the new method of estimation.

For the third essay, first, to account for wind patterns, researchers need to consider a more accurate algorithm that involves wind speed and wind rose. Wind rose is a diagram that shows the relative frequency of wind direction in a particular place. In practice, wind direction and speed could change over time, so to investigate the effects of ambient air pollution, one needs to adjust the neighbors according to the frequency of wind direction and 
speed. For this research, I do not have corresponding information for each county and each year. Empirical results may change with more accurate data for wind patterns. Second, asthma hospitalization is currently the only data available on a county level for Pennsylvania. Having access to asthma prevalence and asthma emergency department visits and conducting new estimations for this asthma related incidents would give us a better estimation of the impact. Occupational pattern may affect the asthma hospitalization. For instance, coal miners are more exposed to asthma prevalence. In addition, age group could affect asthma hospitalization. Children and elderly people suffer from a higher rate of asthma prevalence. Results may change after controlling for occupation scheme and age groups. Controlling for some kind of measurement for the road pollution is the area, which remains for the future works. Having access to the point data pollutions may enable the researchers to have results that are more accurate. Unfortunately, the pollution data for points in county level in a time series is not readily available. One can expect point source data on pollution show greater effects on asthma hospitalization. Finally, a study region applying all the counties in the U.S. will give us a better understanding of the health impacts of the pollution. Unfortunately, data for asthma hospitalization for all the counties in the U.S. is not available in this point. 